\title{
A comparative risk assessment of burden of disease and injury attributable to 67 risk factors and risk factor clusters in 21 regions, 1990-2010: a systematic analysis for the Global Burden of Disease Study 2010
}

\author{
Author \\ Lim, Stephen S, Vos, Theo, Flaxman, Abraham D, Danaei, Goodarz, Shibuya, Kenji, Adair- \\ Rohani, Heather, Amann, Markus, Anderson, H Ross, Andrews, Kathryn G, Aryee, Martin, \\ Atkinson, Charles, Bacchus, Loraine J, Bahalim, Adil N, Balakrishnan, Kalpana, Balmes, John, \\ Barker-Collo, Suzanne, Baxter, Amanda, Bell, Michelle L, Blore, Jed D, Blyth, Fiona, Bonner, \\ Carissa, Borges, Guilherme, Bourne, Rupert, Boussinesq, Michel, Brauer, Michael, Brooks, \\ Peter, Bruce, Nigel G, Brunekreef, Bert, Bryan-Hancock, Claire, Bucello, Chiara, Buchbinder, \\ Rachelle, Bull, Fiona, Burnett, Richard T, Byers, Tim E, Calabria, Bianca, Carapetis, Jonathan, \\ Carnahan, Emily, Chafe, Zoe, Charlson, Fiona, Chen, Honglei, Chen, Jian Shen, Cheng, \\ Andrew Tai-Ann, Child, Jennifer Christine, Cohen, Aaron, Colson, K Ellicott, Cowie, Benjamin C, \\ Darby, Sarah, Darling, Susan, Davis, Adrian, Degenhardt, Louisa, Dentener, Frank, Des Jarlais, \\ Don C, Devries, Karen, Dherani, Mukesh, Ding, Eric L, Dorsey, E Ray, Driscoll, Tim, Edmond, \\ Karen, Ali, Suad Eltahir, Engell, Rebecca E, Erwin, Patricia J, Fahimi, Saman, Falder, Gail, \\ Farzadfar, Farshad, Ferrari, Alize, Finucane, Mariel M, Flaxman, Seth, Fowkes, Francis Gerry \\ R, Freedman, Greg, Freeman, Michael K, Gakidou, Emmanuela, Ghosh, Santu, Giovannucci, \\ Edward, Gmel, Gerhard, Graham, Kathryn, Grainger, Rebecca, Grant, Bridget, Gunnell, David, \\ Gutierrez, Hialy R, Hall, Wayne, Hoek, Hans W, Hogan, Anthony, Hosgood, H Dean, Hoy, \\ Damian, Hu, Howard, Hubbell, Bryan J, Hutchings, Sally J, Ibeanusi, Sydney E, Jacklyn, \\ Gemma L, Jasrasaria, Rashmi, Jonas, Jost B, Kan, Haidong, Kanis, John A, Kassebaum, \\ Nicholas, Kawakami, Norito, Khang, Young-Ho, Khatibzadeh, Shahab, Khoo, Jon-Paul, Kok, \\ Cindy, Laden, Francine, Lalloo, Ratilal, Lan, Qing, Lathlean, Tim, Leasher, Janet L, Leigh, \\ James, Li, Yang, Lin, John Kent, Lipshultz, Steven E, London, Stephanie, Lozano, Rafael, \\ Lu, Yuan, Mak, Joelle, Malekzadeh, Reza, Mallinger, Leslie, Marcenes, Wagner, March, Lyn, \\ Marks, Robin, Martin, Randall, McGale, Paul, McGrath, John, Mehta, Sumi, Mensah, George \\ A, Merriman, Tony R, Micha, Renata, Michaud, Catherine, Mishra, Vinod, Hanafiah, Khayriyyah \\ Mohd, Mokdad, Ali A, Morawska, Lidia, Mozaffarian, Dariush, Murphy, Tasha, Naghavi, \\ Mohsen, Neal, Bruce, Nelson, Paul K, Miquel Nolla, Joan, Norman, Rosana, Olives, Casey, \\ Omer, Saad B, Orchard, Jessica, Osborne, Richard, Ostro, Bart, Page, Andrew, Pandey, Kiran \\ D, Parry, Charles DH, Passmore, Erin, Patra, Jayadeep, Pearce, Neil, Pelizzari, Pamela M, \\ Petzold, Max, Phillips, Michael R, Pope, Dan, Pope, C Arden, Powles, John, Rao, Mayuree, \\ Razavi, Homie, Rehfuess, Eva A, Rehm, Juergen T, Ritz, Beate, Rivara, Frederick P, Roberts, \\ Thomas, Robinson, Carolyn, Rodriguez-Portales, Jose A, Romieu, Isabelle, Room, Robin, \\ Rosenfeld, Lisa C, Roy, Ananya, Rushton, Lesley, Salomon, Joshua A, Sampson, Uchechukwu, \\ Sanchez-Riera, Lidia, Sanman, Ella, Sapkota, Amir, Seedat, Soraya, Shi, Peilin, Shield, Kevin, \\ Shivakoti, Rupak, Singh, Gitanjali M, Sleet, David A, Smith, Emma, Smith, Kirk R, Stapelberg, \\ Nicolas JC, Steenland, Kyle, Stoeckl, Heidi, Stovner, Lars Jacob, Straif, Kurt, Straney, Lahn, \\ Thurston, George D, Tran, Jimmy H, Van Dingenen, Rita, van Donkelaar, Aaron, Veerman, \\ J Lennert, Vijayakumar, Lakshmi, Weintraub, Robert, Weissman, Myrna M, White, Richard \\ A, Whiteford, Harvey, Wiersma, Steven T, Wilkinson, James D, Williams, Hywel C, Williams, \\ Warwick, Wilson, Nicholas, Woolf, Anthony D, Yip, Paul, Zielinski, Jan M, Lopez, Alan D, \\ Murray, Christopher JL, Ezzati, Majid
}

\section{Published}




\section{Journal Title}

The Lancet

\section{Version}

Post-print

\section{DOI}

https://doi.org/10.1016/S0140-6736(12)61766-8

\section{Copyright Statement}

(c) 2012 Elsevier. Licensed under the Creative Commons Attribution-NonCommercialNoDerivatives 4.0 International Licence which permits unrestricted, non-commercial use, distribution and reproduction in any medium, providing that the work is properly cited.

Downloaded from

http://hdl.handle.net/10072/49807

\section{Griffith Research Online}

https://research-repository.griffith.edu.au 


\title{
A comparative risk assessment of burden of disease and injury attributable to 67 risk factors and risk factor clusters in 21 regions, 1990-2010: a systematic analysis for the Global Burden of Disease Study 2010
}

\author{
A full list of authors and affiliations appears at the end of the article.
}

\section{Summary}

Background-Quantification of the disease burden caused by different risks informs prevention by providing an account of health loss different to that provided by a disease-by-disease analysis. No complete revision of global disease burden caused by risk factors has been done since a comparative risk assessment in 2000, and no previous analysis has assessed changes in burden attributable to risk factors over time.

Methods-We estimated deaths and disability-adjusted life years (DALYs; sum of years lived with disability [YLD] and years of life lost [YLL]) attributable to the independent effects of 67 risk factors and clusters of risk factors for 21 regions in 1990 and 2010. We estimated exposure distributions for each year, region, sex, and age group, and relative risks per unit of exposure by systematically reviewing and synthesising published and unpublished data. We used these estimates, together with estimates of cause-specific deaths and DALYs from the Global Burden of Disease Study 2010, to calculate the burden attributable to each risk factor exposure compared with the theoretical-minimum-risk exposure. We incorporated uncertainty in disease burden, relative risks, and exposures into our estimates of attributable burden.

Findings-In 2010, the three leading risk factors for global disease burden were high blood pressure (7.0\% [95\% uncertainty interval 6.2-7.7] of global DALYs), tobacco smoking including second-hand smoke (6.3\% [5.5-7.0]), and alcohol use (5.5\% [5.0-5.9]). In 1990, the leading risks were childhood underweight (7.9\% [6.8-9.4]), household air pollution from solid fuels (HAP; $7 \cdot 0 \%[5 \cdot 6-8 \cdot 3])$, and tobacco smoking including second-hand smoke $(6 \cdot 1 \%$ [5.4-6.8]). Dietary risk factors and physical inactivity collectively accounted for $10 \cdot 0 \%$ (95\% UI 9.2-10.8) of global DALYs in 2010, with the most prominent dietary risks being diets low in fruits and those high in sodium. Several risks that primarily affect childhood communicable diseases, including unimproved water and sanitation and childhood micronutrient deficiencies, fell in rank between

\footnotetext{
${ }^{\ddagger}$ Correspondence to: Dr Stephen S Lim, Institute for, Health Metrics and Evaluation, 2301 Fifth Ave, Suite 600, Seattle, WA 98121, USA, stevelim@uw.edu.

Author listed alphabetically

$\dagger$ Joint senior authors

Contributors

CJLM, SSL, and ME wrote the first draft. SSL, TV, AF, GD, KS, ADL, CJLM, and ME revised the report. ME, CJLM, and ADL designed the study and provided overall guidance. SSL, EC, GF, CA, ESa, KA, REE, and LCR did comparative analyses of risk factors. All other authors developed the estimates of risk-specific exposure, theoretical-minimum-risk exposure distribution, and RR inputs, and checked and interpreted results.
} 
1990 and 2010, with unimproved water we and sanitation accounting for 0.9\% (0.4-1.6) of global DALYs in 2010. However, in most of sub-Saharan Africa childhood underweight, HAP, and nonexclusive and discontinued breastfeeding were the leading risks in 2010, while HAP was the leading risk in south Asia. The leading risk factor in Eastern Europe, most of Latin America, and southern sub-Saharan Africa in 2010 was alcohol use; in most of Asia, North Africa and Middle East, and central Europe it was high blood pressure. Despite declines, tobacco smoking including second-hand smoke remained the leading risk in high-income north America and western Europe. High body-mass index has increased globally and it is the leading risk in Australasia and southern Latin America, and also ranks high in other high-income regions, North Africa and Middle East, and Oceania.

Interpretation-Worldwide, the contribution of different risk factors to disease burden has changed substantially, with a shift away from risks for communicable diseases in children towards those for non-communicable diseases in adults. These changes are related to the ageing population, decreased mortality among children younger than 5 years, changes in cause-of-death composition, and changes in risk factor exposures. New evidence has led to changes in the magnitude of key risks including unimproved water and sanitation, vitamin A and zinc deficiencies, and ambient particulate matter pollution. The extent to which the epidemiological shift has occurred and what the leading risks currently are varies greatly across regions. In much of sub-Saharan Africa, the leading risks are still those associated with poverty and those that affect children.

Funding-Bill \& Melinda Gates Foundation.

\section{Introduction}

Measurement of the burden of diseases and injuries is a crucial input into health policy. Equally as important, is a comparative assessment of the contribution of potentially modifiable risk factors for these diseases and injuries. The attribution of disease burden to various risk factors provides a different account compared with disease-by-disease analysis of the key drivers of patterns and trends in health. It is essential for informing prevention of disease and injury.

Understanding the contribution of risk factors to disease burden has motivated several comparative studies in the past few decades. The seminal work of Doll and Peto ${ }^{1}$ provided a comparative assessment of the importance of different exposures, particularly tobacco smoking, in causing cancer. Peto and colleagues ${ }^{2}$ subsequently estimated the effects of tobacco smoking on mortality in developed countries since 1950. Although these risk factorspecific or cause-specific analyses are useful for policy, a more comprehensive global assessment of burden of disease attributable to risk factors can strengthen the basis for action to reduce disease burden and promote health. The Global Burden of Disease Study (GBD) 1990 provided the first global and regional comparative assessment of mortality and disability adjusted life-years (DALYs) attributable to ten major risk factors. ${ }^{3}$ However, different epidemiological traditions for different risks limited the comparability of the results. Subsequently, Murray and Lopez 4 proposed a framework for global comparative risk assessment, which laid the basis for assessment of 26 risks in $2000 .^{5-7}$ Since this work, WHO has provided estimates for some risks by the same methods but with updated 
exposures and some updates of the effect sizes for each risk. ${ }^{8}$ Analyses have also been done for specific clusters of diseases, like cancers, ${ }^{9}$ or clusters of risk factors, like maternal and child under-nutrition. ${ }^{10}$ National comparative risk assessments (including in Australia, Iran, Japan, Mexico, South Africa, Thailand, USA, and Vietnam) have also been undertaken with similar approaches. ${ }^{11-16}$

GBD 2010 provides an opportunity to re-assess the evidence for exposure and effect sizes of risks for a broad set of risk factors by use of a common framework and methods.

Particularly, since this work was done in parallel with a complete re-assessment of the burden of diseases and injuries in 1990 and 2010, for the first time changes in burden of disease attributable to different risk factors can be analysed over time with comparable methods. Since uncertainty has been estimated for each disease or injury outcome, ${ }^{17,18}$ the comparative risk assessment for GBD 2010 has also enabled us to incorporate uncertainty into the final estimates. We describe the general approach and high-level findings for comparison of the importance of 67 risk factors and clusters of risk factors, globally and for 21 regions of the world, over the past two decades.

\section{Methods}

\section{Overview}

The basic approach for the GBD 2010 comparative risk assessment is to calculate the proportion of deaths or disease burden caused by specific risk factors - eg, ischaemic heart disease caused by increased blood pressure-holding other independent factors unchanged. These calculations were done for 20 age groups, both sexes, and 187 countries and for 1990, 2005 (results for 2005 not shown, available from authors on request), and 2010. We present aggregated results for 21 regions.

Table 1 shows the included risk factors and their organisation into a hierarchy with three levels. Level 1 risks are clusters of risk factors that are related by mechanism, biology, or potential policy intervention. Most risks are presented at level 2. For occupational carcinogens, a third level is included to provide additional detail about specific carcinogens. For suboptimal breastfeeding we also include a third level to distinguish between nonexclusive breastfeeding during the first 6 months and discontinued breastfeeding from 6 to 23 months.

We calculated burden attributable to all (67) risk factors and clusters of risk factors except for physiological risks and air pollution. These two clusters present analytical challenges for computation of the aggregate burden. For example, the effects of high body-mass index are partly mediated through high blood pressure, high total cholesterol, and high fasting plasma glucose, and household air pollution from solid fuels (wood, crop, residues, animal dung, charcoal, and coal) contributes to ambient particulate matter pollution.

We ranked results for 43 risk factors and clusters of risk factors, grouping together occupational carcinogens, non-exclusive and discontinued breastfeeding, and tobacco smoking with second-hand smoke on the basis of common exposure sources. 
Our estimation of disease burden attributable to a risk factor had five steps: 1) selection of risk-outcome pairs to be included in the analysis based on criteria about causal associations; 2) estimation of distributions of exposure to each risk factor in the population; 3) estimation of etiological effect sizes, often relative risk per unit of exposure for each risk-outcome pair; 4) choice of an alternative (counterfactual) exposure distribution to which the current exposure distribution is compared. We selected an optimum exposure distribution, termed the theoretical-minimum-risk exposure distribution for this purpose; and 5) computation of burden attributable to each risk factor, including uncertainty from all sources. Further details about the data and methods used for specific risk factors are available on request.

\section{Selection of risk-outcome pairs}

The inclusion criteria for each risk-outcome pair that we applied were: 1) the likely importance of a risk factor to disease burden or policy based on previous work; 2) availability of sufficient data and methods to enable estimation of exposure distributions by country for at least one of the study periods (1990 and 2010); 3) sufficient evidence for causal effects based on high-quality epidemiological studies in which the findings were unlikely to be caused by bias or chance, analogous to the criteria used for assessment of carcinogens with con vincing or probable evidence (panel). Sufficient data to estimate outcome-specific etiological effect sizes per unit of exposure were also needed; and 4) evidence to support generalisability of effect sizes to populations other than those included in the available epidemiological studies or satisfactory models for extrapolating them. Table 1 shows the risk-outcome pairs that were included in the final analysis, on the basis of these criteria.

\section{Distribution of exposure to each risk factor}

For most risk factors, a systematic search was done to identify published and, when possible, unpublished data sources to estimate risk factor exposure distributions in 1990 and 2010. Strategies to identify data sources included searching survey databases such as the WHO Global Database on Child Growth and Malnutrition, searching general citation databases such as Google Scholar and PubMed, manual searching of reference lists of articles and conference abstracts, and contacting experts in the relevant fields. Data sources included censuses, health examination and nutrition surveys, and community-based epidemiological studies.

Because data for risk factor exposure are often incomplete or missing for many populations, models were used to generate a complete set of current exposure distributions for risk factors for each country and for both years, including uncertainty. Table 1 shows for each risk factor the main sources of data and the modelling approach used for estimation of present risk factor exposure distributions. Briefly, risk factor models were designed to use available data and information for exposures in countries, for several years, and for different age groups to generate estimates for all countries, for both years, and for all relevant age groups. Estimation of exposure was done with statistical models that used predictors such as time, geography, and other variables that were relevant to the exposure of interest- eg, income per person. 
For each risk factor, we tested a wide array of covariates for prediction of exposure distributions, drawing from covariates included in databases created or collated at the Institute for Health Metrics and Evaluation for GBD 2010. If relevant, the model also included age. Finally, each analysis accounted for important study characteristics such as national versus subnational representativeness, and the measures and instruments used for measuring exposure.

In addition to this general approach, specific methods were used for some risk factors. For tobacco including second-hand smoke, much scientific literature exists about alternative methods to estimate cumulative exposure, based on the premise that present prevalence and consumption data do not take into account likely variations in duration and intensity of smoking. In this case, we used the method of Peto and Lopez, ${ }^{2}$ which uses lung cancer mortality as a marker (ie, smoking impact ratio) of cumulative population exposure to smoking for cancers and chronic respiratory disease. We used epidemiological data to estimate lung cancer mortality in non-smokers separately for China, other countries in the high-income Asia Pacific region, and all remaining countries. ${ }^{119,120}$ For all other outcomes, we used 10-year lagged tobacco smoking prevalence. We also applied an approach analogous to the smoking impact ratio for occupational exposure to asbestos, for which we used mesothelioma mortality, separately estimated, as a marker of asbestos exposure.

For ambient particulate matter pollution, two complete, high resolution estimates exist of the concentration of particulate matter smaller than $2.5 \mu \mathrm{m}$ in aerodynamic diameter $\left(\mathrm{PM}_{2.5}\right)$ in ambient air: TM5 estimates-based on a nested three-dimensional global atmospheric chemistry transport model—which simulates both particulate matter and ozone at a high spatial resolution; ${ }^{22,23,121}$ and satellite-based estimates, which are based on satellite observations of aerosol optical depth, a measure of light extinction by aerosols in the total atmospheric column. ${ }^{25}$ TM5 and satellite-based estimates of $\mathrm{PM}_{2.5}$, measured in $\mu \mathrm{g} / \mathrm{m} 3$, were averaged at a $0 \cdot 1^{\circ} \times 0 \cdot 1^{\circ}$ grid cell resolution (equivalent to roughly $11 \mathrm{~km} \times 11 \mathrm{~km}$ at the equator) and linked to available measures of $\mathrm{PM}_{2.5}$ from ground-based monitors. We used a regression model with the average of TM5 and satellite-based estimates as the predictor to estimate ground-based $\mathrm{PM}_{2.5}$ for all grid cells. ${ }^{26}$ For ozone, we relied solely on the TM5 model.

Few population-based surveys have measured zinc deficiency based on serum zinc concentration; ${ }^{122}$ however, intervention trials show a benefit of zinc supplementation for reduction of diarrhoea and lower respiratory infections in populations that have high zinc deficiency. ${ }^{10}$ Because of the paucity of data for serum zinc concentrations, we measured zinc deficiency at the population level on the basis of dietary sources of zinc, expanding on previous work of the International Zinc Nutrition Consultative Group. ${ }^{123}$ This approach uses national food balance sheets produced by the UN Food and Agriculture Organization to estimate a country-specific mean fractional absorption of zinc. The estimated mean daily per person amount of absorbable zinc in the food supply was compared with the mean physiological requirements of the population to calculate the percentage of the population with inadequate zinc intake. 


\section{Effects of risk factors on disease outcomes}

Table 1 shows the sources of effect sizes per unit of exposure for each risk factor. Some effect sizes were based on meta-analyses of epidemiological studies. For several risk factors without recent systematic reviews or for which evidence had not recently been synthesised, new meta-analyses were done as part of GBD 2010. We used effect sizes that had been adjusted for measured confounders but not for factors along the causal pathway. For example, effect sizes for body-mass index were not adjusted for blood pressure. For some risk-outcome pairs, evidence is only available for the relative risk (RR) of morbidity or mortality. In these cases, we assumed that the reported RR would apply equally to morbidity or mortality, unless evidence suggested a differential effect. For example, studies of ambient particulate matter pollution suggest a smaller effect on incidence of cardio vascular and respiratory disease than on mortality; ${ }^{124-126}$ the published work on consumption of seafood omega-3 fatty acids suggests an effect on ischaemic heart disease mortality but not on incidence of ischaemic heart disease. ${ }^{90}$

Evidence for the RR of diarrhoea from unimproved water and sanitation is complicated by the complexity of available epidemiological studies, since the comparison groups varied greatly between studies. The comparison group used varied widely. For example, some studies compare an improved water source (eg, piped water) with an unimproved water source (eg, river water); in other studies the comparison is between two different types of improved water source (eg, piped water $v s$ a protected well). Furthermore, studies often examine a combination of water, sanitation, and hygiene interventions. Previous reviews have yielded conflicting results about the magnitude of the effect sizes. ${ }^{127-131}$

We re-examined the epidemiological evidence for the effects of water and sanitation by reviewing the relation between water, sanitation and hygiene, and diarrhoea, starting with previous reviews. ${ }^{128-131} \mathrm{We}$ did a meta-regression of 119 studies that was designed to adjust for intervention and baseline group characteristics. First, we compared indicator variables for each of the intervention components (improved sanitation, hygiene, point-ofuse water treatment, source water treatment, and piped water) with a reference category (improved water source). Second, we also included indicator variables for the baseline characteristics-ie, whether the baseline was an unimproved or improved water source or sanitation - as covariates to account for the heterogeneous control groups. Our analysis showed a significant effect of both improved water and improved sanitation compared with unimproved water and sanitation; we did not note a significantly greater effect of piped water or point-of-use or source water treatment compared with improved water.

Particulate matter smaller than $2.5 \mu \mathrm{m}$ is a common useful indicator of the risk associated with exposure to a mixture of pollutants from diverse sources and in different environments, including ambient particulate matter pollution from transportation, wind-blown dust, burning of bio mass, and industrial sources; second-hand smoke; burning of biomass and coal for household energy; and active smoking. ${ }^{132,133}$ However, existing studies cover only small concentration ranges-for example, ambient particulate matter pollution studies have been restricted to yearly average concentrations of particulate matter smaller than $2.5 \mu \mathrm{m}$ of roughly $5 \mu \mathrm{g} / \mathrm{m}^{3}$ to $30 \mu \mathrm{g} / \mathrm{m}^{3},{ }^{134-137}$ but much higher concentrations of ambient particulate 
matter have been recorded in polluted cities in Asia and elsewhere. The relation between concentration of small particulate matter and risk of disease is probably non-linear. ${ }^{132,133}$

To inform estimates of risk across the full range of concentrations, we used the approach of Pope and colleagues ${ }^{132}$ and integrated epidemiological evidence for the hazardous effects of particulate matter at different concentrations from different sources and environments. Methods for estimation of the integrated exposure- response curves for each cause are described elsewhere. ${ }^{138}$ Briefly, we compiled study-level estimates of the RR of mortality associated with any or all of ambient air pollution, second-hand smoke, household air pollution, and active smoking for the following outcomes: ischaemic heart disease, stroke, lung cancer, chronic obstructive pulmonary disease, and acute lower respiratory tract infection in children. We evaluated several non-linear functions with up to three parameters for fitting the integrated exposure- response relation and assessed them by calculation of the root mean squared error. An exponential decay with a power of concentration was the functional form that provided the best fit for all five outcomes. The integrated exposureresponse curve was then used to generate effect sizes specific to the amount of ambient particulate matter smaller than $2.5 \mu \mathrm{m}$ for each population. For ischaemic heart disease and stroke, evidence shows that household air pollution affects intermediate outcomes, such as blood pressure, ${ }^{139}$ but not clinical events. For acute lower respiratory tract infection, the integrated exposure- response curve enabled us to extrapolate beyond the partial exposureresponse measured in the RESPIRE trial. ${ }^{140}$ For effects of household air pollution on chronic obstructive pulmonary disease and lung cancer we use the effect size based on new systematic reviews and meta-analyses.

Several dietary factors affect ischaemic heart disease and stroke, including consumption of fruits, vegetables, nuts and seeds, whole grains, processed meat, polyunsaturated fats, and seafood omega-3 fatty acids. ${ }^{81,83,85,87,90-92,141,142}$ We updated earlier systematic reviews and meta-analyses for fruits, vegetables, and seafood omega-3 fatty acids, which included both observational and intervention studies if available. A systematic review ${ }^{143}$ of randomised clinical trials of supplementation with seafood omega-3 fatty acids reported non-significant effects on several outcomes, and a significant effect for mortality from ischaemic heart disease - the primary outcome in GBD 2010. In view of this finding, we tested whether a significant difference exists between the randomised clinical trials of seafood omega-3 fatty acid supplementation and observational studies of seafood-omega 3 fatty acid intake. The effect of seafood omega-3 fatty acids tended to be lower in randomised controlled trials than in observational studies, however, this difference was not statistically significant ( $\mathrm{p}=0 \cdot 057)$. Therefore, we used the effect size based on the combination of randomised clinical trials and observational studies but also did a sensitivity analysis with the effect size based on randomised clinical trials.

Estimates of the RR associated with dietary risk factors are based largely on observational studies that control for age, sex, and other cardiovascular risk factors. However, some early observational studies do not fully control for other dietary components. Protective dietary risk factors such as consumption of fruits, vegetables, and whole grains, tend to be positively correlated with each other and negatively correlated with harmful dietary risk factors such as consumption of processed meat. Therefore, RRs estimated for single risk factors in 
observational studies could overestimate the protective or harmful effect of that risk factor. In effect, the partially adjusted RR will include some of the effects associated with other correlated diet components, particularly since the exposure measure for dietary risk factors is energy adjusted to a standard calorie intake.

To examine this issue, we did further empirical assessments using studies of dietary patterns and randomised controlled feeding studies. Studies of dietary patterns ${ }^{144-148}$ have estimated the effects of beneficial diets (prudent or Mediterranean diets) and harmful diets (western diets); these studies capture the overall effects of differences in dietary components. For example, a prudent diet has lots of fruits, vegetables, fish, and whole grains. For each of the dietary pattern studies we computed the estimated RR for dietary pattern groups with the RRs from the meta-analyses of single dietary risk factors, the reported differences in dietary intake, and assuming a multiplicative relation between RRs for individual components.

Results of this internal validation study show that overall, estimation of the effect of dietary pattern based on the RRs reported for single risk factors was much the same as the effect reported in the study; across four large cohort studies of seven dietary patterns the average ratio for the estimated RR reduction compared with the measured RR reduction was 0.98.

In addition to the dietary pattern studies, we also investigated the evidence for the effects of dietary risk factors from randomised controlled feeding studies, such as $\mathrm{DASH}^{149}$ and OmniHeart, ${ }^{150}$ which measured the effect of dietary changes on blood pressure and LDL cholesterol. We used meta-regression to estimate the pooled effect of fruits, vegetables, nuts and seeds, whole grains, fish, and dietary fibre on systolic blood pressure and LDL cholesterol, based on all randomised controlled feeding studies (six treatment groups from three studies for blood pressure and six treatment groups from two studies for cholesterol). When translated into an effect using the RRs of blood pressure and cholesterol for ischaemic heart disease, the average ratio of the estimated to measured RR reduction was 1.07 for all components and 0.85 when excluding fish, which has mechanisms additional to lowering blood pressure and cholesterol. ${ }^{151}$ These two supplementary analyses suggest that the RRs estimated in the meta-analyses of single dietary risk factors are unlikely to be significantly biased because of residual confounding due to other diet components.

Pooled epidemiological studies of cardiovascular disease risks show that the RR decreases with age, and that the inverse age association is roughly log-linear. Based on a pooled analysis of several risk factors (high blood pressure, high fasting plasma glucose, high total cholesterol, and tobacco smoking), the age at which the RR reaches 1 is often between 100 and 120 years. We therefore estimated age-specific RRs for all cardiovascular risk factors by meta-regression of available data with $\operatorname{logRR}$ as the dependent variable and median age at event as the independent variable with an age intercept $(R R=1)$ at age 110 years. Uncertainty in the RR was generated by simulation analyses. ${ }^{152}$

The causal association between a risk factor and a disease outcome is often informed by a wider body of evidence than epidemiological studies of RRs for specific measures of exposure, especially when disease-specific and age-specific RRs are needed. For example, although smoking is an established cause of cardiovascular diseases, when cohorts are analysed in fine age groups, the $95 \%$ CI for the effect of smoking on stroke spans 1.0 in 
several age groups. ${ }^{38}$ Similarly, randomised trials of zinc supplementation were designed to detect effects on total mortality. ${ }^{36,153} \mathrm{Re}$-analysis of the same trials for disease-specific outcomes, which is necessary to extrapo late effects to populations with different causes of death, reduced their statistical power and gave $95 \%$ CIs that spanned $1 \cdot 0$. To use the broad evidence while accounting for the uncertainty of the subgroup RRs, we included in the uncertainty analysis all draws of the RR distribution, including those that show a protective effect as long as the overall relation for the risk factor across all ages is significant. In other cases, if there are different degrees of exposure for a risk factor, in some exposure categories the RR might not be significant. We have included draws from these posterior distributions if the mean values show a dose-response relation. To fairly represent the extent of our epidemiological knowledge, we have included in the uncertainty analysis draws from the posterior distribution for those exposure categories that show a protective effect.

\section{Theoretical-minimum-risk exposure distributions for counterfactual comparison}

In the comparative risk assessment framework, disease burden attributable to risk factors is calculated with reference to an alternative (counterfactual) distribution of exposure; in GBD 2010, we used an optimal exposure distribution (in terms of effect on population health), termed the theoretical-minimum-risk exposure distribution. For several risk factors, such as tobacco smoking, the choice of theoretical-minimum-risk exposure distribution is clear-ie, $100 \%$ of the population being lifelong non-smokers. However, for many of the other risk factors zero exposure is not possible (eg, blood pressure), or the lowest amount of exposure that is still beneficial is not yet established. In these cases the theoretical-minimum-risk exposure distribution was informed by two considerations: the availability of convincing evidence from epidemiological studies that support a continuous reduction in risk of disease to the chosen distribution; and a distribution that is theoretically possible at the population level (table 1).

For some risk factors, new evidence has resulted in a revision of the theoretical-minimumrisk exposure distribution compared to the previous comparative risk assessment. For example, the previous distribution for systolic blood pressure was a mean of $115 \mathrm{~mm} \mathrm{Hg}$ (SD 6). ${ }^{6}$ However, subsequent randomised trials ${ }^{154}$ of blood pressure-lowering medication suggest that the benefits of lowering blood pressure could continue to $110 \mathrm{~mm} \mathrm{Hg}$ or lower. On this basis, we changed the theoretical-minimum-risk exposure distribution to a mean of 110-115 mm Hg (SD 6). For other exposures, the distribution was increased because of data from new epidemiological studies ${ }^{75}$ — eg, for mean body-mass index we used $21-23 \mathrm{~kg} / \mathrm{m}^{2}$, compared with $21 \mathrm{~kg} / \mathrm{m}^{2}$ used previously.

For ambient particulate matter pollution, we did a sensitivity analysis with an alternative theoretical-minimum-risk exposure distribution that included the effect of regional dust particulate matter. We did so because although particulate exposure from dust could theoretically be reduced, it would probably be prohibitively expensive and could only be done over a very long period. This factor is particularly relevant in areas with high amounts of dust-eg, deserts. Dusty grid cells were identified as those with an ambient air concentration of $\mathrm{PM}_{2.5}$ of $36 \mu \mathrm{g} / \mathrm{m}^{3}$ or more and where the dust fraction from the TM5 chemical transport model was $50 \%$ or more. 


\section{Mortality and disease burden attributable to individual and clusters of risk factors}

We calculated the burden attributable to risk factors with continuous exposure by comparing the present distribution of exposure to the theoretical-minimum-risk exposure distribution for each age group, sex, year (1990 and 2010), and cause according to the following formula:

$$
\mathrm{PAF}=\frac{\int_{\mathrm{x}=0}^{\mathrm{m}} \mathrm{RR}(x) \mathrm{P} 1(x) \mathrm{dx}-\int_{\mathrm{x}=0}^{\mathrm{m}} \mathrm{RR}(x) \mathrm{P} 2(x) \mathrm{dx}}{\int_{\mathrm{x}=0}^{\mathrm{m}} \mathrm{RR}(x) \mathrm{P} 1(x) \mathrm{dx}}
$$

Where PAF is the population attributable fraction (burden attributable to risk factor), $R R(x)$ is the RR at exposure level $\times, P 1(x)$ is the (measured or estimated) population distribution of exposure, $\mathrm{P} 2(\times)$ is the counterfactual distribution of exposure (ie, the theoretical-minimumrisk exposure distribution), and $\mathrm{m}$ the maxi mum exposure level. ${ }^{4}$

Burden attributable to categorical exposures was calculated by comparing exposure categories to a reference category for each age, sex, year, and cause according to the following formula:

$$
\mathrm{PAF}=\frac{\sum_{\mathrm{i}=1}^{\mathrm{n}} \mathrm{P}_{\mathrm{i}}\left(\mathrm{RR}_{\mathrm{i}}-1\right)}{\sum_{\mathrm{i}=1}^{\mathrm{n}} \mathrm{P}_{\mathrm{i}}\left(\mathrm{RR}_{\mathrm{i}}-1\right)+1}
$$

Where $R R_{i}$ is the $R R$ for exposure category $i, P_{i}$ is the fraction of the population in exposure category $\mathrm{i}$, and $\mathrm{n}$ is the number of exposure categories. ${ }^{4}$

We calculated the burden attributable to clusters of risk factors by computing the combined population attributable fraction for risk factors for each age, sex, year, and cause according to the following formula:

$$
\mathrm{PAF}=1-\prod_{\mathrm{r}=1}^{\mathrm{R}}\left(1-\mathrm{PAF}_{\mathrm{r}}\right)
$$

Where $\mathrm{r}$ is each individual risk factor, and $\mathrm{R}$ is the number of risk factors. This approach assumes that risk factors are independent-ie, it does not account for mediation, exposure correlation, or effect size modification that might exist between risk factors in a cluster. ${ }^{155}$

To represent uncertainty in the estimates we used simulation analysis to take 1000 draws from the posterior distribution of exposure, RR, and each relevant outcome for each age, sex, country, year. We accounted for the correlation structure of uncertainty (ie, whether exposure in a country, age group, and sex is high or low might be related to whether it is high or low in other subgroups) by use of the same draw of exposure across different outcomes and the same draw of RR across country, age, and sex subgroups when the RR does not vary by country, age, or sex. We otherwise assumed that the uncertainties in exposure, RR, and underlying burden attributable to the outcome were independent. 
We computed the mean deaths and DALYs attributable to each risk factor and risk factor cluster from the 1000 draws. The $95 \%$ uncertainty intervals (95\% UI) were calculated as the 2.5 th and 97.5 th percentiles of the 1000 draws. We also computed the mean rank and $95 \%$ UI for the 43 risk factors included in the ranking list. The mean of the ranks for a risk factor was not necessarily equivalent to the rank of the mean deaths or mean DALYs attributable to the risk factor.

\section{Role of the funding source}

The sponsor of the study had no role in study design, data collection, data analysis, data interpretation, or writing of the report. The corresponding author had full access to all the data in the study and had final responsibility for the decision to submit for publication.

\section{Results}

Quantification of risk factors in this analysis represents the effects of each individual risk factor, holding all other independent factors constant. The effects of multiple risk factors are not a simple addition of the individual effects and are often smaller than their sums, ${ }^{156}$ especially for cardiovascular diseases, which are affected by several risk factors (eg, table 2). The sum of the individual effects of just the metabolic risk factors at the global level is $121 \%$ and the summation of all the risks is greater than $400 \%$.

We estimated global attributable mortality and DALYs with uncertainty for 1990, and 2010, for each of the 67 risk factors and clusters of risk factors (table 3, 4). The appendix shows full results by region, year, age, and sex for attributable deaths and DALYs. Because of the interest in the combined effects of multiple risk factors, we have approximated the joint effects of clusters of risk factors assuming that risk factors included in each cluster are independent. However, risk factors included in a cluster are not necessarily independent; for example, a substantial part of the burden attributable to high body-mass index is mediated through high blood pressure and high fasting plasma glucose. Others act together and risk factor exposures might be correlated at the individual level, ${ }^{155}$ especially household air pollution and ambient particulate matter pollution, which might have common sources.

For these reasons we have not computed the joint effects for physiological risk factors or air pollution. However, the combined effects of physiological risk factors are probably large, with high blood pressure the leading single risk factor globally, accounting for 9.4 million (95\% UI 8.6 million to 10.1 million) deaths and 7.0\% (6.2-7.7) of global DALYs in 2010, followed by high body-mass index (3.4 million [2.8 million to 4.0 million deaths] and 3.8\% [3.1-4.4] of global DALYs in 2010), high fasting plasma glucose (3.4 million [2.9 million to 3.7 million] deaths and 3.6\% [3.1-4.0] of DALYs), high total cholesterol (2.0 million [1.6 million to 2.5 million] deaths and $1.6 \%$ [1.3-2.0] of DALYs), and low bone mineral density (0.2 million [0.1 million to $0 \cdot 2$ million] deaths and $0 \cdot 21 \%[0 \cdot 17-0 \cdot 25]$ of DALYs).

The joint effects of air pollution are also likely to be large. Household air pollution from solid fuels accounted for 3.5 million (2.7 million to 4.4 million) deaths and 4.5\% (3.4-5.3) of global DALYs in 2010 and ambient particulate matter pollution accounted for 3.1 million (2.7 million to 3.5 million) deaths and $3.1 \%(2.7-3.4)$ of global DALYs. For ambient 
particulate matter pollution, we also did a post-hoc sensitivity analysis excluding the effects of dust, which had a small effect worldwide-attributable global DALYs decreased by $2 \%$ -but large effects in north Africa and Middle East. Household air pollution is an important contributor to ambient particulate matter pollution; we estimate that it accounted for $16 \%$ of the worldwide burden from ambient particulate matter pollution in 2010. The effects of ambient ozone pollution, which increases the risk of chronic obstructive pulmonary disease, were smaller than those of household air pollution from solid fuels or ambient particulate matter pollution $(0.2$ million [0.1 million to 0.3 million] deaths and $0.1 \%$ [0.03-0.2] of global DALYs in 2010).

For other clusters of risk factors for which we approximated the joint effects assuming independence, dietary risk factors and physical inactivity were responsible for the largest disease burden: $10.0 \%(9 \cdot 2-10 \cdot 8)$ of global DALYs in 2010. Of the individual dietary risk factors, the largest attributable burden in 2010 was associated with diets low in fruits (4.9 million [3.8 million to 5.9 million] deaths and $4.2 \%$ [3.3-5.0] of global DALYs), followed by diets high in sodium (4.0 million [3.4 million to 4.6 million]; $2.5 \%$ [1.7-3.3]), low in nuts and seeds (2.5 million [1.6 million to 3.2 million]; $2.1 \%$ [1.3-2.7]), low in whole grains (1.7 million [1.3 million to 2.1 million]; $1.6 \%$ [1.3-1.9]), low in vegetables ( 1.8 million [1.2 million to 2.3 million]; $1.5 \%$ [1.0-2.1]), and low in seafood omega-3 fatty acids ( 1.4 million [1.0 million to 1.8 million]; $1.1 \%$ [0.8-1.5]). Our sensitivity analysis of omega-3 fatty acids using relative risks from randomised trials reduced the attributable burden by more than half, to 0.6 million ( -0.6 million to 1.7 million) deaths, and $0.5 \%$ ( -0.5 to 1.4 ) of global DALYs in 2010. Physical inactivity and low physical activity accounted for 3.2 million (2.7 million to 3.7 million) deaths, and 2.8\% (2.4-3.2) of DALYs in 2010.

Child and maternal undernutrition was responsible for the next largest attributable burden of the risk factor clusters (1.4 million [1.2 million to 1.7 million] deaths; $6.7 \%$ [5.7-7.7] of global DALYs in 2010), with childhood underweight the largest individual contributor ( 0.9 million [0.7 million to 1.0 million]; $3 \cdot 1 \%$ [2.6-3.7]), followed by iron deficiency $(0 \cdot 1$ million [0.09 million to 0.14 million]; $1.9 \%$ [1.4-2.6]), and suboptimal breast feeding ( 0.5 million [0.3 million to 0.8 million]; $1.9 \%$ [1.2-2.7]). Vitamin A and zinc deficiencies amongst children accounted for less than $0.8 \%$ of the disease burden.

The burdens of disease attributable to tobacco smoking including second-hand smoke (6.3 million [5.4 million to $7 \cdot 0$ million] deaths and $6 \cdot 3 \%$ [5.5-7.0] of DALYs) as well as alcohol and drug use (5.0 million [4.7 million to 5.3 million] deaths and 6.5\% [6.0-7.0] of DALYs) were substantial in 2010 . These burdens are mainly driven by active smoking, which accounts for $87 \%$ of the combined burden with second-hand smoke, and alcohol use which accounted for 4.9 million (4.5 million to 5.2 million) deaths and 5.5\% (5.0-5.9) of global DALYs in 2010. Of the remaining risk factor clusters, occupational risk factors accounted for 0.9 million ( 0.7 million to 1.1 million) deaths and $2.5 \%(2.0-3.0)$ of global DALYs in 2010 , followed by sexual abuse and violence $(0 \cdot 2$ million [0.1 million to $0 \cdot 3$ million] deaths and $0.9 \%[0.7-1 \cdot 2]$ DALYs), unimproved water and sanitation, (0.3 million [0 to 0.6 million] deaths and $0.9 \%$ [0.04-1.6] DALYs), and other environmental risks ( 0.7 million [0.6 million to 0.9 million] deaths and $0.6 \%$ [0.5-0.8] DALYs). 
The rest of the results section refers to the 43 risk factors and clusters of risk factors in the rank list. The predominance of non-communicable disease risks in 2010 highlights the global epidemiological transition that has occurred since 1990 (figures 1, 2, 3). In 1990, the leading risks were childhood underweight (7.9\% [6.8-9.4] of global DALYs), household air pollution from solid fuels (7.0\% [5.6-8.3]), and tobacco smoking including second-hand smoke (6.1\% [5.4-6.8]), high blood pressure (5.5\% [4.9-6.0]), and suboptimal breast feeding $(4 \cdot 4 \%$ [2.8-6.1]). With the exception of house hold air pollution, which is a significant contributor to childhood lower respiratory tract infections, the five leading risk factors in 2010 (high blood pressure, tobacco smoking including secondhand smoke, alcohol use, household air pollution, and diets low in fruits) are mainly causes of adult chronic disease, especially cardio vascular diseases and cancers (figures 1,2 ). The burden of disease attributable to other chronic disease risk factors also increased substantially between 1990 and 2010; for example, the global disease burden attributable to high body-mass index increased from 52 million to 94 million DALYs and that of high fasting plasma glucose increased from 56 million to 89 million DALYs over this period.

The rise in global disease burden attributable to chronic disease risk factors has been accompanied by a decrease in the relative importance of risk factors that largely or exclusively cause communicable diseases in children. The global disease burden attributable to childhood underweight halved between 1990 (7.9\% [6.8-9.4] of global DALYs) and 2010 (3.1\% [2.6-3.7]; table 3). Although the fraction of disease burden attributable to iron deficiency fell relatively little, suboptimal breastfeeding, unimproved water, unimproved sanitation, vitamin A deficiency, and zinc deficiency all decreased substantially between 1990, and 2010.

The transition from childhood communicable to non-communicable disease burden is also exemplified by the fall in DALYs caused by household air pollution from solid fuels (despite the rise in its effects on cardiovascular diseases). Although the burden attributable to ambient particulate matter pollution has largely remained unchanged $(3 \cdot 2 \%[2 \cdot 8-3 \cdot 7]$ of global DALYs in 1990 vs 3.0\% [2.6-3.4] in 2010), the contribution of lower respiratory tract infections had fallen sharply by 2010 , with chronic diseases of adults being the dominant health outcome caused by this exposure.

Figure 4 shows the $95 \%$ uncertainty interval in global DALYs attributable to each risk factor and the overall rank for each risk factor. The uncertainty intervals for many risk factors overlap, especially those not in the top five. Unimproved water, unimproved sanitation, vitamin A deficiency, and zinc deficiency have large uncertainty, which reflects the substantial uncertainty in the estimates of etiological effect sizes for these risks.

Some risks were quantified for women only-for example, intimate partner violence, which accounted for $1.5 \%(1.0-2 \cdot 1)$ of DALYs among women in 2010. Important differences between men and women also exist for disease burden attributable to other risk factors, most notably, for tobacco smoking including secondhand smoke and alcohol use (figures 1,2). These risks cause substantially lower burden in women than in men, because women drink less and in less harmful ways than do men, and fewer smoke or have smoked for a shorter time than have men in most regions. ${ }^{157}$ In 2010 , tobacco smoking including second-hand 
smoke accounted for $8.4 \%$ of worldwide disease burden among men (the leading risk factor) compared with 3.7\% among women (fourth highest risk factor). For alcohol use, these sex differences were similarly sub stantial: $7.4 \%$ (third) versus $3.0 \%$ (eighth). The effect of occupational risk factors on population health also differed between sexes-for example, the fraction of disease burden attributable to occupational risk factors for injuries was 18.5 times higher for men than for women in 2010 (20 175000 DALYs for men vs 1090000 for women). Dietary risk factors had broadly similar effects for men and women with the exception of diet low in fruits, for which the fraction of disease burden attributable was 1.5 times larger for men than for women in 2010 (47 979000 DALYs for men vs 32474000 for women). This effect is caused by lower fruit consumption and a larger disease burden from cardiovascular disease in men.

Further disaggregation of mortality and disease burden attributable to risk factors reveals several patterns by age group (appendix). Among children younger than 5 years, childhood underweight was the leading risk factor worldwide in 2010 (12.4\% [10.4-14.7] of global DALYs), followed by non-exclusive or discontinued breast feeding (7.6\% [4.8-10.9]) and household air pollu tion from solid fuels (6.3\% [4.4-8.1]). Vitamin A and zinc deficiencies, unimproved sanitation, and unimproved water each accounted for less than $2 \%$ of disease burden in children younger than 5 years.

For people aged 15-49 years, the leading risk factor worldwide was alcohol use, followed by tobacco smoking including second-hand smoke, high blood pressure, high body-mass index, diet low in fruits, drug use, and occupational risk factors for injuries. Risk factor rankings in this age group stayed broadly similar between 1990, and 2010, with the exception of iron deficiency, which dropped from the fourth leading risk factor in 1990, to ninth in 2010 .

High blood pressure, tobacco smoking including second-hand smoke, alcohol use, and diet low in fruits were all in the top five risk factors for adults aged 50-69 years and adults older than 70 years, in both 1990, and 2010, accounting for a large proportion of disease burden in both age groups. Globally, high blood pressure accounted for more than $20 \%$ of all health loss in adults aged 70 years and older in 2010, and around 15\% in those aged 50-69 years. Tobacco smoking including secondhand smoke accounted for more than $10 \%$ of global disease burden in each of these age groups in 2010.

In all 21 regions, and worldwide, a shift has occurred, from risk factors for childhood communicable disease to risk factors for non-communicable disease. The size of this shift and which risk factors account for the largest burden varies highly between regions (figure 5 , appendix).

In central, eastern, and western sub-Saharan Africa, the share of disease burden attributable to childhood underweight, household air pollution from solid fuels, and suboptimal breastfeeding has fallen sub stantially. However, these risk factors continue to be the leading three causes of disease burden in 2010. The disease burden attributable to risk factors for childhood communicable diseases, such as micronutrient deficiencies and unimproved water and sanitation, has decreased, both as a proportion of total disease burden and in their rank 
order: risk factors for some non-communicable diseases and injury accounted for a larger disease burden in 2010. The most notable of these factors were alcohol use and high blood pressure (appendix).

Compared with other regions of sub-Saharan Africa, southern sub-Saharan Africa had a more mixed pattern of risk factor burden in 1990 (appendix). In 2010, alcohol use was the leading risk factor in southern sub-Saharan Africa, followed by high blood pressure and high bodymass index (figure 6). In addition to high exposure to harmful alcohol use, the effects of alcohol were particularly large because it increases the risk of road traffic and other unintentional and intentional injuries, as well as of tuberculosis, ${ }^{47}$ all of which are large causes of disease and injury burden in this region.

In south Asia, the rise of risk factors for non-communicable diseases is shown by the substantial increase in the burden attributable to tobacco smoking including second-hand smoke, high blood pressure and other metabolic risk factors, dietary risk factors, and alcohol use. However, household air pollution from solid fuels was, despite decreases, the leading risk factor in 2010. Childhood underweight was still the fourth leading risk factor in 2010 , despite its share of disease burden having more than halved from 11.9\% [95\% UI 10.1-14.4] of DALYs in 1990, to 4.0\% [3.2-4.9] in 2010. Other risk factors for communicable disease, such as suboptimal breastfeeding and micronutrient deficiencies, fell sub stantially in the region as child mortality decreased.

In southeast, east, and central Asia, the epidemiological transition was already well advanced in 1990, and by 2010, high blood pressure (which is commonly associated with diets high in sodium as a prominent underlying cause ${ }^{94,158}$ ), tobacco smoking including second-hand smoke, and diets low in fruits were all among the five leading risk factors in these regions. The disease burden attributable to childhood underweight and sub optimal breastfeeding had been largely eliminated in east Asia by 2010, although they remain important in southeast Asia. In these three regions, despite decreases, household air pollution from solid fuels was still a leading risk factor in 2010, ranked third in south-east Asia, sixth in east Asia, and 12th in central Asia. Ambient particulate matter pollution accounted for a larger disease burden than did household air pollution in central and east Asia in 2010, although household solid fuels is an important source of ambient particulate matter pollution in these regions.

The North Africa and Middle East region also had a large shift from risk factors for communicable to non-communicable diseases. In 2010, risk factors for noncommunicable disease almost exclusively dominated the region's causes of loss of health, with high blood pressure and high body-mass index each accounting for roughly $8 \%$ of disease burden, followed by tobacco smoking including second-hand smoke, high fasting plasma glucose, and physical inactivity or low physical activity. Ambient particulate matter pollution (seventh leading risk factor) is a notable cause of disease burden in this region, caused by a combination of polluted cities and dust from the Sahara desert.

Alcohol use was an important cause of disease burden in most of Latin America. It was ranked first in central Latin America, fourth in tropical Latin America, and sixth in Andean 
Latin America in 1990, and first in all these regions in 2010. Risk factors for childhood communicable disease had been largely replaced by those causing non-communicable diseases in these regions by 2010, although household air pollution from solid fuels was still an important risk factor in Andean Latin America in 2010.

One of the most notable findings was the effect of alcohol use in Eastern Europe, where it accounts for almost a quarter of total disease burden. Other risk factors, such as high blood pressure, tobacco smoking including second-hand smoke, high body-mass index, and dietary risks, also feature prominently, underscoring the large underlying burden of cardiovascular disease in the region.

In North America, Australasia, southern Latin America, and western Europe, the share of disease burden attributable to tobacco smoking including second-hand smoke has fallen slightly; it has stayed almost constant in central Europe and high-income Asia Pacific. Tobacco smoking including second-hand smoke was still the leading risk factor in 2010 in North America and western Europe. Important decreases in disease burden are evident for high blood pressure and total cholesterol in North America, Australasia, and western Europe. High blood pressure is a leading risk for health in high-income Asia Pacific (accounting for $8.5 \%$ [95\% UI 7.1-10.1] of disease burden) and central Europe (18.9\% [16.8-20.8]); evidence from individual-level trials of salt and blood pressure and from crosspopulation studies indicates that this result is likely to be driven partly by high salt consumption in these regions. ${ }^{94,158}$ Falls in disease burden attributable to tobacco smoking including second-hand smoke, high blood pressure, and high total cholesterol in highincome regions have been partly offset by the increasing burden caused by high body-mass index. In southern Latin America, high body-mass index accounted for almost $10 \%$ of overall disease burden in 2010, and is the leading risk factor in southern Latin America and Australasia.

Figure 6 summarises these regional patterns, in relation to the proportion of regional burden and attributable DALYs per 1000 people. Regions in figure 6 are ordered by mean age of death, a marker of the epidemiological transition. Figure 6 shows the clear transition away from risk factors for childhood communicable disease towards risk factors for noncommunicable disease, with increasing mean age at death. This change is apparent from the decrease in burden of disease attributable to undernutrition and unimproved water and sanitation, with increased mean age at death, especially when the effect of risks is assessed by DALYs per 1000 people (figure 6C, D). A clear general shift occurs towards a larger proportion of overall burden arising from risk factors for non-communicable diseases, particularly metabolic risks and dietary risk factors (figure 6A, B). However, the absolute burden of risk factors for non-communicable disease does not increase with increasing mean age at death. Rather, its magnitude is lower in high-income regions than in sub-Saharan Africa and south Asia (figure 6C, D), showing the double burden of communicable and noncommunicable disease in regions early in the epidemiological transition.

Some risk factors deviated from the pattern of the proportional burden (percent of regionspecifc DALYs attributable to a risk factor) being closely associated with epidemiological and demographic transition (shift from communicable to non-communicable disease with 
increasing mean age of death). The proportion of DALYs attributable to tobacco smoking including second-hand smoke was largest in North America—where smoking among women has generally been prevalent for a long time—and central and eastern Europe. Central and eastern Europe and central Asia also had the largest proportion of disease burden attributable to risk factors with large effects on cardiovascular diseases, which are disproportionately high in these regions. Exposure to particulate matter from household and ambient sources had the most varied pattern with respect to the epidemiological transition, partly because of the heterogeneous pattern of exposure and the effects on both children and adult causes of ill health. Household air pollution from solid fuels accounted for a large proportion of disease burden in central, eastern, and western sub-Saharan Africa and it is a leading risk factor in some Asian regions and Oceania. In central and east Asia in 2010, ambient particulate matter pollution surpassed household air pollution in terms of its burden.

\section{Discussion}

The results of GBD 2010 suggest that the contributions of risk factors to regional and global burden of diseases and injuries has shifted substantially between 1990, and 2010, from risk factors that mainly cause communicable diseases in children to risk factors that mainly cause non-communicable diseases in adults. The proportion of overall disease burden attributable to childhood underweight — the leading risk factor worldwide in 1990 — had more than halved by 2010, making childhood underweight the eighth risk worldwide, behind six behavioural and physiological risks, and household air pollution from solid fuels. Other risks for child mortality, such as nonexclusive and discontinued breastfeeding, micronutrient deficiencies, and unimproved water and sanitation, have also fallen. However, child and maternal undernutrition risks collectively still account for almost $7 \%$ of disease burden in 2010 , with unimproved water and sanitation accounting for almost $1 \%$. Of the noncommunicable disease risks, high blood pressure, high body-mass index, high fasting plasma glucose, alcohol use, and dietary risks have increased in relative importance. This overall shift has arisen from a combintion of the ageing population, substantial achievements in lowering mortality of children aged younger than 5 years, and changes in risk factor exposure.

These broad global patterns mask enormous regional variation in risks to health. In subSaharan Africa, risks such as childhood underweight, household air pollution from solid fuels, and suboptimal breastfeeding continue to cause a disproportionate amount of health burden, despite decreasing. The shift to risk factors for non-communicable disease was clear in east Asia, North Africa and Middle East, and Latin America. This regional heterogeneity underestimates even greater differences in exposure to, and health effects of, risk factors in national and subnational populations. These differences should be further elucidated in country-specific analyses using the framework and methods reported here.

Our analysis shows the large burden of disease attributable to primary and secondary tobacco smoking and to particulate matter pollution in household and ambient environments. The magnitude of disease burden from particulate matter is substantially higher than estimated in previous comparative risk assessment analyses. For example, ambient particulate matter pollution was estimated in the previous comparative risk assessment ${ }^{7}$ to 
account for $0.4 \%$ of DALYs in 2000 compared with $3 \cdot 1 \%$ in GBD 2010 based on interpolating our 1990 and 2005 results; for household air pollution from solid fuels the comparison is $2.7 \%$ in the previous comparative risk assessment versus $5.3 \%$ based on GBD 2010.

Several reasons could account for this difference. First, accumulation of evidence from epidemiological studies about diseases caused by particulate matter, and the use of an integrated exposure-response curve, has led to the inclusion of more outcomes than before. For example, health effects for ischaemic heart disease and stroke were not previously included for household air pollution from solid fuels, and lung cancer was included for coal smoke only. Second, the previous assessment of ambient particulate matter pollution was restricted to medium and large cities. High-resolution satellite data and chemical transport models have enabled us to quantify exposure and burden for all rural and urban populations. Third, the previous assessment of ambient particulate matter pollution did not include additional increments of risk above a concentration of $50 \mu \mathrm{g} / \mathrm{m}^{3}$ for $\mathrm{PM}_{2.5}$, because of the narrow range of ambient particulate matter pollution levels reported in epidemiological studies. The use of an integrated exposure-response curve enabled us to estimate a continuous risk function across the full range of particulate matter concentrations, which covers the very high concentrations of ambient particulate matter exposure measured in, for example, parts of east Asia.

Our integrated exposure-response curve, however, does not address how different sources of particulate matter interact in terms of effects and overlapping exposures. Studies ${ }^{124,159,160}$ have reported broadly similar effect sizes for ambient particulate matter by smoking status (never, former, and current smokers). Other evidence ${ }^{161}$ shows that the effects diminish with increasing exposure for active smoking, a pattern incorporated into our exposure- response curves. We applied the effects of ambient particulate matter to both smokers and nonsmokers alike to be consistent with the epidemiological evidence that emphasises independent effects of ambient particulate matter. The reasons for the independent effects of different sources of particulate matter should be further investigated. They might include different compositions of particulate matter by source, or different time patterns of exposure $^{162}$ - eg, exposure to particulate matter from active smoking is characterised by episodic, high doses whereas exposure to ambient particulate matter is more constant over time.

These limitations aside, the large attributable burden documented in our analysis represents a major shift in our understanding of disease burden arising from particulate matter and emphasises the need to design alternative fuels for household cooking and heating, ${ }^{163}$ implement more stringent regulation of vehicle and industrial emissions, ${ }^{164-166}$ reduce agricultural burning or land clearing by fire, ${ }^{167}$ and curb and reverse deforestation and desertification to reduce ambient particulate matter from dust. ${ }^{168-171}$ A large share of ambient particulate matter in Asia and sub-Saharan Africa originates from solid fuel. ${ }^{172,173}$ Therefore the two exposures are related, and alternative cooking and heating fuels would have benefits for people who currently use solid fuels as well as those who do not, but live in the same community. ${ }^{173}$ 
Unimproved water and unimproved sanitation together accounted for $0.9 \%$ of DALYs in 2010 , compared with $2.1 \%$ in 1990 . These proportions are substantially smaller than the $6.8 \%$ for 1990 , and $3.7 \%$ for 2000 , estimated in previous GBD studies for water, sanitation, and hygiene combined. ${ }^{3,7}$ The relatively small burden estimated for 2010 is partly related to decreases in diarrhoeal disease mortality since 1990, and partly to differences in the distributions of deaths by underlying cause of death. We have also done an updated metaanalysis of quasi experimental and experimental studies. Historical demographic analyses suggest that the introduction of piped water into cities in the late 19th and early 20th centuries had a large beneficial effect on mortality. ${ }^{174}$ However, our re-analysis both when restricted to experimental studies and when also including quasi experimental studies did not detect a significantly improved effect of household water connections over improved water sources. Similarly, we did not find a significantly improved effect of water quality interventions, consistent with the findings reported by Cairncross and colleagues, ${ }^{128}$ which showed that masked point-of-use water quality interventions did not have a significant effect on self-reported diarrhoea. As a result of this reassessment, we restricted our analysis to improved water and improved sanitation compared with unimproved sources following the MDG definitions. However, the interventions used in previous studies might not have achieved their full efficacy because of the quality of implementation. The real burden from water and sanitation could therefore be underestimated if well-implemented household connect ions and water quality interventions have a larger effect than improved water sources alone, and if the combination of poor water and sanitation has a larger effect than a sample interaction of individual effects. More definitive epidemiological evidence is needed to assess the effects of low quality versus high quality water, household connections versus improved water sources, and exposure based on travel time to water source. ${ }^{175}$ Also, we could not include an assessment of personal hygiene because of the paucity of national exposure data.

Our findings on the burden of micronutrients are also substantially smaller than those in the previous comparative risk assessment for 2000 and in estimates for 2004 by Black and colleagues ${ }^{10}$ in The Lancet's Maternal and Child Undernutrition Series. For example, Black and colleagues estimated 668000 deaths caused by vitamin A deficiency in 2004; we estimated a quarter (168 000 deaths) for 2005; for zinc deficiency, the differences are similarly large (453 000 vs 120 000). These differences stem from many sources. First, the estimates of Black and colleagues were based on 10.3 million child deaths worldwide, itself based on WHO estimates of global child deaths for 2004. This estimate is substantially larger than those reported by UNICEF ${ }^{176}$ and the Institute for Health Metrics and Evaluation ${ }^{177}$ at the time of Black and colleagues' publication.

Large differences also exist for cause-specific mortality, especially in relation to diarrhoea and lower respiratory tract infections (which can be affected by both of these risks) versus malaria (which is not). ${ }^{176}$ The estimates also differ because of differences in the availability and interpretation of epidemiological evidence for disease outcomes and effect sizes. Maternal mortality and malaria as outcomes of vitamin A deficiency were included in the 2000 comparative risk assessment but they were not included in the present report because recent epidemiological evidence did not show a significant effect of supplementation on 
these outcomes. Furthermore, we excluded neonatal vitamin A deficiency since it is the subject of three ongoing randomised trials. The age at which the effects of zinc deficiency begin was increased from birth in the 2000 comparative risk assessment, to 6 months in $2004,{ }^{10}$ and to 12 months in the present analysis based on a reassessment of existing and new supplementation trials. Furthermore, we quantified the proportion of the population who are vitamin A or zinc deficient instead of classing whole countries as exposed or nonexposed. The evolving epidemiology of exposure to micronutrient deficiency and the subsequent health effects suggests a need to systematically reconsider most single nutrient supplementation for children in preventive strategies to lower child mortality, as suggested by the 2000 comparative risk assessment and later analyses. ${ }^{10}$ Therapeutic zinc supplementation in health-care settings is feasible, as is iron supplementation during pregnancy. ${ }^{174-179}$ Our findings support the need for strengthened policy about promotion of optimal breastfeeding practices and nutritional programmes that improve child growth. The estimated number of child deaths caused by underweight has also changed substantially over successive studies: in GBD 1990 it was estimated to be 5.9 million deaths in $1990,{ }^{180}$ in the comparative risk assessment study for 2000 as 3.7 million deaths, ${ }^{7}$ and 1.9 million deaths in 2004. ${ }^{10}$ In GBD 2010 we estimated 2.3 million deaths for 1990 and 0.9 million deaths for 2010.

The evolution of estimates for deaths caused by childhood under weight is because of improvements in assessment of the population at risk. These improvements come from systematic analysis of the available data on underweight, a major modification of RRs after the change in the WHO standard in 2006, and differences in estimates of total and causespecific mortality. We have also assessed the burden attributable to childhood wasting and childhood stunting. These analyses produce quite similar findings, for example, worldwide, childhood wasting accounted for 0.7 million deaths in 2010, and childhood stunting for 0.9 million deaths, compared with 0.9 million deaths for childhood under weight (the effects of these risks cannot be added).

The global burden of disease attributable to tobacco smoking including second-hand smoke has changed little, with decreases in high-income regions offset by increases in regions such as south east Asia and, to a lesser extent, east and south Asia. The burden attributable to alcohol use has increased substantially in eastern Europe since 1990, mainly because of a rise in the effects of heavy drinking on cardiovascular diseases. ${ }^{181}$ The high burden in eastern Europe was also identified in the 2000 comparative risk assessment but the data for patterns of alcohol consumption and their effects were weaker, whereas now they are supported by more surveys and epidemiological studies. ${ }^{182}$ High blood pressure, high bodymass index, and high fasting plasma glucose are leading risk factors for disease worldwide, with blood pressure having large effects on population health in all regions, including lowincome regions in sub-Saharan Africa and south Asia. This finding is consistent with previous comparative risk assessment analyses. The disease burden in south Asia and subSaharan Africa, caused by increased blood pressure, ${ }^{70}$ has increased its absolute and relative importance in risk factor rankings. The large burden of high blood pressure emphasises the importance of implementing both population-wide and high-risk approaches to reduction of blood pressure. ${ }^{183,184}$ The worldwide increase in body-mass index and blood glucose is of particular concern in view of the absence of effective interventions. ${ }^{62,74}$ In contrast to these 
risks, the burden of high total cholesterol is lower than that estimated in the 2000 comparative risk assessment, because the effects on ischaemic stroke were negligible at old ages when data from the Asia-Pacific Cohort Studies Collaboration and Prospective Studies Collaboration were pooled, ${ }^{68,185}$ and because exposure has fallen in high-income countries. ${ }^{67}$

A recent study estimated that $5 \cdot 3$ million deaths were attributable to physical inactivity in 2008. ${ }^{186}$ This number, which has been widely quoted and equated with the number of deaths attributable to tobacco smoking, ${ }^{187}$ used effect sizes for all-cause mortality obtained from cohorts of adults mainly from North America and Europe and applied these effects to deaths at all ages. This approach not only assumes that the cause distribution is the same in all populations, irrespective of region and age structure, but also extends the effects to people younger than those in the cohort study, including to infants and children. In other words, a proportion of deaths from maternal causes, neonatal causes, and children's infectious diseases and HIV were attributed to physical inactivity. ${ }^{186}$ The prevalence of inactivity also included people who had sedentary patterns as well as those in the low (insufficient) activity group. By contrast, our approach—calculating attributable burden by cause and age group, and accounting for exposure in four categories—estimated substantially fewer attributable deaths: 3.2 million ( 2.7 million to 3.7 million) in $2010,56 \%$ of what we attribute to tobacco smoking when second-hand smoke is excluded. This discrepancy shows the importance of comparable risk factor assessments and the importance of estimation of attributable burden taking into account differences in underlying disease and injury patterns across populations.

We have expanded the set of components of diet included from a combined category of fruits and vegetables in the 2000 comparative risk assessment to 15 components in GBD 2010; together these dietary risk factors account for a tenth of global disease burden. Of the dietary risk factors, the aetiological effect sizes for sodium, polyunsaturated fatty acids replacing saturated fatty acids, and seafood omega-3 fatty acids were informed fully (for sodium) or partly by randomised controlled trials. Disease burden attributable to diet high in sodium was a third of that for high blood pressure. The theoretical-minimum-risk exposure distribution was selected on the basis of values reported in randomised trials; studies of populations with low prevalence of cardiovascular disease suggest that benefits are likely to continue to lower levels. ${ }^{158}$

The large attributable burden for dietary risk factors such as diets low in fruits, vegetables, whole grains, nuts and seeds, and seafood omega- 3 fatty acids might surprise some readers. The large burden is caused by both high exposure-eg, low intake of fruits in many regions - and large effect sizes. We did supplementary analyses using information from studies of dietary patterns and randomised controlled feeding studies to examine the robustness of the effect sizes used in GBD 2010. The findings of these supplementary analyses were consistent with those from the meta-analyses of single risk factors. However, we stress that these results should still be interpreted with caution, particularly because of the debate surrounding the effects of seafood omega- 3 fatty acids. ${ }^{143,188}$ Empirical assessments show that the pooled effect of risks and interventions trends towards a null result over time $e^{189,190}$ and this pattern could apply to seafood omega-3 fatty acids since the earlier, primarily observational effect sizes tended to show a larger effect than did the more recent randomised 
controlled trials. Because the difference between results of observational studies and randomised controlled trials is not statistically significant we have quantified the attributable burden by use of the combined effect size. However, the validity of this approach could change as new evidence accumulates. Also, evidence from randomised controlled trials does not exist for several of the dietary components with a large attributable burden-fruits, vegetables, and nuts and seeds - although, as previously noted, evidence from randomised controlled trials does exist for inter mediate outcomes. Further work is needed to confirm the effect size of dietary components and to establish to what degree the benefits continue, preferably through intervention studies of fatal and non-fatal events.

The extended analysis of components of diet does not include saturated fat beyond its replacement by polyunsaturated fats. Ecological studies suggest that saturated fat intake is a significant risk factor for mortality from ischaemic heart disease. ${ }^{191}$ However, observational studies indicate that there might be no benefits if saturated fat reduction is associated with an increase in carbohydrates, ${ }^{91}$ which is also supported by the absence of benefits from a low fat diet in the Women's Health Initiative. ${ }^{192}$ Together with data for seafood omega-3 fatty acids, these findings show the complexity of the relation between dietary fat and health and suggest that the traditional health education message focused on lowering saturated fat alone needs to be expanded greatly to encompass several other key components of diet, including increased consumption of healthy foods that are presently missing from most diets.

The strengths of our study include a more comprehensive set of risk factors than any previous global or national analysis, consistent analyses in 1990, and 2010, which enables assessment of changes in risk factor burden, the incorporation of substantially more data for risk-factor exposure, improved methods to deal with missing and incomparable data, strong emphasis on comparability of methods related to exposure, disease outcomes, and effect sizes, and use of theoretical-minimum-risk exposure distribution as the consistent alternative exposure distribution with which current exposures are compared.

Like all population-based analysis, our study also has some limitations. First, despite the massive improvement in the availability of exposure data and methods, exposure estimates for many risk factors are affected by data limitations, especially for 2010 , since fewer data could be included. This limitation will become even more salient in applications of our methods to individual countries and shows the importance of surveillance of national risk factors as a crucial component of national health information systems. More importantly, for some risk factors we have less direct measures of exposure than for others. For example, for household air pollution from solid fuels we measured exposure on the basis of household fuel use rather than personal exposure to particulate matter; for other risks, such as blood pressure, we have direct biological measurements of exposure.

Second, the presence of residual confounding in the estimates of effect sizes cannot be definitively ruled out, particularly for those without evidence from intervention studies, either because they have not yet been done or the risk is not amenable to intervention. For example, no large-scale trials have been done of interventions for high body-mass index that measured cause-specific deaths although effects on disease incidence have been investigated in trials. ${ }^{193}$ Observational studies of the effect sizes for body-mass index have controlled for 
some potential confounders. ${ }^{75-77}$ As noted, the pooled effect of risks and interventions trends towards the null result over time; ${ }^{189,190}$ the implication being that risks for which only a few studies have been done might have their effect overestimated compared with risks for which a large body of evidence exists.

Third, with the exception of risk factors for which much evidence has been accumulated across diverse populations and age groups, such as the metabolic risks, uncertainty remains as to the extent to which effect sizes are generalisable to different populations. Similarly, the large body of epidemiological evidence for cardiovascular risk factors shows a relation between age and the effect size of risk factors for cardiovascular disease. Such age-related changes might be present for other outcomes. Fourth, we have combined epidemiological evidence for effect sizes using studies across different periods, which could mask underlying temporal changes in risk; no data presently exist to enable an examination of the extent to which effect sizes might change over time.

Fifth, we have excluded risks for which insufficient information exists to enable estimation of exposure, or for which the evidence of effect sizes is scarce. This approach excludes several risk-outcome pairs that have been previously included in global and regional assessments of risk factor attributable burden, such as unsafe sex and global climate change. Unsafe sexual practices were included in the 2000 comparative risk assessment but we excluded it because of the absence of robust estimates of exposure or available approaches to determine the proportion of HIV infection that is attributable to unsafe sexual practices by country over time. If quantifiable, unsafe sexual practices would probably account for a large fraction of global health burden; the direct burden of HIV is 3.3\% of DALYs in 2010; other sexually transmitted infections account for $0.4 \%$ of DALYs. Similarly, we have been unable to control for confounding in observational studies of late initiation of breastfeeding, which is associated with an increased risk of neonatal mortality. Infants who might too ill or weak to breastfeed are more likely to die. In our analysis, we could not assess low birthweight as an outcome for maternal iron deficiency, despite evidence from random ised trials. Similarly, we could not assess low birthweight as an outcome for maternal alcohol use. Low birthweight was not a disease outcome in GBD 2010 but is associated with an increased risk of neonatal mortality. We excluded several other risk-outcome pairs that had insufficient evidence to estimate effect sizes or that had substantial potential of residual confounding - eg, the effect of addictive drugs (cannabis, amphetamines, and opioids) on unintentional and intentional injuries; or the effects of intimate partner violence, on HIV or other sexually transmitted infections.

Sixth, we included few risks that affected three of the leading communicable diseasesHIV/AIDs, tuberculosis, and malaria (beyond deaths in childhood). Overall, we have not included risks for 126 of the 241 most detailed causes included in the GBD, which account for $26.3 \%$ of global disease health burden. This shortcoming emphasises the need for a more deliberate research focus to identify and quantify risk factors for the outcomes for which there are presently no risks or few large risks.

Seventh, we have quantified the attributable burden of risk factors, holding all other independent factors constant. For clusters of risk factors we have approximated the joint 
effects, assuming that risk factors within each cluster are independent. A more accurate quantification of the joint effects of multiple risk factors is an important area for future research. Finally, it is important to stress that the size of the attributable risk factor burden does not equal priority for action since prioritisation also depends on availability, cost, and effectiveness of inter vention strategies to reduce exposures to these risks.

Public policy to improve the health of populations will be more effective if it addresses the major causes of disease burden. Even small reductions of population exposure to large risks will yield substantial health gains. ${ }^{194}$ The principal advantage of doing a comprehensive and comparable scientific assessment of disease burden caused by different risk factors is that it provides the evidence base for informing discussion about policy. Coupled with evidence of their present burden, most of the leading risk factors, except high body-mass index and high fasting plasma glucose, have decreased in at least some regions and countries, showing that substantial reduction of their effect through targeted prevention strategies is feasible. If predictions about huge increases in disease burden worldwide are to be proved wrong, then countries, with appropriate global public health leadership, must urgently implement measures to control exposure to leading hazards, particularly risks for non-communicable diseases.

\section{Supplementary Material}

Refer to Web version on PubMed Central for supplementary material.

\section{Authors}

Stephen S Lim ${ }^{\ddagger}$, Theo Vos, Abraham D Flaxman, Goodarz Danaei, Kenji Shibuya, Heather Adair-Rohani, Markus Amann", H Ross Anderson", Kathryn G Andrews*, Martin Aryee*, Charles Atkinson*, Loraine J Bacchus*, Adil N Bahalim, Kalpana Balakrishnan*, John Balmes ${ }^{*}$, Suzanne Barker-Collo*, Amanda Baxter", Michelle L Bell $^{*}$, Jed D Blore ${ }^{*}$, Fiona Blyth ${ }^{*}$, Carissa Bonner", Guilherme Borges ${ }^{*}$, Rupert Bourne*, Michel Boussinesq ${ }^{*}$, Michael Brauer ${ }^{*}$, Peter Brooks ${ }^{*}$, Nigel G Bruce*, Bert Brunekreef ${ }^{*}$, Claire Bryan-Hancock ${ }^{*}$, Chiara Bucello*, Rachelle Buchbinder ${ }^{*}$, Fiona Bull$^{*}$, Richard T Burnett ${ }^{*}$ Tim E Byers ${ }^{*}$, Bianca Calabria ${ }^{*}$, Jonathan Carapetis ${ }^{*}$, Emily Carnahan", Zoe Chafe*, Fiona Charlson", Honglei Chen", Jian Shen Chen*, Andrew Tai-Ann Cheng ${ }^{*}$, Jennifer Christine Child ${ }^{*}$, Aaron Cohen*, K Ellicott Colson ${ }^{*}$, Benjamin C Cowie ${ }^{*}$, Sarah Darby*, Susan Darling ${ }^{*}$, Adrian Davis*, Louisa Degenhardt ${ }^{\star}$, Frank Dentener ${ }^{\star}$, Don C Des Jarlais ${ }^{*}$, Karen Devries ${ }^{*}$, Mukesh Dherani", Eric L Ding ${ }^{*}$, E Ray Dorsey ${ }^{*}$, Tim Driscoll ${ }^{*}$, Karen Edmond ${ }^{*}$, Suad Eltahir Ali $^{*}$, Rebecca E Engell ${ }^{*}$, Patricia J Erwin ${ }^{*}$, Saman Fahimi ${ }^{*}$, Gail Falder ${ }^{*}$, Farshad Farzadfar", Alize Ferrari", Mariel M Finucane*, Seth Flaxman ${ }^{\star}$, Francis Gerry R Fowkes ${ }^{*}$, Greg Freedman", Michael K Freeman*, Emmanuela Gakidou*, Santu Ghosh", Edward Giovannucci", Gerhard Gmel", Kathryn Graham, Rebecca Grainger ${ }^{*}$, Bridget Grant ${ }^{\star}$, David Gunnell ${ }^{\star}$, Hialy R Gutierrez ${ }^{*}$, Wayne Hall${ }^{*}$, Hans W Hoek $^{*}$, Anthony Hogan ${ }^{*}, \mathrm{H}$ Dean Hosgood III*, Damian Hoy ${ }^{*}$, Howard Hu*, Bryan J Hubbell", Sally J Hutchings ${ }^{*}$, Sydney E Ibeanusi ${ }^{*}$, Gemma L Jacklyn ${ }^{*}$, Rashmi Jasrasaria*, Jost B Jonas", Haidong Kan*, John A Kanis", Nicholas Kassebaum*, 
Norito Kawakami", Young-Ho Khang ${ }^{*}$, Shahab Khatibzadeh*, Jon-Paul Khoo*, Cindy Kok ${ }^{*}$, Francine Laden ${ }^{*}$, Ratilal Lalloo*, Qing Lan ${ }^{*}$, Tim Lathlean*, Janet L Leasher", James Leigh", Yang Li", John Kent Lin", Steven E Lipshultz*, Stephanie London*, Rafael Lozano*, Yuan Lu*, Joelle Mak*, Reza Malekzadeh*, Leslie Mallinger", Wagner Marcenes*, Lyn March", Robin Marks", Randall Martin, Paul McGale”, John McGrath", Sumi Mehta*, George A Mensah", Tony R Merriman", Renata Micha ${ }^{*}$, Catherine Michaud", Vinod Mishra*, Khayriyyah Mohd Hanafiah", Ali A Mokdad", Lidia Morawska*, Dariush Mozaff arian*, Tasha Murphy ${ }^{*}$, Mohsen Naghavi ${ }^{*}$, Bruce Neal $^{\star}$, Paul K Nelson ${ }^{*}$, Joan Miquel Nolla*, Rosana Norman ${ }^{*}$, Casey Olives ${ }^{*}$, Saad B Omer ${ }^{*}$, Jessica Orchard ${ }^{*}$, Richard Osborne*, Bart Ostro ${ }^{*}$, Andrew Page ${ }^{*}$, Kiran D Pandey ${ }^{*}$, Charles D H Parry ${ }^{*}$, Erin Passmore*, Jayadeep Patra*, Neil Pearce*, Pamela M Pelizzari", Max Petzold*, Michael R Phillips*, Dan Pope*, C Arden Pope III, John Powles ${ }^{*}$, Mayuree Rao*, Homie Razavi", Eva A Rehfuess ${ }^{*}$, Jürgen T Rehm*, Beate Ritz*, Frederick P Rivara*, Thomas Roberts*, Carolyn Robinson*, Jose A Rodriguez-Portales*, Isabelle Romieu*, Robin Room*, Lisa C Rosenfeld", Ananya Roy ${ }^{*}$, Lesley Rushton", Joshua A Salomon*, Uchechukwu Sampson", Lidia Sanchez-Riera", Ella Sanman*, Amir Sapkota*, Soraya Seedat", Peilin Shi", Kevin Shield", Rupak Shivakoti", Gitanjali M Singh", David A Sleet ${ }^{\star}$, Emma Smith*, Kirk R Smith", Nicolas J C Stapelberg ${ }^{*}$, Kyle Steenland", Heidi Stöckl ${ }^{*}$, Lars Jacob Stovner ${ }^{*}$, Kurt Straif*, Lahn Straney ${ }^{*}$, George D Thurston*, Jimmy H Tran*, Rita Van Dingenen*, Aaron van Donkelaar*, J Lennert Veerman*, Lakshmi Vijayakumar", Robert Weintraub*, Myrna M Weissman*, Richard A White*, Harvey Whiteford*, Steven T Wiersma*, James D Wilkinson", Hywel C Williams", Warwick Williams", Nicholas Wilson", Anthony D Woolf ${ }^{*}$, Paul Yip ${ }^{*}$, Jan M Zielinski ${ }^{*}$, Alan D Lopez ${ }^{\dagger}$, Christopher J L Murray ${ }^{\dagger}$, and Majid Ezzati ${ }^{\dagger}$ Institute for Health Metrics and Evaluation (S S Lim PhD, A D Flaxman PhD, K G Andrews MPH, C Atkinson BS, E Carnahan BA, K E Colson BA, R E Engell BA, G Freedman BA, M K Freeman BA, E Gakidou PhD, R Jasrasaria BA, Prof R Lozano MD, L Mallinger MPH, A A Mokdad MD, T Murphy PhD, M Naghavi PhD, T Roberts BA, L C Rosenfeld MPH, E Sanman BS, L Straney PhD, Prof C J L Murray MD), Department of Anesthesiology and Pain Medicine (N Kassebaum MD), University of Washington, Seattle, WA, USA (C Olives PhD, Prof F P Rivara MD); Queensland Centre for Mental Health Research (A Baxter MPH, J-P Khoo MBBS, A Ferrari BPsySc, Prof H Whiteford MBBS), School of Population Health (Prof T Vos PhD, F Charlson MPH, A Page PhD, Prof A D Lopez PhD, J D Blore PhD, R Norman PhD), Brain Institute (Prof J McGrath MD), University of Queensland, Brisbane, QLD, Australia (Prof W Hall PhD, J L Veerman PhD); Department of Biostatistics (M M Finucane PhD), Department of Epidemiology (S Khatibzadeh MD, P Shi PhD), School of Public Health (G Danaei MD, E L Ding ScD, Prof E Giovannucci MD, F Laden ScD, J K Lin AB, Y Lu MS, R Micha PhD, D Mozaff arian MD, M Rao BA, Prof J A Salomon PhD, G M Singh PhD, R A White MA), Medical School (D Mozaff arian), Harvard University, Boston, MA, USA; Department of Global Health Policy (Prof K Shibuya MD), University of Tokyo, Tokyo, Japan (Prof N Kawakami MD); School of Public Health (Prof J Balmes MD), University of California, Berkeley, Berkeley, CA, USA (H Adair-Rohani MPH, Z Chafe MPH, Prof K R Smith PhD, J H 
Tran MA); International Institute for Applied Systems Analysis, Laxenburg, Austria (M Amann PhD); St George's, University of London, London, UK (Prof H R Anderson MD); Bloomberg School of Public Health (K Mohd Hanafi ah MSPH), School of Medicine (M Aryee PhD), Johns Hopkins University, Baltimore, MD, USA (E R Dorsey MD, R Shivakoti BA); London School of Hygiene and Tropical Medicine, London, UK (L J Bacchus PhD, J C Child MSc, K Devries PhD, K Edmond PhD, G Falder MSc, J Mak MSc, Prof N Pearce PhD, H Stockl PhD); Independent Consultant, Geneva, Switzerland (A N Bahalim MEng); Sri Ramachandra University, Chennai, India (Prof K Balakrishnan PhD, S Ghosh MS); University of Auckland, Auckland, New Zealand (S Barker-Collo PhD); Yale University, New Haven, CT, USA (Prof M L Bell PhD); School of Public Health ( Leigh MBBS, T Driscoll PhD), Department of Rheumatology, Northern Clinical School (E Smith PhD), Institute of Bone and Joint Research (J S Chen PhD, Prof L March MD, L Sanchez-Riera MD, N Wilson PhD), University of Sydney, Sydney, NSW, Australia (F Blyth PhD, C Bonner MPH, S Darling MPH, G L Jacklyn MPH, J Orchard MPH, E Passmore MPH); National Institute of Psychiatry, Mexico City, Mexico (Prof G Borges ScD); National Autonomous University, Mexico City, Mexico (Prof G Borges); Vision and Eye Research Unit, Anglia Ruskin University, Cambridge, UK (Prof R Bourne MD); Institut de Recherche pour le Développement, Martinique, France (M Boussinesq MD); University of British Columbia, Vancouver, BC, Canada (Prof M Brauer ScD); Department of Pediatrics (R Weintraub MBBS), Centre for Health Policy, Programs and Economics (Prof L Degenhardt PhD), School of Population Health (Prof R Room PhD), University of Melbourne, Melbourne, VIC, Australia (Prof P Brooks MD, Prof R Marks MBBS); University of Liverpool, Liverpool, UK (Prof N G Bruce MBBS, M Dherani PhD, D Pope PhD); Insititute for Risk Assessment Sciences, Utrecht University, Utrecht, Netherlands (Prof B Brunekreef PhD); Flinders University, Adelaide, SA, Australia (C BryanHancock BPsych, T Lathlean MA); National Drug and Alcohol Research Centre (B Calabria BPsyc, Prof L Degenhardt, P K Nelson MHSc), University of New South Wales, Sydney, NSW, Australia (C Bucello BPsyc); Cabrini Institute, Malvern, VIC, Australia (Prof R Buchbinder MBBS); Monash University, Melbourne, VIC, Australia (Prof R Buchbinder, D Hoy PhD); Telethon Institute for Child Health Research, Centre for Child Health Research (Prof J Carapetis MBBS), University of Western Australia, Perth, WA, Australia (Prof F Bull PhD); Health Canada, Ottawa, ON, Canada (R T Burnett PhD, J M Zielinski PhD); Colorado School of Public Health, Aurora, CO, USA (Prof T E Byers MD); National Institute of Environmental Health Sciences, Research Triangle Park, NC, USA (H Chen PhD, S London MD); Institute of Biomedical Sciences, Academia Sinica, Taipei, Taiwan (Prof A T-A Cheng MD); Health Eff ects Institute, Boston, MA, USA (A Cohen MPH); Victorian Infectious Diseases Reference Laboratory, Melbourne, VIC, Australia (B C Cowie MBBS); Clinical Trial Services Unit (P McGale PhD), University of Oxford, Oxford, UK (Prof $S$ Darby PhD); MRC Hearing and Communication Group, Manchester, UK (Prof A Davis PhD); European Commission, Joint Research Centre, Brussels, Belgium ( $F$ Dentener PhD, R Van Dingenen PhD); Beth Israel Medical Center, New York City, NY, USA (D C Des Jarlais PhD); Federal Ministry of Health, Khartoum, Sudan (S 
Eltahir Ali Mcs); Mayo Clinic, Rochester, MN, USA (P J Erwin MLS); Institute of Public Health (J Powles MBBS), Department of Public Health and Primary Care, University of Cambridge, Cambridge, UK (S Fahimi MD); Digestive Disease Research Center (Prof R Malekzadeh MD), Tehran University of Medical Sciences, Tehran, Iran (F Farzadfar MD); Carnegie Mellon University, Pittsburgh, PA, USA (S Flaxman BA); University of Edinburgh, Edinburgh, Scotland, UK (Prof F G R Fowkes FRCPE); Addiction Info Switzerland, Lausanne, Switzerland (Prof G Gmel $\mathrm{PhD}$ ); Centre for Addiction and Mental Health, Toronto, ON, Canada (K Graham $\mathrm{PhD}$, Prof J T Rehm PhD, K Shield MHSc); University of Otago, Dunedin, New Zealand (R Grainger PhD, T R Merriman PhD); Occupational and Environmental Epidemiology Branch, Division of Cancer Epidemiology and Genetics, National Cancer Institute (Q Lan PhD), National Institutes of Health, Bethesda, MD, USA (R Grainger, B Grant PhD); University of Bristol, Bristol, UK (Prof D Gunnell DSc); College of Physicians and Surgeons (Prof M M Weissman PhD), Mailman School of Public Health, Columbia University, New York City, NY, USA (H R Gutierrez BS, Prof M M Weissman); Parnassia Psychiatric Institute, The Hague, Netherlands (Prof H W Hoek MD); Australian National University, Canberra, ACT, Australia (A Hogan PhD); Albert Einstein College of Medicine, Yeshiva University, New York City, NY, USA (H D Hosgood III PhD); Dalla Lana School of Public Health, University of Toronto, Toronto, ON, Canada (Prof H Hu MD); US Environmental Protection Agency, Washington, DC, USA (B J Hubbell PhD); MRC-HPA Centre for Environment and Health, Department of Epidemiology and Biostatistics, School of Public Health, Imperial College London, London, UK (Prof M Ezzati PhD, S J Hutchings BSc, L Rushton PhD); University of Port Harcourt, Port Harcourt, Nigeria (S E Ibeanusi MBBS); Department of Ophthalmology, Medical Faculty Mannheim of the Ruprecht Karls University Heidelberg, Heidelberg, Germany (Prof J B Jonas MD); Fudan University, Shanghai, China (H Kan MD); University of Sheffi eld, Sheffi eld, UK (Prof J A Kanis MD); Department of Preventive Medicine, University of Ulsan College of Medicine, Seoul, South Korea (Prof Y-H Khang MD); Spinal Cord Injury Network, Glebe, New Zealand (C Kok PhD); School of Dentistry and Oral Health (Prof R Lalloo PhD), Population and Social Health Research Program (Prof R Lalloo), Griffi th University, Brisbane, QLD, Australia (N J C Stapelberg MBBS); Nova Southeastern University, Fort Lauderdale, FL, USA (J L Leasher OD); Critical Care and Trauma Division (Y Li MBBS), The George Institute for Global Health, Sydney, NSW, Australia (Prof B Neal PhD); Miller School of Medicine, University of Miami, Miami, FL, USA (Prof S E Lipshultz MD, Prof J D Wilkinson MD); Queen Mary University of London, London, UK (Prof W Marcenes PhD); Dalhousie University, Halifax, NS, Canada (Prof R Martin PhD, A van Donkelaar PhD); Global Alliance for Clean Cookstoves, Washington, DC, USA (S Mehta PhD); Department of Medicine, University of Cape Town, Cape Town, South Africa (Prof G A Mensah $\mathrm{MD}$ ); Agricultural University of Athens, Athens, Greece (R Micha); China Medical Board, Boston, MA, USA (C Michaud MD); United Nations Population Division, New York City, NY, USA (V Mishra PhD); Queensland Univeristy of Technology, Brisbane, QLD, Australia (Prof L Morawska PhD); Rheumatology Department (Prof J M Nolla MD), Institut d'Investigacio Biomedica de Bellvitge, Hospital Universitari 
de Bellvitge, Barcelona, Spain (L Sanchez-Riera); School of Public Health (S B Omer MBBS, K Steenland PhD), School of Medicine, Emory University, Atlanta, GA, USA (S B Omer); Deakin University, Melbourne, VIC, Australia (Prof R Osborne PhD); California Environmental Protection Agency, Sacramento, CA, USA (B Ostro PhD); The World Bank, Washington DC, USA (K D Pandey PhD); South African Medical Research Council, Cape Town, South Africa (Prof C D H Parry $\mathrm{PhD}$ ); St Michael Hospital, Toronto, ON, Canada (J Patra PhD); Centers for Medicare and Medicaid Services, Baltimore, MD, USA (P M Pelizzari MPH); Centre for Applied Biostatistics, Sahlgrenska Academy at University of Gothenburg, Gothenburg, Sweden (Prof M Petzold PhD); Shanghai Mental Health Center, Shanghai Jiao Tong University School of Medicine, Shanghai, China (Prof M R Phillips MD); Brigham Young University, Provo, UT, USA (Prof C A Pope III PhD); Center for Disease Analysis, Louisville, CO, USA (H Razavi PhD); Ludwig Maximilians Universität Munich, Munich, Germany (E A Rehfuess PhD); University of California, Los Angeles, Los Angeles, CA, USA (Prof B Ritz MD); University of California, San Francisco, San Francisco, CA, USA (C Robinson BS); P Universidad Católica de Chile, Santiago, Chile (Prof J A Rodriguez-Portales MD); International Agency for Research on Cancer, Lyon, France (I Romieu MD, K Straif MD); Centre for Alcohol Policy Research, Turning Point Alcohol \& Drug Centre, Fitzroy, SA, Australia (Prof R Room); Environmental and Occupational Health Sciences, University of Medicine and Dentistry of New Jersey, Newark, NJ, USA (A Roy ScD); Vanderbilt University, Nashville, TN, USA (Prof U Sampson MD); School of Public Health, University of Maryland, Baltimore, MD, USA (A Sapkota PhD); Stellenbosch University, Stellenbosch, South Africa (Prof S Seedat PhD); National Center for Injury Prevention and Control (D A Sleet PhD), Centers for Disease Control and Prevention, Baltimore, MD, USA (S T Wiersma MD); Department of Neuroscience, Norwegian University of Science and Technology, Trondheim, Norway (Prof L J Stovner PhD); New York University, New York City, NY, USA (Prof G D Thurston ScD); Voluntary Health Services, Sneha, Chennai, India (Prof L Vijayakumar MBBS); Royal Children's Hospital and Critical Care and Neurosciences Theme, Murdoch Children's Research Institute, Melbourne, VIC, Australia (R Weintraub); University of Nottingham, Nottingham, UK (Prof H C Williams PhD); National Acoustic Laboratories, Sydney, NSW, Australia (W Williams PhD); Royal Cornwall Hospital, Truro, UK (Prof A D Woolf MBBS); and Centre for Suicide Research and Prevention, The University of Hong Kong, Hong Kong, China (Prof P Yip PhD)

\section{Affiliations}

Institute for Health Metrics and Evaluation (S S Lim PhD, A D Flaxman PhD, K G Andrews MPH, C Atkinson BS, E Carnahan BA, K E Colson BA, R E Engell BA, G Freedman BA, M K Freeman BA, E Gakidou PhD, R Jasrasaria BA, Prof R Lozano MD, L Mallinger MPH, A A Mokdad MD, T Murphy PhD, M Naghavi PhD, T Roberts BA, L C Rosenfeld MPH, E Sanman BS, L Straney PhD, Prof C J L Murray MD), Department of Anesthesiology and Pain Medicine (N Kassebaum MD), University of Washington, Seattle, WA, USA (C Olives PhD, Prof F P Rivara MD); Queensland 
Centre for Mental Health Research (A Baxter MPH, J-P Khoo MBBS, A Ferrari BPsySc, Prof H Whiteford MBBS), School of Population Health (Prof T Vos PhD, F Charlson MPH, A Page PhD, Prof A D Lopez PhD, J D Blore PhD, R Norman PhD), Brain Institute (Prof J McGrath MD), University of Queensland, Brisbane, QLD, Australia (Prof W Hall PhD, J L Veerman PhD); Department of Biostatistics (M M Finucane PhD), Department of Epidemiology (S Khatibzadeh MD, P Shi PhD), School of Public Health (G Danaei MD, E L Ding ScD, Prof E Giovannucci MD, F Laden ScD, J K Lin AB, Y Lu MS, R Micha PhD, D Mozaff arian MD, M Rao BA, Prof J A Salomon PhD, G M Singh PhD, R A White MA), Medical School (D Mozaff arian), Harvard University, Boston, MA, USA; Department of Global Health Policy (Prof K Shibuya MD), University of Tokyo, Tokyo, Japan (Prof N Kawakami MD); School of Public Health (Prof J Balmes MD), University of California, Berkeley, Berkeley, CA, USA (H Adair-Rohani MPH, Z Chafe MPH, Prof K R Smith PhD, J H Tran MA); International Institute for Applied Systems Analysis, Laxenburg, Austria (M Amann PhD); St George's, University of London, London, UK (Prof H R Anderson MD); Bloomberg School of Public Health (K Mohd Hanafi ah MSPH), School of Medicine (M Aryee PhD), Johns Hopkins University, Baltimore, MD, USA (E R Dorsey MD, R Shivakoti BA); London School of Hygiene and Tropical Medicine, London, UK (L J Bacchus PhD, J C Child MSc, K Devries PhD, K Edmond PhD, G Falder MSc, J Mak MSc, Prof N Pearce PhD, H Stockl PhD); Independent Consultant, Geneva, Switzerland (A N Bahalim MEng); Sri Ramachandra University, Chennai, India (Prof K Balakrishnan PhD, S Ghosh MS); University of Auckland, Auckland, New Zealand (S Barker-Collo PhD); Yale University, New Haven, CT, USA (Prof M L Bell PhD); School of Public Health (J Leigh MBBS, T Driscoll PhD), Department of Rheumatology, Northern Clinical School (E Smith PhD), Institute of Bone and Joint Research (J S Chen PhD, Prof L March MD, L Sanchez-Riera MD, N Wilson PhD), University of Sydney, Sydney, NSW, Australia (F Blyth PhD, C Bonner MPH, S Darling MPH, G L Jacklyn MPH, J Orchard MPH, E Passmore MPH); National Institute of Psychiatry, Mexico City, Mexico (Prof G Borges ScD); National Autonomous University, Mexico City, Mexico (Prof G Borges); Vision and Eye Research Unit, Anglia Ruskin University, Cambridge, UK (Prof R Bourne MD); Institut de Recherche pour le Développement, Martinique, France (M Boussinesq MD); University of British Columbia, Vancouver, BC, Canada (Prof M Brauer ScD); Department of Pediatrics (R Weintraub MBBS), Centre for Health Policy, Programs and Economics (Prof L Degenhardt PhD), School of Population Health (Prof R Room PhD), University of Melbourne, Melbourne, VIC, Australia (Prof P Brooks MD, Prof R Marks MBBS); University of Liverpool, Liverpool, UK (Prof N G Bruce MBBS, M Dherani PhD, D Pope PhD); Insititute for Risk Assessment Sciences, Utrecht University, Utrecht, Netherlands (Prof B Brunekreef PhD); Flinders University, Adelaide, SA, Australia (C BryanHancock BPsych, T Lathlean MA); National Drug and Alcohol Research Centre (B Calabria BPsyc, Prof L Degenhardt, P K Nelson MHSc), University of New South Wales, Sydney, NSW, Australia (C Bucello BPsyc); Cabrini Institute, Malvern, VIC, Australia (Prof R Buchbinder MBBS); Monash University, Melbourne, VIC, Australia (Prof R Buchbinder, D Hoy PhD); Telethon Institute for Child Health Research, 
Centre for Child Health Research (Prof J Carapetis MBBS), University of Western Australia, Perth, WA, Australia (Prof F Bull PhD); Health Canada, Ottawa, ON, Canada (R T Burnett PhD, J M Zielinski PhD); Colorado School of Public Health, Aurora, CO, USA (Prof T E Byers MD); National Institute of Environmental Health Sciences, Research Triangle Park, NC, USA (H Chen PhD, S London MD); Institute of Biomedical Sciences, Academia Sinica, Taipei, Taiwan (Prof A T-A Cheng MD); Health Eff ects Institute, Boston, MA, USA (A Cohen MPH); Victorian Infectious Diseases Reference Laboratory, Melbourne, VIC, Australia (B C Cowie MBBS); Clinical Trial Services Unit (P McGale PhD), University of Oxford, Oxford, UK (Prof $S$ Darby PhD); MRC Hearing and Communication Group, Manchester, UK (Prof A Davis PhD); European Commission, Joint Research Centre, Brussels, Belgium (F Dentener PhD, R Van Dingenen PhD); Beth Israel Medical Center, New York City, NY, USA (D C Des Jarlais PhD); Federal Ministry of Health, Khartoum, Sudan (S Eltahir Ali Mcs); Mayo Clinic, Rochester, MN, USA (P J Erwin MLS); Institute of Public Health (J Powles MBBS), Department of Public Health and Primary Care, University of Cambridge, Cambridge, UK (S Fahimi MD); Digestive Disease Research Center (Prof R Malekzadeh MD), Tehran University of Medical Sciences, Tehran, Iran (F Farzadfar MD); Carnegie Mellon University, Pittsburgh, PA, USA (S Flaxman BA); University of Edinburgh, Edinburgh, Scotland, UK (Prof F G R Fowkes FRCPE); Addiction Info Switzerland, Lausanne, Switzerland (Prof G Gmel $\mathrm{PhD}$ ); Centre for Addiction and Mental Health, Toronto, ON, Canada (K Graham $\mathrm{PhD}$, Prof J T Rehm PhD, K Shield MHSc); University of Otago, Dunedin, New Zealand (R Grainger PhD, T R Merriman PhD); Occupational and Environmental Epidemiology Branch, Division of Cancer Epidemiology and Genetics, National Cancer Institute (Q Lan PhD), National Institutes of Health, Bethesda, MD, USA ( $R$ Grainger, B Grant PhD); University of Bristol, Bristol, UK (Prof D Gunnell DSc); College of Physicians and Surgeons (Prof M M Weissman PhD), Mailman School of Public Health, Columbia University, New York City, NY, USA (H R Gutierrez BS, Prof M M Weissman); Parnassia Psychiatric Institute, The Hague, Netherlands (Prof H W Hoek MD); Australian National University, Canberra, ACT, Australia (A Hogan PhD); Albert Einstein College of Medicine, Yeshiva University, New York City, NY, USA (H D Hosgood III PhD); Dalla Lana School of Public Health, University of Toronto, Toronto, ON, Canada (Prof H Hu MD); US Environmental Protection Agency, Washington, DC, USA (B J Hubbell PhD); MRC-HPA Centre for Environment and Health, Department of Epidemiology and Biostatistics, School of Public Health, Imperial College London, London, UK (Prof M Ezzati PhD, S J Hutchings BSc, L Rushton PhD); University of Port Harcourt, Port Harcourt, Nigeria (S E Ibeanusi MBBS); Department of Ophthalmology, Medical Faculty Mannheim of the Ruprecht Karls University Heidelberg, Heidelberg, Germany (Prof J B Jonas MD); Fudan University, Shanghai, China (H Kan MD); University of Sheffi eld, Sheffi eld, UK (Prof J A Kanis MD); Department of Preventive Medicine, University of Ulsan College of Medicine, Seoul, South Korea (Prof Y-H Khang MD); Spinal Cord Injury Network, Glebe, New Zealand (C Kok PhD); School of Dentistry and Oral Health (Prof R Lalloo PhD), Population and Social Health Research Program (Prof R Lalloo), Griffi th University, Brisbane, QLD, Australia (N J C Stapelberg MBBS); 
Nova Southeastern University, Fort Lauderdale, FL, USA (J L Leasher OD); Critical Care and Trauma Division (Y Li MBBS), The George Institute for Global Health, Sydney, NSW, Australia (Prof B Neal PhD); Miller School of Medicine, University of Miami, Miami, FL, USA (Prof S E Lipshultz MD, Prof J D Wilkinson MD); Queen Mary University of London, London, UK (Prof W Marcenes PhD); Dalhousie University, Halifax, NS, Canada (Prof R Martin PhD, A van Donkelaar PhD); Global Alliance for Clean Cookstoves, Washington, DC, USA (S Mehta PhD); Department of Medicine, University of Cape Town, Cape Town, South Africa (Prof G A Mensah MD); Agricultural University of Athens, Athens, Greece (R Micha); China Medical Board, Boston, MA, USA (C Michaud MD); United Nations Population Division, New York City, NY, USA (V Mishra PhD); Queensland Univeristy of Technology, Brisbane, QLD, Australia (Prof L Morawska PhD); Rheumatology Department (Prof J M Nolla MD), Institut d'Investigacio Biomedica de Bellvitge, Hospital Universitari de Bellvitge, Barcelona, Spain (L Sanchez-Riera); School of Public Health (S B Omer MBBS, K Steenland PhD), School of Medicine, Emory University, Atlanta, GA, USA (S B Omer); Deakin University, Melbourne, VIC, Australia (Prof R Osborne PhD); California Environmental Protection Agency, Sacramento, CA, USA (B Ostro PhD); The World Bank, Washington DC, USA (K D Pandey PhD); South African Medical Research Council, Cape Town, South Africa (Prof C D H Parry $\mathrm{PhD}$ ); St Michael Hospital, Toronto, ON, Canada (J Patra PhD); Centers for Medicare and Medicaid Services, Baltimore, MD, USA (P M Pelizzari MPH); Centre for Applied Biostatistics, Sahlgrenska Academy at University of Gothenburg, Gothenburg, Sweden (Prof M Petzold PhD); Shanghai Mental Health Center, Shanghai Jiao Tong University School of Medicine, Shanghai, China (Prof M R Phillips MD); Brigham Young University, Provo, UT, USA (Prof C A Pope III PhD); Center for Disease Analysis, Louisville, CO, USA (H Razavi PhD); Ludwig Maximilians Universität Munich, Munich, Germany (E A Rehfuess PhD); University of California, Los Angeles, Los Angeles, CA, USA (Prof B Ritz MD); University of California, San Francisco, San Francisco, CA, USA (C Robinson BS); P Universidad Católica de Chile, Santiago, Chile (Prof J A Rodriguez-Portales MD); International Agency for Research on Cancer, Lyon, France (I Romieu MD, K Straif $\mathrm{MD}$ ); Centre for Alcohol Policy Research, Turning Point Alcohol \& Drug Centre, Fitzroy, SA, Australia (Prof R Room); Environmental and Occupational Health Sciences, University of Medicine and Dentistry of New Jersey, Newark, NJ, USA (A Roy ScD); Vanderbilt University, Nashville, TN, USA (Prof U Sampson MD); School of Public Health, University of Maryland, Baltimore, MD, USA (A Sapkota PhD); Stellenbosch University, Stellenbosch, South Africa (Prof S Seedat PhD); National Center for Injury Prevention and Control (D A Sleet PhD), Centers for Disease Control and Prevention, Baltimore, MD, USA (S T Wiersma MD); Department of Neuroscience, Norwegian University of Science and Technology, Trondheim, Norway (Prof L J Stovner PhD); New York University, New York City, NY, USA (Prof G D Thurston ScD); Voluntary Health Services, Sneha, Chennai, India (Prof L Vijayakumar MBBS); Royal Children's Hospital and Critical Care and Neurosciences Theme, Murdoch Children's Research Institute, Melbourne, VIC, Australia (R Weintraub); University of Nottingham, Nottingham, UK (Prof H C 


\author{
Williams PhD); National Acoustic Laboratories, Sydney, NSW, Australia (W Williams \\ PhD); Royal Cornwall Hospital, Truro, UK (Prof A D Woolf MBBS); and Centre for \\ Suicide Research and Prevention, The University of Hong Kong, Hong Kong, China \\ (Prof P Yip PhD)
}

\title{
Acknowledgments
}

We thank the countless individuals who have contributed to the Global Burden of Disease Study 2010 in various capacities. We specifically acknowledge the important contribution to this work from multiple staff members of the World Health Organization. We also thank the following organisations that hosted consultations during the final stages of the analytical process, providing valuable feedback about the results and the data to improve the study's findings overall: Pan American Health Organization; Eastern Mediterranean Regional Office of WHO; UNAIDS; Ministry of Health, Brazil; China Centers for Disease Control; and the University of Zambia. We thank Regina Guthold, Jordis Ott, Annette Pruss-Ustun, and Gretchen A Stevens for their collaboration and input into the analyses and estimates. Finally, we acknowledge the extensive support from all staff members at the Institute for Health Metrics and Evaluation and specifically thank: James Bullard, Andrew Ernst, and Serkan Yalcin for their tireless support of the computational infrastructure required to produce the results; Linda A Ettinger for her expert administrative support to facilitate communication and coordination amongst the authors; Peter Speyer, Abigail McLain, Katherine Leach-Kemon, and Eden Stork for their persistent and valuable work to gain access to and catalogue as much data as possible to inform the estimates; and Erin C Mullany for her systematic efforts in organising drafts of papers, formatting correspondence with expert groups, and preparing the final manuscript. $\mathrm{J}$ Balmes, Z Chafe, and K R Smith acknowledge that their aspects of the research were also supported by USEPA and the Shell Foundation, neither of which had any role in design, data collection, analysis, interpretation, or decisions related to publication. R Bourne acknowledges Institutional Support: Vision \& Eye Research Unit, Postgraduate Medical Institute, Anglia Ruskin University, Cambridge, UK. Funding support: Fight for Sight (Dr Hans and Mrs Gertrude Hirsch award). R Buchbinder was partially supported by an Australian National Health and Medical Research Council Practitioner Fellowship, Monash University, and Cabrini Health. A J Cohen received support from the Health Effects Institute and The William and Flora Hewlett Foundation. S Darby was supported by Cancer Research UK. L Degenhardt was supported by an Australian National Health and Medical Research Council Senior Research Fellowship. T Driscoll was supported in part by funding from the National Occupational Health and Safety Commission (now Safe work Australia). K M Hanafiah's work for the GBD hepatitis C prevalence study was funded partly by Johns Hopkins Vaccine Initiative Scholarship and partly by WHO. H W Hoek acknowledges the support of: the Parnassia Psychiatric Institute, The Hague, Netherlands; the Department of Psychiatry, University Medical Center Groningen, University of Groningen, Netherlands; and the Department of Epidemiology, Columbia University, New York, USA. D Hoy was supported by the Bill \& Melinda Gates Foundation and the Australian National Health and Medical Research Council. N Kawakami notes that data used in the study was collected through support from the following grants: The World Mental Health Japan is supported by the Grant for Research on Psychiatric and Neurological Diseases and Mental Health (H13-SHOGAI-023, H14TOKUBETSU-026, H16-KOKORO-013) from the Japan Ministry of Health, Labour, and Welfare. He thanks staff members, filed coordinators, and interviewers of the WMH Japan 2002-2004 Survey. Q Lan was supported in part by the Intramural Research Program of the NIH (National Cancer Institute). S London is supported by the Division of Intramural Research, National Institute of Environmental Health Sciences, USA. T R Merriman acknowledges the Health Research Council of New Zealand. B Neal was supported in his contribution to this work by an Australian Research Council Future Fellowship and a National Health and Medical Research Council of Australia Senior Research Fellowship. C Olives was supported in his contribution to this work by an Australian Research Council Future Fellowship and a National Health and Medical Research Council of Australia Senior Research Fellowship. E A Rehfuess acknowledges financial support from the Munich Centre of Health Sciences. R Room's position at the University of Melbourne and Turning Point Alcohol and Drug Centre is funded by the Foundation for Alcohol Research and Education and the Victorian Department of Health. J A Salomon received support from the Burke Global Health Fellowship while working on this study. U Sampson was supported in part by: The Harold Amos Medical Faculty Development Award of the Robert Wood Johnson Foundation; The Vanderbilt Clinical and Translational Scholars Award. L Sanchez-Riera acknowledges the Spanish Society of Rheumatology for their funds. S Seedat is supported by the South African Research Chairs Initiative, hosted by the Department of Science and Technology and the National Research Foundation. G D Thurston was supported in part by grant ES00260 from the National Institute of Environmental Health Sciences. J M Zielinski acknowledges institutional support from: Health Canada, University of Ottawa, and WHO (International Radon Project). M Ezzati's research is supported by a Strategic Award from the UK Medical Research Council (MRC) and by the National Institute for Health Research Comprehensive Biomedical research Centre at Imperial College Healthcare NHS Trust. Work on micronutrient deficiencies was supported by the Nutrition Impact Model Study (NIMS) funded by the Bill \& Melinda Gates Foundation. The GBD Osteoporosis Expert Group was supported by the Spanish Rheumatology Association, Institute of Bone and Joint Research, University of Sydney. The GBD Osteoporosis Expert Group also acknowledges the contributions made by Professor Philip Sambrook who passed away in April, 2012.

\section{Conflicts of interest}


A Davis is employed by the NHS on works for the UK Dept of Health as lead adviser on audiology. E R Dorsey has been a consultant for Medtronic and Lundbeck and has received grant support from Lundbeck and Prana Biotechnology. M Ezzati chaired a session and gave a talk at the World Cardiology Congress (WCC), with travel cost reimbursed by the World Heart Federation. At the WCC, he also gave a talk at a session organised by Pepsico with no financial remuneration. G A Mensah is a former employee of PepsiCo. D Mozaffarian has received: ad hoc travel reimbursement and/or honoraria for one-time specific presentations on diet and cardiometabolic diseases from Nutrition Impact (9/10), the International Life Sciences Institute (12/10), Bunge (11/11), Pollock Institute (3/12), and Quaker Oats (4/12; modest); and Unilever's North America Scientific Advisory Board (modest). B Neal is the Chair of the Australian Division of World Action on Salt and Health. He has consulted to Roche and Takeda. He has received lecture fees, travel fees, or reimbursements from Abbott, Amgen, AstraZeneca, George Clinical, GlaxoSmithKline, Novartis, PepsiCo, Pfizer, Pharmacy Guild of Australia, Roche, Sanofi-Aventis, Seervier, and Tanabe. He holds research support from the Australian Food and Grocery Council, Bupa Australia, Johnson and Johnson, Merck Schering-Plough, Roche, Servier, and United Healthcare Group. He is not employed by a commercial entity and has no equity ownership or stock options, patents or royalties, or any other financial or nonfinancial support that might be viewed as a conflict of interest. L Rushton received honorarium for board membership of the European Centre for Ecotoxicology and Toxicology of Chemicals and research grants to Imperial College London (as PI) from the European Chemical Industry Council and CONCAWE.

\section{References}

1. Doll R, Peto R. The causes of cancer: quantitative estimates of avoidable risks of cancer in the United States today. J Natl Cancer Inst. 1981; 66:1191-1308. [PubMed: 7017215]

2. Peto R, Boreham J, Lopez AD, Thun M, Heath C. Mortality from tobacco in developed countries: indirect estimation from national vital statistics. Lancet. 1992; 339:1268-1278. [PubMed: 1349675]

3. Murray, C.; Lopez, AD. The global burden of disease: a comprehensive assessment of mortality and disability from diseases, injuries, and risk factors in 1990 and projected in 2020. Cambridge: Harvard University Press; 1996.

4. Murray CJ, Lopez AD. On the comparable quantification of health risks: lessons from the Global Burden of Disease Study. Epidemiology. 1999; 10:594-605. [PubMed: 10468439]

5. WHO. Geneva: World Health Organization; 2002. The World Health Report 2002-Reducing Risks, Promoting Healthy Life.

6. Ezzati, M.; Lopez, AD.; Rodgers, A.; Murray, CJ. Comparative quantification of health risks: global and regional burden of diseases attributable to selected major risk factors. Geneva: World Health Organization; 2004.

7. Ezzati M, Lopez AD, Rodgers A, Vander Hoorn S, Murray CJ. the Comparative Risk Assessment Collaborating Group. Selected major risk factors and global and regional burden of disease. Lancet. 2002; 360:1347-1360. [PubMed: 12423980]

8. WHO. Geneva: World Health Organization; 2009. Global health risks: morality and burden of disease attributable to selected major risks.

9. Danaei G, Vander Hoorn S, Lopez AD, Murray CJ, Ezzati M. the The Comparative Risk Assessment collaborating group. (Cancers). Causes of cancer in the world: comparative risk assessment of nine behavioural and environmental risk factors. Lancet. 2005; 366:1784-1793. [PubMed: 16298215]

10. Black RE, Allen LH, Bhutta ZA, et al. Maternal and child undernutrition: global and regional exposures and health consequences. Lancet. 2008; 371:243-260. [PubMed: 18207566]

11. Danaei G, Ding EL, Mozaffarian D, et al. The preventable causes of death in the United States: comparative risk assessment of dietary, lifestyle, and metabolic risk factors. PLoS Med. 2009; 6:e1000058. [PubMed: 19399161]

12. Stevens G, Dias RH, Thomas KJA, et al. Characterizing the epidemiological transition in Mexico: national and subnational burden of diseases, injuries, and risk factors. PLoS Med. 2008; 5:e125. [PubMed: 18563960]

13. Begg SJ, Vos T, Barker B, Stanley L, Lopez AD. Burden of disease and injury in Australia in the new millennium: measuring health loss from diseases, injuries and risk factors. Med J Aust. 2008; 188:36-40. [PubMed: 18205562]

14. Norman R, Bradshaw D, Schneider M, et al. A comparative risk assessment for South Africa in 2000: towards promoting health and preventing disease. S Afr Med J. 2007; 97:637-641.

[PubMed: 17952221] 
15. Ikeda $\mathrm{N}$, Inoue $\mathrm{M}$, Iso $\mathrm{H}$, et al. Adult mortality attributable to preventable risk factors for noncommunicable diseases and injuries in Japan: a comparative risk assessment. PLoS Med. 2012; 9:e1001160. [PubMed: 22291576]

16. Farzadfar F, Danaei G, Namdaritabar H, et al. National and subnational mortality effects of metabolic risk factors and smoking in Iran: a comparative risk assessment. Popul Health Metr. 2011; 9:55. [PubMed: 21989074]

17. Murray CJL, Vos T, Lozano R, et al. Disability-adjusted life years (DALYs) for 291 diseases and injuries in 21 regions, 1990-2010: a systematic analysis for the Global Burden of Disease Study 2010. Lancet. 2012; 380:2197-2223. [PubMed: 23245608]

18. Vos T, Flaxman AD, Naghavi M, et al. Years lived with disability (YLD) for 1160 sequelae of 289 diseases and injuries 1990-2010: a systematic analysis for the Global Burden of Disease Study 2010. Lancet. 2012; 380:2163-2196. [PubMed: 23245607]

19. Wiener, N. Extrapolation, interpolation, and smoothing of stationary time series. Cambridge, MA: MIT Press; 1949.

20. Paciorek, P. Nonstationary Gaussian process for regression and spatial modeling. Pittsburgh, PA: Carnegie Mellon University; 2003.

21. Thompson P. Optimum smoothing of two-dimensional fields. Tellus. 1956; 8:84-93.

22. Dentener F, Drevet J, Lamarque JF, et al. Nitrogen and sulfur deposition on regional and global scales: a multimodel evaluation. Global Biogeochem Cycles. 2006 published online Oct 28.

23. Fiore AM, Dentener FJ, Wild O, et al. Multimodel estimates of intercontinental source-receptor relationships for ozone pollution. J Geophys Res. 2009; 114:21.

24. Stevenson DS, Dentener FJ, Schultz MG, et al. Multimodel ensemble simulations of present-day and near-future tropospheric ozone. J Geophys Res. 2006; 111

25. van Donkelaar A, Martin RV, Brauer M, et al. Global Estimates of Ambient Fine Particulate Matter Concentrations from Satellite-Based Aerosol Optical Depth: Development and Application. Environ Health Perspect. 2010; 118:847-855. [PubMed: 20519161]

26. Brauer M, Amann M, Burnett RT, et al. Exposure assessment for estimation of the global burden of disease attributable to outdoor air pollution. Environ Sci Technol. 2012; 46:652-660. [PubMed: 22148428]

27. Jerrett M, Burnett RT, Pope CA 3rd, et al. Long-term ozone exposure and mortality. N Engl J Med. 2009; 360:1085-1095. [PubMed: 19279340]

28. Darby S, Hill D, Auvinen A, et al. Radon in homes and risk of lung cancer: collaborative analysis of individual data from 13 European case-control studies. BMJ. 2005; 330:223. [PubMed: 15613366]

29. US Department of Health and Human Services, Public Health Service, Centers for Disease Control. [accessed Nov 19, 2012] Preventing lead poisoning in young children. Centers for Disease Control. 1991. http://wonder.cdc.gov/wonder/prevguid/p0000029/p0000029.asp

30. Lanphear BP, Hornung R, Khoury J, et al. Low-level environmental lead exposure and children's intellectual function: an international pooled analysis. Environ Health Perspect. 2005; 113:894899. [PubMed: 16002379]

31. Navas-Acien A, Schwartz BS, Rothenberg SJ, Hu H, Silbergeld EK, Guallar E. Bone lead levels and blood pressure endpoints: a meta-analysis. Epidemiology. 2008; 19:496-504. [PubMed: 18414090]

32. Lamberti LM, Fischer Walker CL, Noiman A, Victora C, Black RE. Breastfeeding and the risk for diarrhea morbidity and mortality. BMC Public Health. 2011; 11(suppl 3):S15. [PubMed: 21501432]

33. Stoltzfus, RJ.; Mullany, L.; Black, RE. Iron Deficiency Anaemia. In: Ezzati, M.; Lopez, AD.; Rodgers, A.; Murray, CJ., editors. Comparative quantification of health risks: Global and regional burden of disease attributable to selected major risk factors. Geneva: World Health Organization; 2004. p. 163-209.

34. Imdad A, Herzer K, Mayo-Wilson E, Yakoob MY, Bhutta ZA. Vitamin A supplementation for preventing morbidity and mortality in children from 6 months to 5 years of age. Cochrane Database Syst Rev. 2010; 12 CD008524. 
35. Imdad A, Yakoob MY, Sudfeld C, Haider BA, Black RE, Bhutta ZA. Impact of vitamin A supplementation on infant and childhood mortality. BMC Public Health. 2011; 11(suppl 3):S20. [PubMed: 21501438]

36. Yakoob MY, Theodoratou E, Jabeen A, et al. Preventive zinc supplementation in developing countries: impact on mortality and morbidity due to diarrhea, pneumonia and malaria. BMC Public Health. 2011; 11(suppl 3):S23. [PubMed: 21501441]

37. Foreman K, Lozano R, Lopez A, Murray C. Modeling causes of death: an integrated approach using CODEm. Popul Health Metr. 2012; 10:1. [PubMed: 22226226]

38. Oza S, Thun MJ, Henley SJ, Lopez AD, Ezzati M. How many deaths are attributable to smoking in the United States? Comparison of methods for estimating smoking-attributable mortality when smoking prevalence changes. Prev Med. 2011; 52:428-433. [PubMed: 21530575]

39. Ezzati M, Henley SJ, Lopez AD, Thun MJ. Role of smoking in global and regional cancer epidemiology: current patterns and data needs. Int J Cancer. 2005; 116:963-971. [PubMed: 15880414]

40. Ezzati M, Henley SJ, Thun MJ, Lopez AD. Role of smoking in global and regional cardiovascular mortality. Circulation. 2005; 112:489-497. [PubMed: 16027251]

41. US Department of Health and Human Services. Atlanta, GA: Department of Health and Human Services, Centers for Disease Control and Prevention, Coordinating Center for Health Promotion, National Center for Chronic Disease Prevention and Health Promotion, Office on Smoking and Health; 2006. The Health Consequences of Involuntary Exposure to Tobacco Smoke: A Report of the Surgeon General.

42. Oono IP, Mackay DF, Pell JP. Meta-analysis of the association between secondhand smoke exposure and stroke. J Public Health (Oxf). 2011; 33:496-502. [PubMed: 21422014]

43. Jones LL, Hashim A, McKeever T, Cook DG, Britton J, Leonardi-Bee J. Parental and household smoking and the increased risk of bronchitis, bronchiolitis and other lower respiratory infections in infancy: systematic review and meta-analysis. Respir Res. 2011; 12:5. [PubMed: 21219618]

44. Jones LL, Hassanien A, Cook DG, Britton J, Leonardi-Bee J. Parental smoking and the risk of middle ear disease in children: a systematic review and meta-analysis. Arch Pediatr Adolesc Med. 2012; 166:18-27. [PubMed: 21893640]

45. Shield KD, Rehm M, Patra J, Sornpaisarn B, Rehm J. Global and Country Specific Adult per capita Consumption of Alcohol, 2008. SUCHT-Zeitschrift für Wissenschaft und Praxis/Journal of Addiction Research and Practice. 2011; 57:99-117.

46. Lönnroth K, Williams BG, Stadlin S, Jaramillo E, Dye C. Alcohol use as a risk factor for tuberculosis—a systematic review. BMC Public Health. 2008; 8:289. [PubMed: 18702821]

47. Rehm J, Samokhvalov AV, Neuman MG, et al. The association between alcohol use, alcohol use disorders and tuberculosis (TB). A systematic review. BMC Public Health. 2009; 9:450. [PubMed: 19961618]

48. Samokhvalov AV, Irving HM, Rehm J. Alcohol consumption as a risk factor for pneumonia: a systematic review and meta-analysis. Epidemiol Infect. 2010; 138:1789-1795. [PubMed: 20380771]

49. Patra J, Bakker R, Irving H, Jaddoe VWV, Malini S, Rehm J. Dose-response relationship between alcohol consumption before and during pregnancy and the risks of low birthweight, preterm birth and small for gestational age (SGA)-a systematic review and meta-analyses. BJOG. 2011; 118:1411-1421. [PubMed: 21729235]

50. Corrao G, Bagnardi V, Zambon A, La Vecchia C. A meta-analysis of alcohol consumption and the risk of 15 diseases. Prev Med. 2004; 38:613-619. [PubMed: 15066364]

51. Baan R, Straif K, Grosse Y, et al. Carcinogenicity of alcoholic beverages. Lancet Oncol. 2007; 8:292-293. [PubMed: 17431955]

52. Baliunas DO, Taylor BJ, Irving $\mathrm{H}$, et al. Alcohol as a risk factor for type 2 diabetes: A systematic review and meta-analysis. Diabetes Care. 2009; 32:2123-2132. [PubMed: 19875607]

53. Taylor B, Irving HM, Kanteres F, et al. The more you drink, the harder you fall: a systematic review and meta-analysis of how acute alcohol consumption and injury or collision risk increase together. Drug Alcohol Depend. 2010; 110:108-116. [PubMed: 20236774] 
54. Roerecke, M.; Rehm, J. Alcohol consumption and the risk for morbidity and mortality of ischemic heart disease-a systemic review and meta-analysis. Toronto, ON: Centre for Addiction and Mental Health; 2011.

55. Roerecke M, Rehm J. Irregular heavy drinking occasions and risk of ischemic heart disease: a systematic review and meta-analysis. Am J Epidemiol. 2010; 171:633-644. [PubMed: 20142394]

56. Patra J, Taylor B, Irving H, et al. Alcohol consumption and the risk of morbidity and mortality for different stroke types - a systematic review and meta-analysis. BMC Public Health. 2010; 10:258. [PubMed: 20482788]

57. Samokhvalov AV, Irving HM, Rehm J. Alcohol consumption as a risk factor for atrial fibrillation: a systematic review and meta-analysis. Eur J Cardiovasc Prev Rehabil. 2010; 17:706-712. [PubMed: 21461366]

58. Irving HM, Samokhvalov AV, Rehm J. Alcohol as a risk factor for pancreatitis. A systematic review and meta-analysis. JOP. 2009; 10:387-392. [PubMed: 19581740]

59. Samokhvalov AV, Irving H, Mohapatra S, Rehm J. Alcohol consumption, unprovoked seizures, and epilepsy: a systematic review and meta-analysis. Epilepsia. 2010; 51:1177-1184. [PubMed: 20074233]

60. Van Den Berg C, Smit C, Van Brussel G, Coutinho R, Prins M. Full participation in harm reduction programmes is associated with decreased risk for human immunodeficiency virus and hepatitis $\mathrm{C}$ virus: evidence from the Amsterdam Cohort Studies among drug users. Addiction. 2007; 102:1454-1462. [PubMed: 17697278]

61. Foti DJ, Kotov R, Guey LT, Bromet EJ. Cannabis use and the course of schizophrenia: 10-year follow-up after first hospitalization. Am J Psychiatry. 2010; 167:987-993. [PubMed: 20478874]

62. Danaei G, Finucane MM, Lu Y, et al. National, regional, and global trends in fasting plasma glucose and diabetes prevalence since 1980: systematic analysis of health examination surveys and epidemiological studies with 370 country-years and 2.7 million participants. Lancet. 2011; 378:31-40. [PubMed: 21705069]

63. Sarwar N, Gao P, Seshasai SRK, et al. Diabetes mellitus, fasting blood glucose concentration, and risk of vascular disease: a collaborative meta-analysis of 102 prospective studies. Lancet. 2010; 375:2215-2222. [PubMed: 20609967]

64. Lawes CMM, Parag V, Bennett DA, et al. Blood glucose and risk of cardiovascular disease in the Asia Pacific region. Diabetes Care. 2004; 27:2836-2842. [PubMed: 15562194]

65. Balkau B. The DECODE study. Diabetes epidemiology: collaborative analysis of diagnostic criteria in Europe. Diabetes Metab. 2000; 26:282-286. [PubMed: 11011220]

66. Jeon CY, Murray MB. Diabetes Mellitus Increases the Risk of Active Tuberculosis: A Systematic Review of 13 Observational Studies. PLoS Med. 2008; 5:e152. [PubMed: 18630984]

67. Farzadfar F, Finucane MM, Danaei G, et al. National, regional, and global trends in serum total cholesterol since 1980: systematic analysis of health examination surveys and epidemiological studies with 321 country-years and 3.0 million participants. Lancet. 2011; 377:578-586. [PubMed: 21295847]

68. Zhang X, Patel A, Horibe H, et al. Cholesterol, coronary heart disease, and stroke in the Asia Pacific region. Int J Epidemiol. 2003; 32:563-572. [PubMed: 12913030]

69. Danesh J, Erqou S, Walker M, et al. the The Emerging Risk Factors Collaboration. analysis of individual data on lipid, inflammatory and other markers in over 1.1 million participants in 104 prospective studies of cardiovascular diseases. Eur J Epidemiol. 2007; 22:839-869. [PubMed: 17876711]

70. Danaei G, Finucane MM, Lin JK, et al. National, regional, and global trends in systolic blood pressure since 1980: systematic analysis of health examination surveys and epidemiological studies with 786 country-years and 5.4 million participants. Lancet. 2011; 377:568-577. [PubMed: 21295844]

71. Lewington S, Clarke R, Qizilbash N, Peto R, Collins R. Age-specific relevance of usual blood pressure to vascular mortality: a meta-analysis of individual data for one million adults in 61 prospective studies. Lancet. 2002; 360:1903-1913. [PubMed: 12493255]

72. Lawes CMM, Rodgers A, Bennett DA, et al. Blood pressure and cardiovascular disease in the Asia Pacific region. J Hypertens. 2003; 21:707-716. [PubMed: 12658016] 
73. Foote C, Lin J, et al. The Renal Risk Collaboration. The effect of blood pressure on kidney failure: a systematic review and meta-analysis in 2.7 million participants (unpublished).

74. Finucane MM, Stevens GA, Cowan MJ, et al. National, regional, and global trends in body-mass index since 1980: systematic analysis of health examination surveys and epidemiological studies with 960 country-years and 9.1 million participants. Lancet. 2011; 377:557-567. [PubMed: 21295846]

75. Whitlock G, Lewington S, Sherliker P, et al. Body-mass index and cause-specific mortality in 900 000 adults: collaborative analyses of 57 prospective studies. Lancet. 2009; 373:1083-1096. [PubMed: 19299006]

76. Ni Mhurchu C, Rodgers A, Pan WH, Gu DF, Woodward M. Body mass index and cardiovascular disease in the Asia-Pacific Region: an overview of 33 cohorts involving 310000 participants. Int J Epidemiol. 2004; 33:751-758. [PubMed: 15105409]

77. Wormser D, Kaptoge S, Di Angelantonio E, et al. Separate and combined associations of bodymass index and abdominal adiposity with cardiovascular disease: collaborative analysis of 58 prospective studies. Lancet. 2011; 377:1085-1095. [PubMed: 21397319]

78. Renehan AG, Tyson M, Egger M, Heller RF, Zwahlen M. Body-mass index and incidence of cancer: a systematic review and meta-analysis of prospective observational studies. Lancet. 2008; 371:569-578. [PubMed: 18280327]

79. Looker AC, Wahner HW, Dunn WL, et al. Updated data on proximal femur bone mineral levels of US adults. Osteoporos Int. 1998; 8:468-489. [PubMed: 9850356]

80. Johnell O, Kanis JA, Oden A, et al. Predictive value of BMD for hip and other fractures. J Bone Miner Res. 2005; 20:1185-1194. [PubMed: 15940371]

81. He FJ, Nowson CA, Lucas M, MacGregor GA. Increased consumption of fruit and vegetables is related to a reduced risk of coronary heart disease: meta-analysis of cohort studies. J Hum Hypertens. 2007; 21:717-728. [PubMed: 17443205]

82. World Cancer Research Fund, American Institute for Cancer Research. Washington, D.C.: AICR; 2007. Food, Nutrition, and Physical Activity, and the Prevention of Cancer: A Global Perspective.

83. Mellen PB, Walsh TF, Herrington DM. Whole grain intake and cardiovascular disease: a metaanalysis. Nutr Metab Cardiovasc Dis. 2008; 18:283-290. [PubMed: 17449231]

84. de Munter JSL, Hu FB, Spiegelman D, Franz M, van Dam RM. Whole grain, bran, and germ intake and risk of type 2 diabetes: a prospective cohort study and systematic review. PLoS Med. 2007; 4:e261. [PubMed: 17760498]

85. Kelly JH Jr, Sabaté J. Nuts and coronary heart disease: an epidemiological perspective. Br J Nutr. 2006; 96(suppl 2):S61-S67. [PubMed: 17125535]

86. Pan A, Sun Q, Bernstein AM, et al. Red meat consumption and risk of type 2 diabetes: 3 cohorts of US adults and an updated meta-analysis. Am J Clin Nutr. 2011; 94:1088-1096. [PubMed: 21831992]

87. Micha R, Wallace SK, Mozaffarian D. Red and processed meat consumption and risk of incident coronary heart disease, stroke, and diabetes mellitus: a systematic review and meta-analysis. Circulation. 2010; 121:2271-2283. [PubMed: 20479151]

88. Pereira MA, O’Reilly E, Augustsson K, et al. Dietary fiber and risk of coronary heart disease: a pooled analysis of cohort studies. Arch Intern Med. 2004; 164:370-376. [PubMed: 14980987]

89. Cho E, Smith-Warner SA, Spiegelman D, et al. Dairy foods, calcium, and colorectal cancer: a pooled analysis of 10 cohort studies. J Natl Cancer Inst. 2004; 96:1015-1022. [PubMed: 15240785]

90. Mozaffarian D, Rimm EB. Fish intake, contaminants, and human health: evaluating the risks and the benefits. JAMA. 2006; 296:1885-1899. [PubMed: 17047219]

91. Jakobsen MU, O'Reilly EJ, Heitmann BL, et al. Major types of dietary fat and risk of coronary heart disease: a pooled analysis of 11 cohort studies. Am J Clin Nutr. 2009; 89:1425-1432. [PubMed: 19211817]

92. Mozaffarian D, Micha R, Wallace S. Effects on coronary heart disease of increasing polyunsaturated fat in place of saturated fat: a systematic review and meta-analysis of randomized controlled trials. PLoS Med. 2010; 7:e1000252. [PubMed: 20351774] 
93. Mozaffarian D, Clarke R. Quantitative effects on cardiovascular risk factors and coronary heart disease risk of replacing partially hydrogenated vegetable oils with other fats and oils. Eur J Clin Nutr. 2009; 63(suppl 2):S22-S33. [PubMed: 19424216]

94. He FJ, MacGregor GA. Effect of modest salt reduction on blood pressure: a meta-analysis of randomized trials. Implications for public health. J Hum Hypertens. 2002; 16:761-770. [PubMed: 12444537]

95. Hutchings S, Rushton L. Toward risk reduction: predicting the future burden of occupational cancer. Am J Epidemiol. 2011; 173:1069-1077. [PubMed: 21447477]

96. Goodman M, Morgan RW, Ray R, Malloy CD, Zhao K. Cancer in asbestos-exposed occupational cohorts: a meta-analysis. Cancer Causes Control. 1999; 10:453-465. [PubMed: 10530617]

97. Rake C, Gilham C, Hatch J, Darnton A, Hodgson J, Peto J. Occupational, domestic and environmental mesothelioma risks in the British population: a case-control study. Br J Cancer. 2009; 100:1175-1183. [PubMed: 19259084]

98. Camargo MC, Stayner LT, Straif K, et al. Occupational exposure to asbestos and ovarian cancer: a meta-analysis. Environ Health Perspect. 2011; 119:1211-1217. [PubMed: 21642044]

99. Nelson DI, Concha-Barrientos M, Driscoll T, et al. The global burden of selected occupational diseases and injury risks: Methodology and summary. Am J Ind Med. 2005; 48:400-418. [PubMed: 16299700]

100. Hutchings SJ, Rushton L. Occupational cancer in Britain. Statistical methodology. Br J Cancer. 2012; 107(suppl 1):S8-S17. [PubMed: 22710683]

101. Lee-Feldstein A. Cumulative exposure to arsenic and its relationship to respiratory cancer among copper smelter employees. J Occup Med. 1986; 28:296-302. [PubMed: 3701479]

102. Khalade A, Jaakkola MS, Pukkala E, Jaakkola JJK. Exposure to benzene at work and the risk of leukemia: a systematic review and meta-analysis. Environ Health. 2010; 9:31. [PubMed: 20584305]

103. Schubauer-Berigan MK, Deddens JA, Couch JR, Petersen MR. Risk of lung cancer associated with quantitative beryllium exposure metrics within an occupational cohort. Occup Environ Med. 2011; 68:354-360. [PubMed: 21084327]

104. Rosenman KD, Stanbury M. Risk of lung cancer among former chromium smelter workers. Am J Ind Med. 1996; 29:491-500. [PubMed: 8732922]

105. Lipsett M, Campleman S. Occupational exposure to diesel exhaust and lung cancer: a metaanalysis. Am J Public Health. 1999; 89:1009-1017. [PubMed: 10394308]

106. Stayner L, Bena J, Sasco AJ, et al. Lung cancer risk and workplace exposure to environmental tobacco smoke. Am J Public Health. 2007; 97:545-551. [PubMed: 17267733]

107. Collins JJ, Lineker GA. A review and meta-analysis of formaldehyde exposure and leukemia. Regul Toxicol Pharmacol. 2004; 40:81-91. [PubMed: 15450712]

108. Hauptmann M, Lubin JH, Stewart PA, Hayes RB, Blair A. Mortality from solid cancers among workers in formaldehyde industries. Am J Epidemiol. 2004; 159:1117-1130. [PubMed: 15191929]

109. Grimsrud TK, Berge SR, Haldorsen T, Andersen A. Can lung cancer risk among nickel refinery workers be explained by occupational exposures other than nickel? Epidemiology. 2005; 16:146154. [PubMed: 15703528]

110. Grimsrud TK, Peto J. Persisting risk of nickel related lung cancer and nasal cancer among Clydach refiners. Occup Environ Med. 2006; 63:365-366. [PubMed: 16621856]

111. Armstrong B, Hutchinson E, Unwin J, Fletcher T. Lung cancer risk after exposure to polycyclic aromatic hydrocarbons: a review and meta-analysis. Environ Health Perspect. 2004; 112:970978. [PubMed: 15198916]

112. Kurihara N, Wada O. Silicosis and smoking strongly increase lung cancer risk in silica-exposed workers. Ind Health. 2004; 42:303-314. [PubMed: 15295901]

113. Soskolne CL, Jhangri GS, Siemiatycki J, et al. Occupational exposure to sulfuric acid in southern Ontario, Canada, in association with laryngeal cancer. Scand J Work Environ Health. 1992; 18:225-232. [PubMed: 1411364] 
114. Karjalainen A, Kurppa K, Martikainen R, Klaukka T, Karjalainen J. Work is related to a substantial portion of adult-onset asthma incidence in the Finnish population. Am J Respir Crit Care Med. 2001; 164:565-568. [PubMed: 11520716]

115. Karjalainen A, Kurppa K, Martikainen R, Karjalainen J, Klaukka T. Exploration of asthma risk by occupation--extended analysis of an incidence study of the Finnish population. Scand J Work Environ Health. 2002; 28:49-57. [PubMed: 11871852]

116. Kogevinas M, Antó JM, Sunyer J, Tobias A, Kromhout H, Burney P. Occupational asthma in Europe and other industrialised areas: a population-based study. European Community Respiratory Health Survey Study Group. Lancet. 1999; 353:1750-1754. [PubMed: 10347988]

117. Beydoun HA, Beydoun MA, Kaufman JS, Lo B, Zonderman AB. Intimate partner violence against adult women and its association with major depressive disorder, depressive symptoms and postpartum depression: a systematic review and meta-analysis. Soc Sci Med. 2012; 75:959975. [PubMed: 22694991]

118. World Cancer Research Fund. AICR. Washington, DC: American Institute for Cancer Research; 2007. Food, Nutrition, and Physical Activity, and the Prevention of Cancer: A Global Perspective.

119. Liu BQ, Peto R, Chen ZM, et al. Emerging tobacco hazards in China: 1. Retrospective proportional mortality study of one million deaths. BMJ. 1998; 317:1411-1422. [PubMed: 9822393]

120. Thun MJ, Hannan LM, Adams-Campbell LL, et al. Lung cancer occurrence in never-smokers: an analysis of 13 cohorts and 22 cancer registry studies. PLoS Med. 2008; 5:e185. [PubMed: 18788891]

121. Huijnen V, Williams J, van Weele M, et al. The global chemistry transport model TM5: description and evaluation of the tropospheric chemistry version 3.0. Geoscientific Model Development. 2010; 3:445-473.

122. Caufield, LE.; Black, RE. Zinc Deficiency. In: Ezzati, M.; Lopez, AD.; Rodgers, A.; Murray, C., editors. Comparative quantification of health risks: global and regional burden of disease attributable to selected major risk factors. Geneva: World Health Organization; 2004. p. 729-882.

123. Wessells KP, Brown KH. Estimating global prevalence of zinc deficiency: results based on zinc availability in national food supplies and the prevalence of stunting. PLoS One. 2012; 7:e50568. [PubMed: 23209782]

124. Miller KA, Siscovick DS, Sheppard L, et al. Long-term exposure to air pollution and incidence of cardiovascular events in women. N Engl J Med. 2007; 356:447-458. [PubMed: 17267905]

125. Puett RC, Hart JE, Yanosky JD, et al. Chronic fine and coarse particulate exposure, mortality, and coronary heart disease in the Nurses' Health Study. Environ Health Perspect. 2009; 117:16971701. [PubMed: 20049120]

126. Lipsett MJ, Ostro BD, Reynolds P, et al. Long-term exposure to air pollution and cardiorespiratory disease in the California teachers study cohort. Am J Respir Crit Care Med. 2011; 184:828-835. [PubMed: 21700913]

127. Fink G, Günther I, Hill K. The effect of water and sanitation on child health: evidence from the demographic and health surveys 1986-2007. Int J Epidemiol. 2011; 40:1196-1204. [PubMed: 21724576]

128. Cairncross S, Hunt C, Boisson S, et al. Water, sanitation and hygiene for the prevention of diarrhoea. Int J Epidemiol. 2010; 39(suppl 1):i193-i205. [PubMed: 20348121]

129. Waddington, H.; Snilstveit, B.; White, H.; Fewtrell, L. Water, sanitation and hygiene interventions to combat childhood diarrhea in developing countries. Washington, DC: International Initiative for Impact Evaluation; 2009.

130. Fewtrell L, Kaufmann RB, Kay D, Enanoria W, Haller L, Colford JM Jr. Water, sanitation, and hygiene interventions to reduce diarrhoea in less developed countries: a systematic review and meta-analysis. Lancet Infect Dis. 2005; 5:42-52. [PubMed: 15620560]

131. Clasen TF, Bostoen K, Schmidt W-P, et al. Interventions to improve disposal of human excreta for preventing diarrhoea. Cochrane Database Syst Rev. 2010 CD007180. 
132. Pope CA 3rd, Burnett RT, Turner MC, et al. Lung cancer and cardiovascular disease mortality associated with ambient air pollution and cigarette smoke: shape of the exposure-response relationships. Environ Health Perspect. 2011; 119:1616-1621. [PubMed: 21768054]

133. Pope CA 3rd, Burnett RT, Krewski D, et al. Cardiovascular mortality and exposure to airborne fine particulate matter and cigarette smoke: shape of the exposure-response relationship. Circulation. 2009; 120:941-948. [PubMed: 19720932]

134. Krewski D, Jerrett M, Burnett RT, et al. Extended follow-up and spatial analysis of the American Cancer Society study linking particulate air pollution and mortality. Res Rep Health Eff Inst. 2009; 140:5-114. [PubMed: 19627030]

135. Brook RD, Rajagopalan S, Pope CA 3rd, et al. Particulate matter air pollution and cardiovascular disease: an update to the scientific statement from the American Heart Association. Circulation. 2010; 121:2331-2378. [PubMed: 20458016]

136. Committee on the Medical Effects of Air Pollutants. Long-Term Exposure to Air Pollution: Effect on Mortality. London: Health Protection Agency; 2009.

137. Cooke RM, Wilson AM, Tuomisto JT, Morales O, Tainio M, Evans JS. A probabilistic characterization of the relationship between fine particulate matter and mortality: elicitation of European experts. Environ Sci Technol. 2007; 41:6598-6605. [PubMed: 17948814]

138. Burnett RT, Pope CA 3rd, Ezzati M, et al. A unified risk function for estimating the global burden of mortality attributable to fine particulate matter exposure. (in press).

139. Baumgartner J, Schauer JJ, Ezzati M, et al. Indoor air pollution and blood pressure in adult women living in rural China. Environ Health Perspect. 2011; 119:1390-1395. [PubMed: 21724522]

140. Smith KR, McCracken JP, Weber MW, et al. Effect of reduction in household air pollution on childhood pneumonia in Guatemala (RESPIRE): a randomised controlled trial. Lancet. 2011; 378:1717-1726. [PubMed: 22078686]

141. He K, Song Y, Daviglus ML, et al. Fish consumption and incidence of stroke: a meta-analysis of cohort studies. Stroke. 2004; 35:1538-1542. [PubMed: 15155968]

142. He K, Song Y, Daviglus ML, et al. Accumulated evidence on fish consumption and coronary heart disease mortality: a meta-analysis of cohort studies. Circulation. 2004; 109:2705-2711. [PubMed: 15184295]

143. Rizos EC, Ntzani EE, Bika E, Kostapanos MS, Elisaf MS. Association between omega-3 fatty acid supplementation and risk of major cardiovascular disease events: a systematic review and meta-analysis. JAMA. 2012; 308:1024-1033. [PubMed: 22968891]

144. Trichopoulou A, Bamia C, Trichopoulos D. Anatomy of health effects of Mediterranean diet: Greek EPIC prospective cohort study. BMJ. 2009; 338:b2337. [PubMed: 19549997]

145. Hu FB, Rimm EB, Stampfer MJ, Ascherio A, Spiegelman D, Willett WC. Prospective study of major dietary patterns and risk of coronary heart disease in men. Am J Clin Nutr. 2000; 72:912921. [PubMed: 11010931]

146. Fung TT, Willett WC, Stampfer MJ, Manson JE, Hu FB. Dietary patterns and the risk of coronary heart disease in women. Arch Intern Med. 2001; 161:1857-1862. [PubMed: 11493127]

147. Fung TT, Rexrode KM, Mantzoros CS, Manson JE, Willett WC, Hu FB. Mediterranean diet and incidence of and mortality from coronary heart disease and stroke in women. Circulation. 2009; 119:1093-1100. [PubMed: 19221219]

148. Martínez-González MA, Garcia-Lopez M, Bes-Rastrollo M, et al. Mediterranean diet and the incidence of cardiovascular disease: a Spanish cohort. Nutr Metab Cardiovasc Dis. 2011; 21:237-244. [PubMed: 20096543]

149. Appel LJ, Moore TJ, Obarzanek E, et al. A clinical trial of the effects of dietary patterns on blood pressure. DASH Collaborative Research Group. N Engl J Med. 1997; 336:1117-1124. [PubMed: 9099655]

150. Appel LJ, Sacks FM, Carey VJ, et al. Effects of protein, monounsaturated fat, and carbohydrate intake on blood pressure and serum lipids: results of the OmniHeart randomized trial. JAMA. 2005; 294:2455-2464. [PubMed: 16287956] 
151. Mozaffarian D, Wu JHY. Omega-3 fatty acids and cardiovascular disease: effects on risk factors, molecular pathways, and clinical events. J Am Coll Cardiol. 2011; 58:2047-2067. [PubMed: 22051327]

152. King G, Tomz M, Wittenberg J. Making the most of statistical analyses: improving interpretation and presentation. Am J Pol Sci. 2000; 44:347-361.

153. Sazawal S, Black RE, Ramsan M, et al. Effect of zinc supplementation on mortality in children aged 1-48 months: a community-based randomised placebo-controlled trial. Lancet. 2007; 369:927-934. [PubMed: 17368154]

154. Law MR, Morris JK, Wald NJ. Use of blood pressure lowering drugs in the prevention of cardiovascular disease: meta-analysis of 147 randomised trials in the context of expectations from prospective epidemiological studies. BMJ. 2009; 338:b1665. [PubMed: 19454737]

155. Ezzati M, Vander Hoorn S, Rodgers A, Lopez AD, Mathers CD, Murray CJ. Estimates of global and regional potential health gains from reducing multiple major risk factors. Lancet. 2003; 362:271-280. [PubMed: 12892956]

156. Rothman KJ. Causes. Am J Epidemiol. 1976; 104:587-592. [PubMed: 998606]

157. Thun M, Peto R, Boreham J, Lopez AD. Stages of the cigarette epidemic on entering its second century. Tob Control. 2012; 21:96-101. [PubMed: 22345230]

158. Elliott P, Stamler J, Nichols R, et al. Intersalt revisited: further analyses of 24 hour sodium excretion and blood pressure within and across populations. Intersalt Cooperative Research Group. BMJ. 1996; 312:1249-1253. [PubMed: 8634612]

159. Pope CA 3rd, Burnett RT, Thurston GD, et al. Cardiovascular mortality and long-term exposure to particulate air pollution: epidemiological evidence of general pathophysiological pathways of disease. Circulation. 2004; 109:71-77. [PubMed: 14676145]

160. Lepeule J, Laden F, Dockery D, Schwartz J. Chronic exposure to fine particles and mortality: an extended follow-up of the Harvard Six Cities study from 1974 to 2009. Environ Health Perspect. 2012; 120:965-970. [PubMed: 22456598]

161. Ambrose JA, Barua RS. The pathophysiology of cigarette smoking and cardiovascular disease: an update. J Am Coll Cardiol. 2004; 43:1731-1737. [PubMed: 15145091]

162. Pope C, Brook R, Burnett R, Dockery D. How is cardiovascular disease mortality risk affected by duration and intensity of fine particulate matter exposure? An integration of the epidemiologic evidence. Air Qual Atmos Health. 2011; 4:5-14.

163. Bailis R, Ezzati M, Kammen DM. Mortality and greenhouse gas impacts of biomass and petroleum energy futures in Africa. Science. 2005; 308:98-103. [PubMed: 15802601]

164. Pope CA 3rd, Ezzati M, Dockery DW. Fine-particulate air pollution and life expectancy in the United States. N Engl J Med. 2009; 360:376-386. [PubMed: 19164188]

165. HEI Accountability Working Group. Communication 11. Boston: Health Effects Institute; 2003. Assessing Health Impact of Air Quality Regulations: Concepts and Methods for Acountability Research.

166. Health Effects Institute. Communication 15. Boston: Health Effects Institute; 2010. Proceedings of an HEI Workshop on Further Research to Assess the Health Impacts of Actions Taken to Improve Air Quality.

167. Johnston FH, Henderson SB, Chen Y, et al. Estimated global mortality attributable to smoke from landscape fires. Environ Health Perspect. 2012; 120:695-701. [PubMed: 22456494]

168. Normile D. Ecology. Getting at the roots of killer dust storms. Science. 2007; 317:314-316. [PubMed: 17641178]

169. Amiraslani F, Dragovich D. Combating desertification in Iran over the last 50 years: an overview of changing approaches. J Environ Manage. 2011; 92:1-13. [PubMed: 20855149]

170. Wang XM, Zhang CX, Dong ZB, Hasi E. Has the Three Norths Forest Shelterbelt Program solved the desertification and dust storm problems in arid and semiarid China? J Arid Environ. 2010; 74:13-22.

171. Wang X, Dong Z, Zhang J, Liu L. Modern dust storms in China: an overview. J Arid Environ. 2004; 58:559-574. 
172. Dionisio KL, Rooney MS, Arku RE, et al. Within-neighborhood patterns and sources of particle pollution: mobile monitoring and geographic information system analysis in four communities in Accra, Ghana. Environ Health Perspect. 2010; 118:607-613. [PubMed: 20056591]

173. Zhou Z, Dionisio KL, Arku RE, et al. Household and community poverty, biomass use, and air pollution in Accra, Ghana. Proc Natl Acad Sci USA. 2011; 108:11028-11033. [PubMed: 21690396]

174. Preston SH, Van de Walle E. Urban French mortality in the nineteenth century. Popul Stud (Camb). 1978; 32:275-297. [PubMed: 11630579]

175. Wang X, Hunter PR. A systematic review and meta-analysis of the association between selfreported diarrheal disease and distance from home to water source. Am J Trop Med Hyg. 2010; 83:582-584. [PubMed: 20810824]

176. Lozano R, Naghavi M, Foreman K, et al. Global and regional mortality from 235 causes of death for 20 age groups in 1990 and 2010: a systematic analysis for the Global Burden of Disease Study 2010. Lancet. 2012; 380:2095-2128. [PubMed: 23245604]

177. Lukacik M, Thomas RL, Aranda JV. A meta-analysis of the effects of oral zinc in the treatment of acute and persistent diarrhea. Pediatrics. 2008; 121:326-336. [PubMed: 18245424]

178. Cogswell ME, Parvanta I, Ickes L, Yip R, Brittenham GM. Iron supplementation during pregnancy, anemia, and birth weight: a randomized controlled trial. Am J Clin Nutr. 2003; 78:773-781. [PubMed: 14522736]

179. Zeng L, Dibley MJ, Cheng Y, et al. Impact of micronutrient supplementation during pregnancy on birth weight, duration of gestation, and perinatal mortality in rural western China: double blind cluster randomised controlled trial. BMJ. 2008; 337:a2001. [PubMed: 18996930]

180. Murray, CJ.; Lopez, AD. Boston: Harvard School of Public Health on behalf of the World Health Organization and the World Bank; 1996. The Global Burden of Disease: a comprehensive assessment of mortality and disability from diseases, injuries, and risk factors in 1990 and projected to 2020 .

181. Zaridze D, Maximovitch D, Lazarev A, et al. Alcohol poisoning is a main determinant of recent mortality trends in Russia: evidence from a detailed analysis of mortality statistics and autopsies. Int J Epidemiol. 2009; 38:143-153. [PubMed: 18775875]

182. Rehm J, Baliunas D, Borges GLG, et al. The relation between different dimensions of alcohol consumption and burden of disease: an overview. Addiction. 2010; 105:817-843. [PubMed: 20331573]

183. Asaria P, Chisholm D, Mathers C, Ezzati M, Beaglehole R. Chronic disease prevention: health effects and financial costs of strategies to reduce salt intake and control tobacco use. Lancet. 2007; 370:2044-2053. [PubMed: 18063027]

184. Lim SS, Gaziano TA, Gakidou E, et al. Prevention of cardiovascular disease in high-risk individuals in low-income and middle-income countries: health effects and costs. Lancet. 2007; 370:2054-2062. [PubMed: 18063025]

185. Lewington S, Whitlock G, Clarke R, et al. Blood cholesterol and vascular mortality by age, sex, and blood pressure: a meta-analysis of individual data from 61 prospective studies with 55000 vascular deaths. Lancet. 2007; 370:1829-1839. [PubMed: 18061058]

186. Lee I-M, Shiroma EJ, Lobelo F, et al. Effect of physical inactivity on major non-communicable diseases worldwide: an analysis of burden of disease and life expectancy. Lancet. 2012; 380:219-229. [PubMed: 22818936]

187. Das P, Horton R. Rethinking our approach to physical activity. Lancet. 2012; 380:189-190. [PubMed: 22818931]

188. Hu FB, Manson JE. Omega-3 fatty acids and secondary prevention of cardiovascular disease-is it just a fish tale?: Comment on 'efficacy of omega-3 fatty acid supplements (eicosapentaenoic acid and docosahexaenoic acid) in the secondary prevention of cardiovascular disease'. Arch Intern Med. 2012; 172:694-696. [PubMed: 22493410]

189. Ioannidis JPA. Why most published research findings are false. PLoS Med. 2005; 2:e124. [PubMed: 16060722]

190. Ioannidis JPA. Contradicted and initially stronger effects in highly cited clinical research. JAMA. 2005; 294:218-228. [PubMed: 16014596] 
191. Slattery ML, Randall DE. Trends in coronary heart disease mortality and food consumption in the United States between 1909 and 1980. Am J Clin Nutr. 1988; 47:1060-1067. [PubMed: 3376904]

192. Howard BV, Van Horn L, Hsia J, et al. Low-fat dietary pattern and risk of cardiovascular disease: the Women's Health Initiative Randomized Controlled Dietary Modification Trial. JAMA. 2006; 295:655-666. [PubMed: 16467234]

193. Knowler WC, Barrett-Connor E, Fowler SE, et al. Reduction in the incidence of type 2 diabetes with lifestyle intervention or metformin. N Engl J Med. 2002; 346:393-403. [PubMed: 11832527]

194. Rose G. Sick individuals and sick populations. Int J Epidemiol. 2001; 30:427-432. [PubMed: 11416056] 


\section{Panel: The World Cancer Research Fund grading system ${ }^{118}$}

\section{Convincing evidence}

Evidence based on epidemiological studies showing consistent associations between exposure and disease, with little or no evidence to the contrary. The available evidence is based on a substantial number of studies including prospective observational studies and where relevant, randomised controlled trials of sufficient size, duration, and quality showing consistent effects. The association should be biologically plausible.

\section{Probable evidence}

Evidence based on epidemiological studies showing fairly consistent associations between exposure and disease, but for which there are perceived shortcomings in the available evidence or some evidence to the contrary, which precludes a more definite judgment. Shortcomings in the evidence may be any of the following: insufficient duration of trials (or studies); insufficient trials (or studies) available; inadequate sample sizes; or incomplete follow-up. Laboratory evidence is usually supportive. The association should be biologically plausible.

\section{Possible evidence}

Evidence based mainly on findings from case-control and cross-sectional studies. Insufficient randomised controlled trials, observational studies, or non-randomised controlled trials are available. Evidence based on non-epidemiological studies, such as clinical and laboratory investigations, is supportive. More trials are needed to support the tentative associations, which should be biologically plausible.

\section{Insufficient evidence}

Evidence based on findings of a few studies which are suggestive, but insufficient to establish an association between exposure and disease. Little or no evidence is available from randomised controlled trials. More well-designed research is needed to support the tentative associations. 


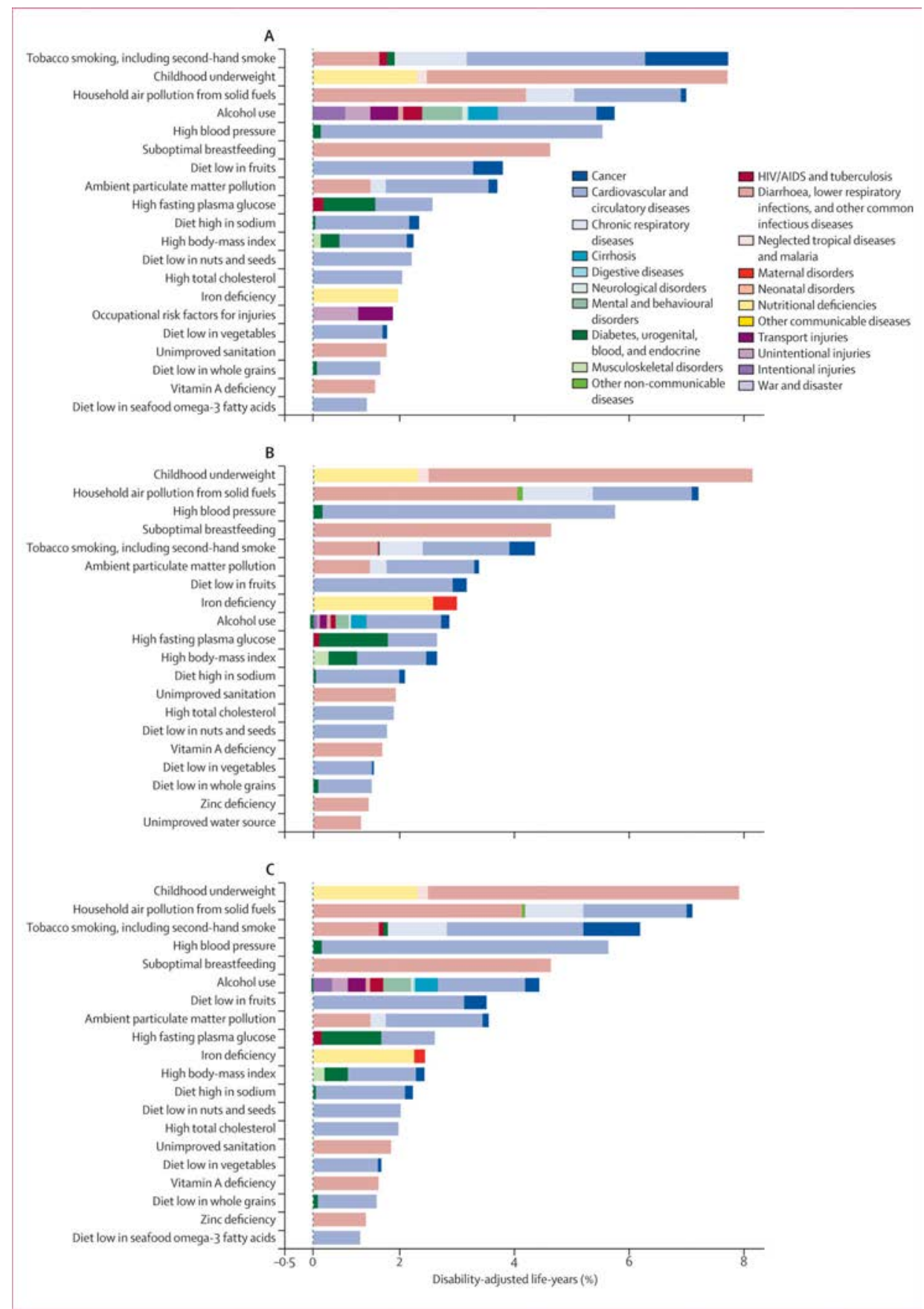

Figure 1. Burden of disease attributable to 20 leading risk factors in 1990, expressed as a percentage of global disability-adjusted life-years

For men (A), women (B), and both sexes (C). 


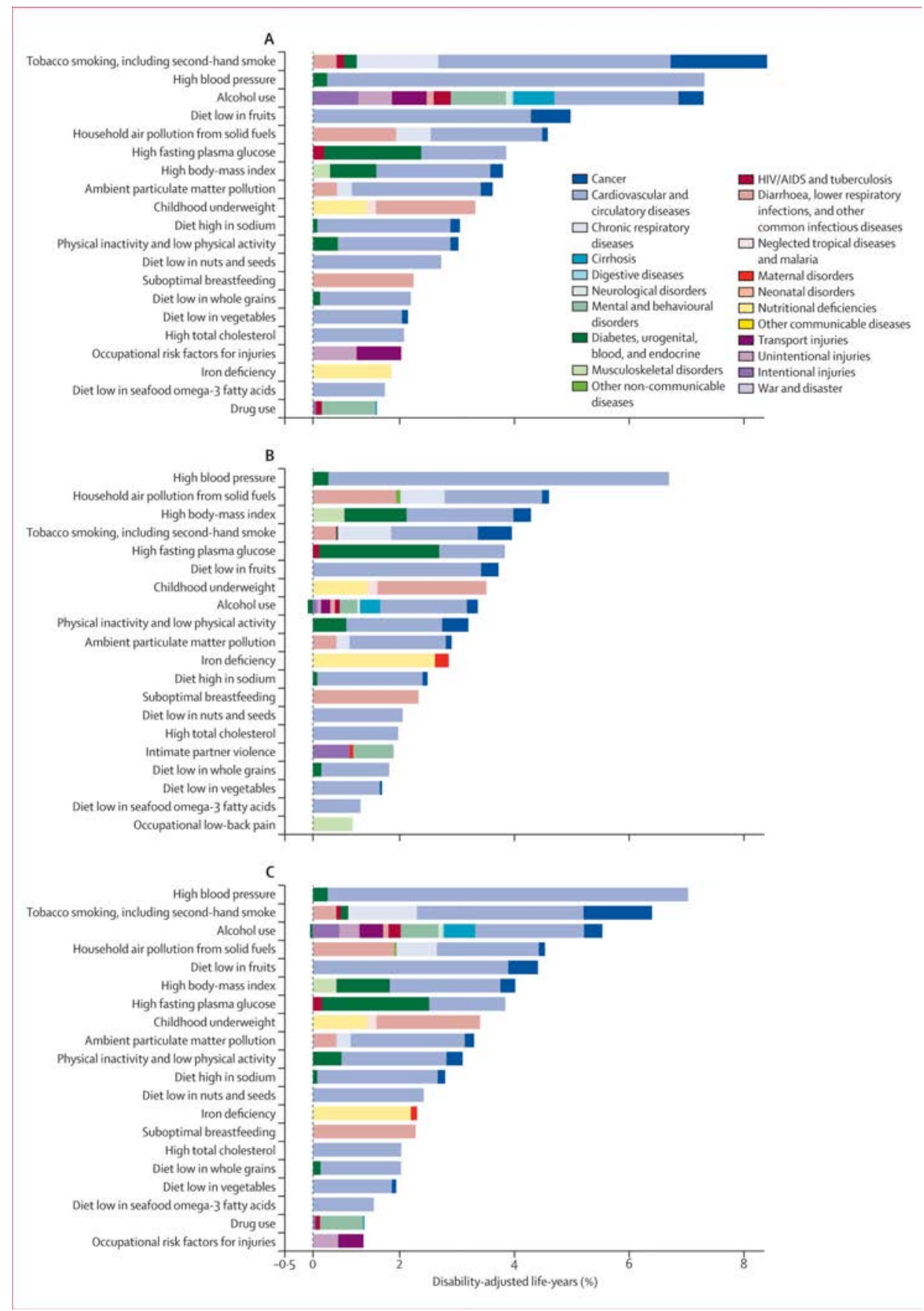

Figure 2. Burden of disease attributable to 20 leading risk factors in 2010 , expressed as a percentage of global disability-adjusted life-years

For men (A), women (B), and both sexes (C). 


\begin{tabular}{|c|c|c|c|c|}
\hline \multicolumn{2}{|r|}{1990} & \multicolumn{3}{|c|}{2010} \\
\hline \multicolumn{2}{|l|}{$\begin{array}{l}\text { Mean rank } \\
(95 \% \text { UI) }\end{array}$} & Risk factor & $\begin{array}{l}\text { Mean rank } \\
(95 \% \text { UI) }\end{array}$ & $\%$ change ( $95 \%$ UI) \\
\hline $1.1(1-2)$ & 1 Childhood underweight & 1 High blood pressure & $1.1(1-2)$ & $27 \%(19$ to 34$)$ \\
\hline $2 \cdot 1(1-4)$ & 2 Household air pollution & 2 Smoking (excluding SHS) & $1.9(1-2)$ & $3 \%(-5$ to 11$)$ \\
\hline $2 \cdot 9(2-4)$ & 3 Smoking (excluding SHS) & 3 Alcohol use & $3 \cdot 0(2-4)$ & $28 \%(17$ to 39$)$ \\
\hline $4 \cdot 0(3-5)$ & 4 High blood pressure & 4 Household air pollution & $4.7(3-7)$ & $-37 \%(-44$ to -29$)$ \\
\hline $5 \cdot 4(3-8)$ & 5 Suboptimal breastfeeding & 5 Low fruit & $5 \cdot 0(4-8)$ & $29 \%(25$ to 34$)$ \\
\hline $5 \cdot 6(5-6)$ & 6 Alcohol use & 6 High body-mass index & $6 \cdot 1(4-8)$ & $82 \%(71$ to 95$)$ \\
\hline $7 \cdot 4(6-8)$ & 7 Ambient PM pollution & 7 High fasting plasma glucose & $6 \cdot 6(5-8)$ & $58 \%(43$ to 73$)$ \\
\hline $7 \cdot 4(6-8)$ & 8 Low fruit & 8 Childhood underweight & $8 \cdot 5(6-11)$ & $-61 \%(-66$ to -55$)$ \\
\hline $9 \cdot 7(9-12)$ & 9 High fasting plasma glucose & 9 Ambient PM pollution & $8.9(7-11)$ & $-7 \%(-13$ to -1$)$ \\
\hline $10 \cdot 9(9-14)$ & 10 High body-mass index & 10 Physical inactivity & $9 \cdot 9(8-12)$ & $0 \%(0$ to 0$)$ \\
\hline $11.1(9-15)$ & 11 Iron deficiency & 11 High sodium & $11.2(8-15)$ & $33 \%(27$ to 39$)$ \\
\hline $12 \cdot 3(9-17)$ & 12 High sodium & 12 Low nuts and seeds & $12 \cdot 9(11-17)$ & $27 \%(18$ to 32$)$ \\
\hline $13.9(10-19)$ & 13 Low nuts and seeds & 13 Iron deficiency & $13.5(11-17)$ & $-7 \%(-11$ to -4$)$ \\
\hline $14 \cdot 1(11-17)$ & 14 High total cholesterol & 14 Suboptimal breastfeeding & $13 \cdot 8(10-18)$ & $-57 \%(-63$ to -51$)$ \\
\hline $16 \cdot 2(9-38)$ & 15 Sanitation & 15 High total cholesterol & $15 \cdot 2(12-17)$ & $3 \%(-13$ to 19$)$ \\
\hline $16 \cdot 7(13-21)$ & 16 Low vegetables & 16 Low whole grains & $15 \cdot 3(13-17)$ & $39 \%(32$ to 45$)$ \\
\hline $17 \cdot 1(10-23)$ & 17 Vitamin A deficiency & 17 Low vegetables & $15.8(12-19)$ & $22 \%(16$ to 28$)$ \\
\hline $17 \cdot 3(15-20)$ & 18 Low whole grains & 18 Low omega- 3 & $18 \cdot 7(17-23)$ & $30 \%(21$ to 35$)$ \\
\hline $20 \cdot 0(13-29)$ & 19 Zinc deficiency & 19 Drug use & $20 \cdot 2(18-23)$ & $57 \%(42$ to 72$)$ \\
\hline $20.6(17-25)$ & 20 Low omega- 3 & 20 Occupational injury & $20 \cdot 4(18-23)$ & $12 \%(-22$ to 58$)$ \\
\hline $20.8(18-24)$ & 21 Occupational injury & 21 Occupational low back pain & $21.2(18-25)$ & $22 \%$ (11 to 35$)$ \\
\hline $21 \cdot 7(14-34)$ & 22 Unimproved water & 22 High processed meat & $22 \cdot 0(17-31)$ & $22 \%(2$ to 44$)$ \\
\hline $22.6(19-26)$ & 23 Occupational low back pain & 23 Intimate partner violence & $23.8(20-28)$ & $0 \%(0$ to 0$)$ \\
\hline $23.2(19-29)$ & 24 High processed meat & 24 Low fibre & $24 \cdot 4(19-32)$ & $23 \%(13$ to 33$)$ \\
\hline \multirow[t]{5}{*}{$24 \cdot 2(21-26)$} & 25 Drug use & 25 Lead & $25 \cdot 5(23-29)$ & $160 \%$ (143 to 176$)$ \\
\hline & 26 Low fibre & 26 Sanitation & & \\
\hline & 30 Lead & 29 Vitamin A deficiency & & \\
\hline & & 31 Zinc deficiency & & \\
\hline & & 33 Unimproved water & & ..- Descending order in rank \\
\hline
\end{tabular}

Figure 3. Global risk factor ranks with $95 \%$ UI for all ages and sexes combined in 1990, and 2010, and percentage change

$\mathrm{PM}=$ particulate matter. $\mathrm{UI}=$ uncertainty interval. $\mathrm{SHS}=$ second-hand smoke. An interactive version of this figure is available online at http://healthmetricsandevaluation.org/gbd/ visualizations/regional. 


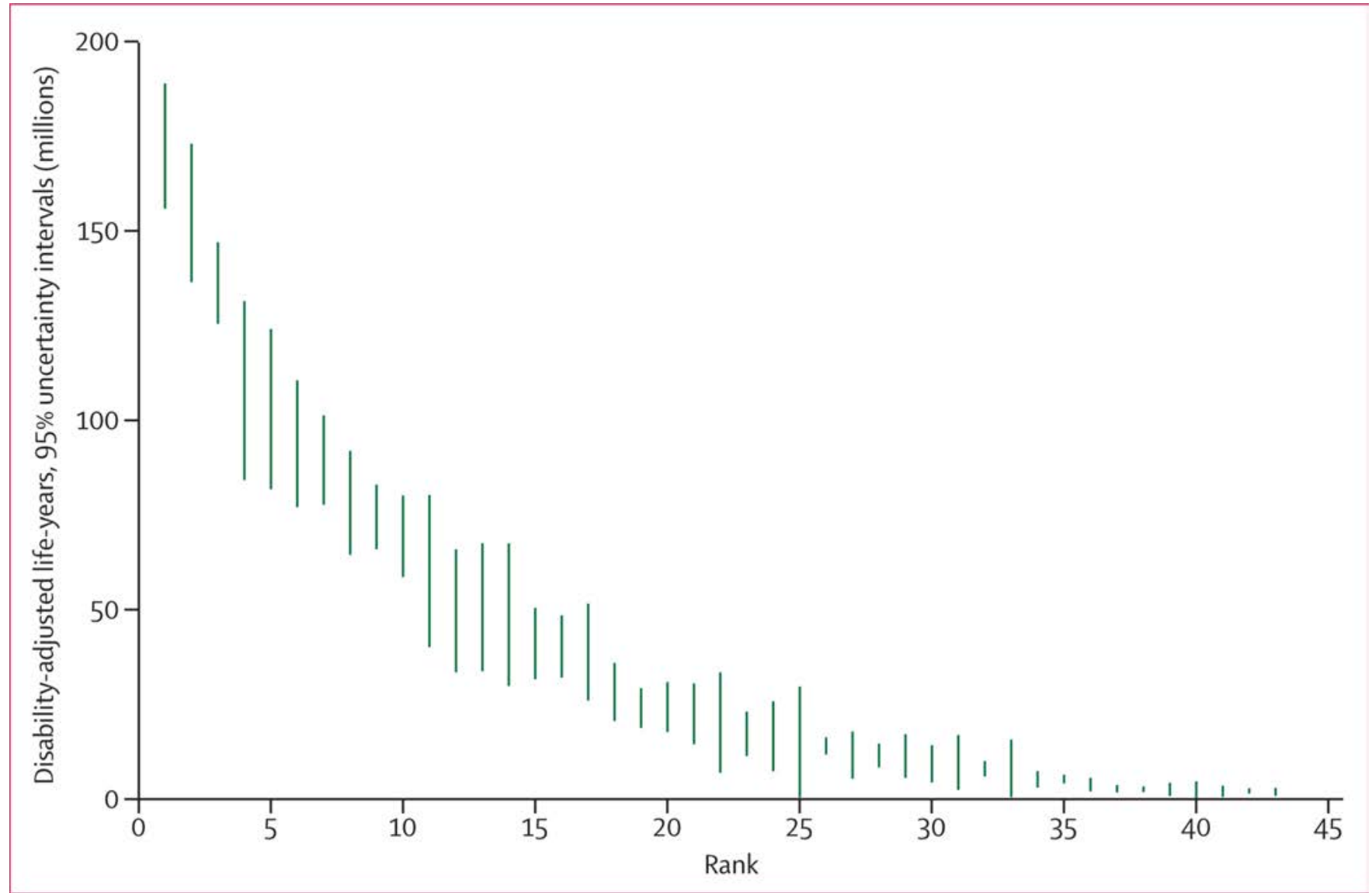

Figure $4.95 \%$ uncertainty intervals for risk factors ranked by global attributable disabilityadjusted life-years, 2010

An interactive version of this figure is available online at http://

healthmetricsandevaluation.org/gbd/visualizations/regional 


\begin{tabular}{|c|c|c|c|c|c|c|c|c|c|c|c|c|c|c|c|c|c|c|c|c|c|c|}
\hline 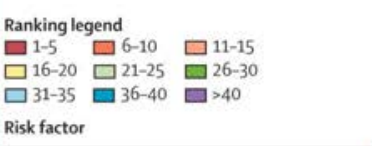 & $\frac{8 \pi}{\frac{8}{5}}$ & 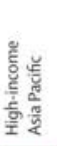 & 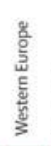 & $\frac{\frac{\pi}{3}}{\frac{3}{2}}$ & 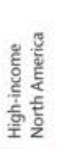 & 总 & 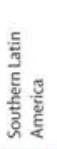 & 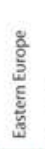 & $\begin{array}{l}\frac{\pi}{4} \\
\frac{3}{4}\end{array}$ & ه & 焉 & 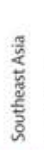 & 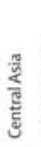 & 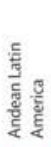 & 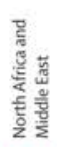 & 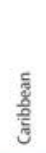 & 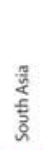 & 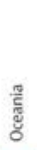 & 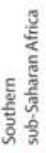 & 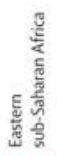 & 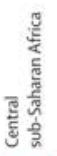 & 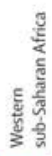 \\
\hline High blood pressure & 1 & 1 & 2 & 3 & 4 & 1 & 2 & 2 & 1 & 2 & 4 & 1 & 1 & 2 & 1 & 1 & 3 & 6 & 2 & 6 & 5 & 6 \\
\hline Tobacco smoking, including second-hand smoke & 2 & 2 & 1 & 2 & 1 & 3 & 3 & 3 & 2 & & 5 & 2 & 3 & & 3 & 3 & 2 & 3 & 5 & 7 & 12 & 10 \\
\hline Akohol use & 3 & 3 & 4 & 4 & 3 & 2 & 4 & 1 & 6 & 1 & 1 & 6 & 2 & & 11 & 5 & 8 & 5 & 1 & 5 & 6 & \\
\hline lousehold air pollution from solid fuels & 4 & 42 & . & .. & . & 14 & 23 & 20 & 5 & 18 & 11 & 3 & 12 & 7 & 13 & 9 & 1 & 4 & 7 & $\overline{2}$ & $\overline{2}$ & \\
\hline Diet low in fruits & 5 & 5 & 7 & 7 & 7 & 5 & 6 & 5 & 3 & 6 & 7 & 4 & 5 & 10 & 6 & 8 & 5 & 9 & 8 & 8 & 11 & 13 \\
\hline ligh body-mass index & 6 & 8 & 3 & 1 & 2 & 4 & 1 & 4 & 9 & 3 & 2 & 9 & 4 & 3 & 2 & 2 & 17 & 2 & 3 & 14 & 18 & 15 \\
\hline ligh fasting plasma glucose & 7 & 7 & 6 & 6 & 5 & 7 & 5 & 10 & 8 & 5 & 3 & 5 & 7 & 6 & 4 & 4 & 7 & 1 & 6 & 10 & 13 & 11 \\
\hline Childhood underweight & 8 & 39 & 38 & 37 & 39 & 38 & 38 & 38 & 38 & 32 & 23 & 13 & 25 & 18 & 21 & 14 & 4 & 8 & 9 & 1 & 1 & \\
\hline Ambient particulate matter pollution & 9 & 9 & 11 & 26 & 14 & 12 & 24 & 14 & 4 & 27 & 19 & 11 & 10 & 24 & 7 & 19 & 6 & 32 & 25 & 16 & 14 & 7 \\
\hline Physical inactivity and low physical activity & 10 & 4 & 5 & 5 & 6 & 6 & 7 & 7 & 10 & 8 & 6 & 8 & 9 & 8 & 5 & 7 & 11 & 7 & 11 & 15 & 15 & 16 \\
\hline Diet high in sodium & 11 & 6 & 10 & 11 & 11 & 9 & 11 & 9 & 7 & 9 & 13 & 7 & 6 & 13 & 8 & 15 & 14 & 16 & 13 & 21 & 17 & 18 \\
\hline iet low in nuts and seeds & 12 & 11 & 9 & 8 & 8 & 8 & 8 & 8 & 12 & 10 & 8 & 15 & 8 & 12 & 9 & 10 & 13 & 13 & 16 & 22 & 16 & 21 \\
\hline ron deficiency & 13 & 20 & 32 & 21 & 35 & 22 & 17 & 21 & 19 & 14 & 12 & 12 & 17 & 4 & 12 & 6 & 9 & 11 & 10 & 4 & 4 & \\
\hline uboptimal breastffeeding & 14 & .. &. & 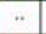 & $*$ & $*$ & 27 & 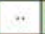 & 24 & 22 & 15 & 14 & 16 & 9 & 15 & 13 & 10 & 10 & 4 & 3 & 3. & \\
\hline tigh total cholesterol & 15 & 12 & 8 & 9 & 9 & 10 & 9 & 6 & 13 & 11 & 10 & 16 & 14 & 16 & 10 & 16 & 20 & 14 & 19 & 28 & 27 & 30 \\
\hline Diet low in whole grains & 16 & 10 & 16 & 16 & 17 & 11 & 12 & 11 & 11 & 12 & 14 & 26 & 13 & 17 & 14 & 12 & 15 & 15 & 32 & 24 & 19 & 24 \\
\hline iet low in vegetables & 17 & 14 & 13 & 12 & 13 & 13 & 10 & 12 & 15 & 16 & 20 & 10 & 11 & 14 & 18 & 11 & 16 & 12 & 15 & 23 & 23 & 20 \\
\hline Diet low in seafood omega- 3 fatty acids & 18 & 17 & 15 & 13 & 16 & 16 & 14 & 13 & 17 & 17 & 18 & 19 & 15 & 23 & 16 & 17 & 18 & 20 & 23 & 27 & 25 & 25 \\
\hline Pruguse & 19 & 13 & 14 & 10 & 10 & 20 & 13 & 17 & 18 & 13 & 16 & 18 & 20 & 11 & 19 & 18 & 22 & 19 & 12 & 19 & 24 & 22 \\
\hline Occupational risk factors for injuries & 20 & 24 & 24 & 20 & 25 & 26 & 16 & 25 & 20 & 19 & 22 & 23 & 21 & 21 & 23 & 31 & 12 & 22 & 22 & 20 & 22 & 17 \\
\hline Occupational low back pain & 21 & 15 & 17 & 15 & 23 & 18 & 20 & 24 & 14 & 15 & 24 & 17 & 24 & 22 & 20 & 26 & 23 & 17 & 24 & 17 & 21 & 19 \\
\hline Diet high in processed meat & 22 & 22 & 12 & 14 & 12 & 15 & 18 & 15 & 29 & 7 & 9 & 27 & 19 & 15 & 27 & 24 & 25 & 27 & 28 & 31 & 28 & 28 \\
\hline ntimate partner violence & 23 & 18 & 22 & 23 & 22 & 25 & 21 & 22 & 21 & 23 & 26 & 22 & 27 & 19 & 25 & 23 & 21 & 25 & 14 & 18 & 20 & 23 \\
\hline iet low in fibre & 24 & 16 & 18 & 18 & 18 & 19 & 15 & 16 & 16 & 25 & 28 & 20 & 18 & 28 & 22 & 22 & 33 & 21 & 33 & 36 & 34 & 36 \\
\hline Inimproved sanitation & 25 & 38 & 39 & 39 & 41 & 42 & 40 & 40 & 40 & 40 & 38 & 30 & 37 & 31 & 32 & 28 & 19 & 18 & 18 & 9 & 8 & 9 \\
\hline ead exposure & 26 & 23 & 21 & 19 & 24 & 17 & 19 & 23 & 22 & 20 & 25 & 24 & 23 & 20 & 26 & 21 & 24 & 30 & 20 & 25 & 26 & 26 \\
\hline Diet low in polyunsaturated fa & 27 & 19 & 19 & 17 & 20 & 21 & 22 & 18 & 26 & 24 & 27 & 21 & 22 & 29 & 24 & 25 & 32 & 23 & 30 & 33 & 30 & 29 \\
\hline Diet high in trans fatty acids & 28 & 29 & 23 & 24 & 15 & 23 & 28 & 19 & 28 & 21 & 21 & 33 & 26 & 27 & 17 & 38 & 28 & 34 & 35 & 37 & 36 & 37 \\
\hline Vitamin Adeficiency & 29 & 40 & 40 & 38 & 40 & 41 & 41 & 42 & 43 & 41 & 37 & 32 & 34 & 34 & 37 & 33 & 30 & 31 & 17 & 11 & 7 & 8 \\
\hline Occupational particulate matter, gases, and fumes & 30 & 34 & 33 & 32 & 28 & 32 & 33 & 31 & 23 & 29 & 32 & 28 & 29 & 33 & 31 & 34 & 26 & 33 & 29 & 29 & 29 & 31 \\
\hline Zinc deficiency & 31 & 37 & 37 & 36 & 37 & 39 & 39 & 39 & 39 & 39 & 29 & 29 & 28 & 25 & 35 & 27 & 31 & 28 & 21 & 13 & 10 & 14 \\
\hline Diet high in sugar-sweetened beverages. & 32 & 28 & 31 & 31 & 19 & 33 & 26 & 27 & 37 & 26 & 17 & 25 & 32 & 30 & 28 & 20 & 27 & 26 & 26 & 32 & 32 & 34 \\
\hline Childhood sexual abuse & 33 & 26 & 25 & 22 & 21 & 30 & 25 & 26 & 30 & 28 & 30 & 37 & 30 & 26 & 29 & 30 & 29 & 35 & 31 & 26 & 31 & 27 \\
\hline Unimproved water source & 34 & 41 & 41 & 40 & 38 & 40 & 42 & 41 & 42 & 42 & 40 & 31 & 36 & 35 & 30 & 29 & 34 & 24 & 27 & 12 & 9 & 12 \\
\hline ow bone mineral density & 35 & 21 & 20 & 25 & 26 & 24 & 30 & 28 & 25 & 30 & 33 & 35 & 35 & 36 & 34 & 32 & 36 & 37 & 38 & 35 & 37 & 33 \\
\hline Occupational noise & 36 & 33 & 35 & 34 & 36 & 35 & 35 & 35 & 33 & 33 & 31 & 34 & 31 & 32 & 36 & 35 & 37 & 36 & 34 & 30 & 33 & 32 \\
\hline Occupational carcinogens & 37 & 31 & 26 & 29 & 31 & 34 & 32 & 34 & 27 & 38 & 35 & 38 & 33 & 40 & 38 & 40 & 39 & 41 & 37 & 41 & 42 & 42 \\
\hline Diet low in calcium & 38 & 25 & 28 & 27 & 29 & 27 & 29 & 30 & 31 & 34 & 39 & 39 & 39 & 39 & 40 & 37 & 40 & 39 & 39 & 38 & 39 & 38 \\
\hline Ambient ozone pollution & 39 & 36 & 36 & 41 & 33 & 36 & 43 & 3) & 34 & 43 & 43 & 43 & 43 & 43 & 43 & 43 & 35 & 43 & 43 & 42 & 38 & 41 \\
\hline Residential radon & 40 & 32 & 27 & 35 & 27 & 28 & 36 & 33 & 32 & 36 & 41 & 41 & 38 & 42 & 41 & 42 & 41 & 42 & 42 & 43 & 43 & 43 \\
\hline Diet low in milk & 41 & 27 & 29 & 30 & 30 & 29 & 34 & 32 & 35 & 37 & 42 & 40 & 41 & 41 & 42 & 39 & 42 & 40 & 41 & 39 & 41 & 39 \\
\hline Occupational asthmagens & 42 & 35 & 34 & 33 & 34 & 37 & 37 & 36 & 41 & 35 & 36 & 36 & 42 & 37 & 39 & 36 & 38 & 29 & 36 & 34 & 35 & 35 \\
\hline Diet high in red meat & 43 & 30 & 30 & 28 & 32 & 31 & 31 & 29 & 36 & 31 & 34 & 42 & 40 & 38 & 33 & 41 & 43 & 38 & 40 & 40 & 40 & 40 \\
\hline
\end{tabular}

Figure 5. Risk factors ranked by attributable burden of disease, 2010

Regions are ordered by mean life expectancy. No data=attributable disability-adjusted lifeyears were not quantified. 


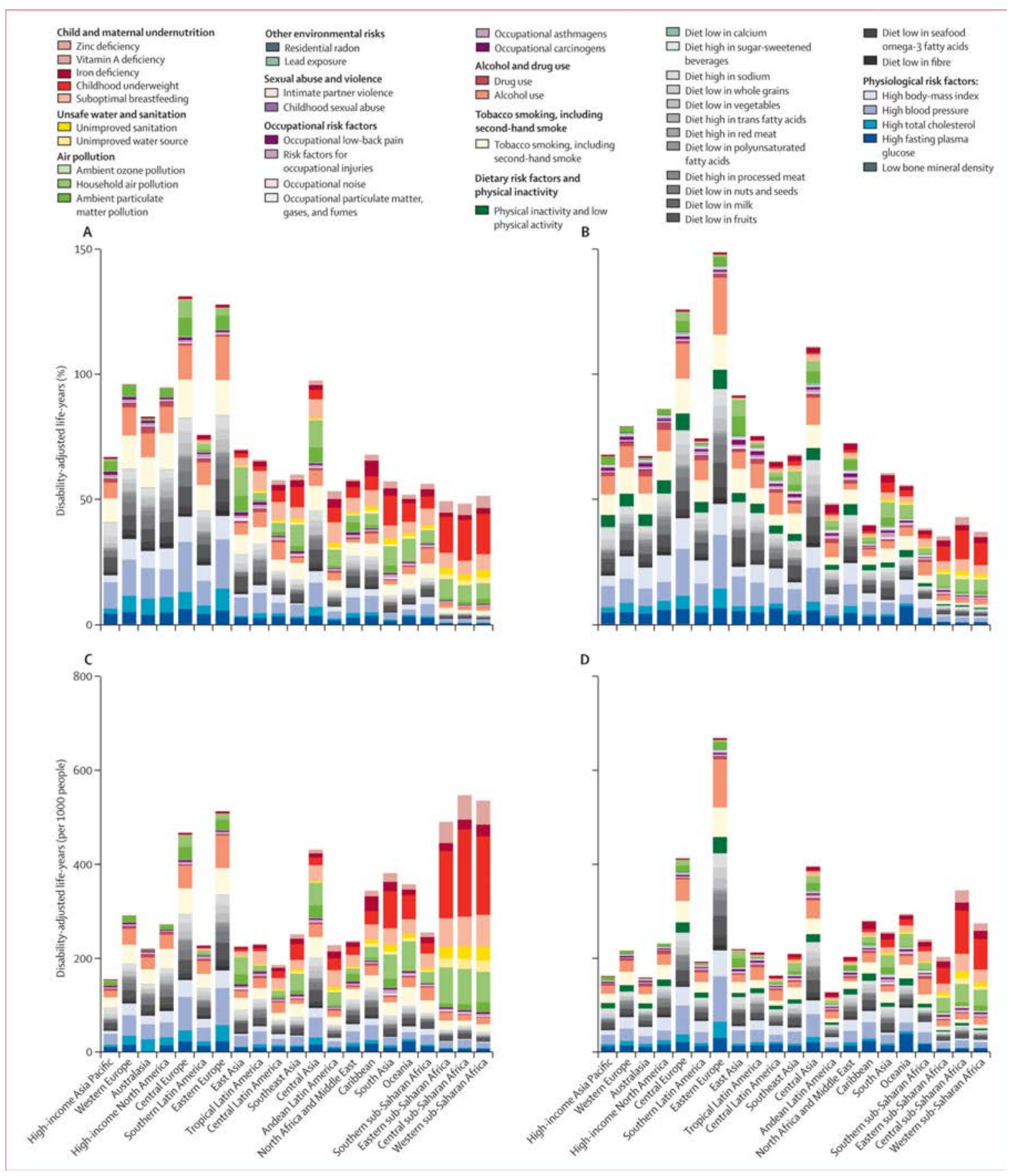

Figure 6. Attributable burden for each risk factor

As percentage of disability-adjusted life-years in 1990 (A), and 2010 (B), and as disabilityadjusted life-years per 1000 people in 1990 (C), and 2010 (D). Regions ordered by mean life expectancy. Burden of disease attributable to individual risk factors are shown sequentially for ease of presentation. In reality, the burden attributable to different risks overlaps because of multicausality and because the effects of some risk factors are partly mediated through 
other, more proximal, risks. An interactive version of this figure is available online at http:// healthmetricsandevaluation.org/gbd/visualizations/regional. 


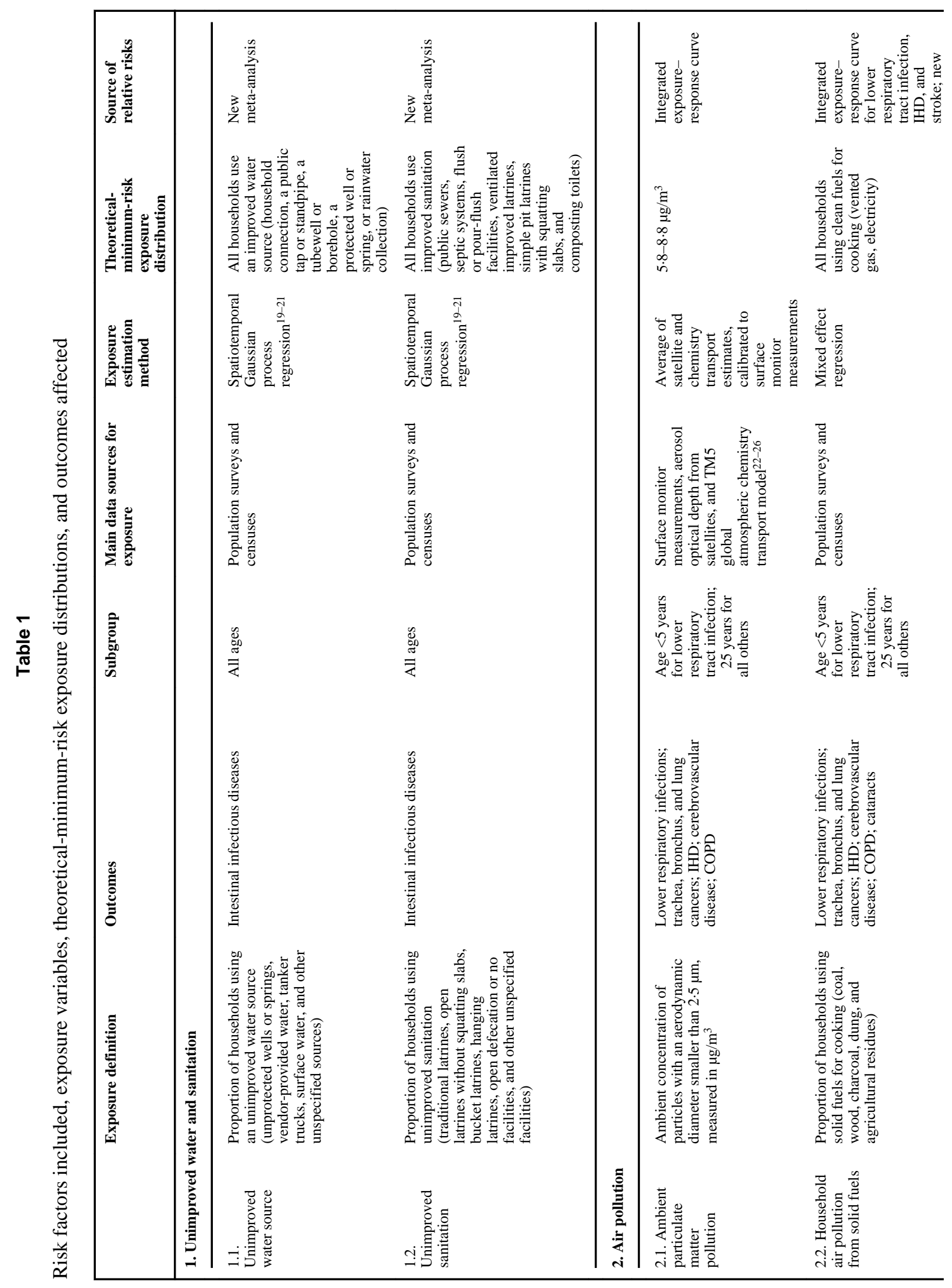




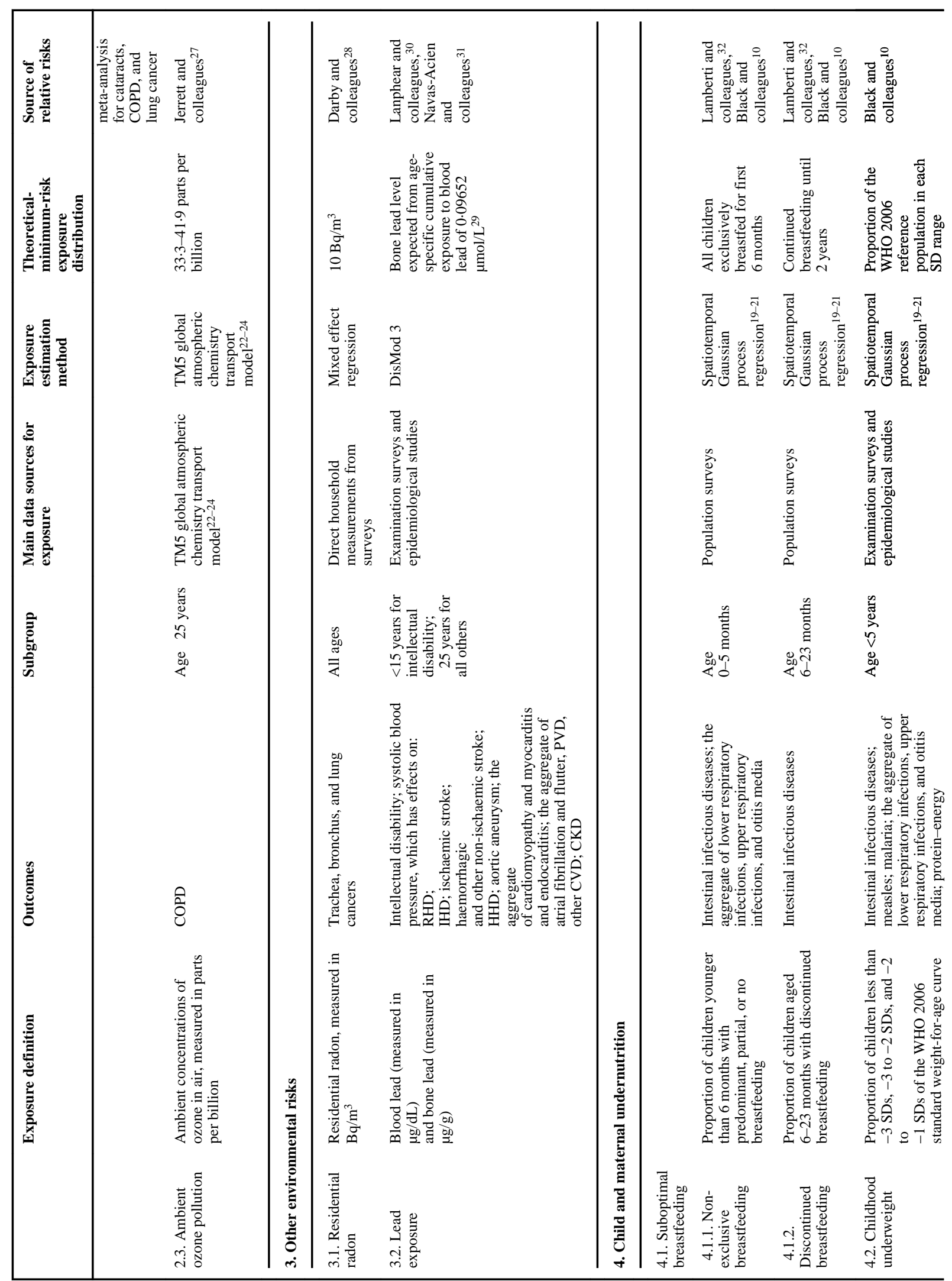




\begin{tabular}{|c|c|c|c|c|c|}
\hline 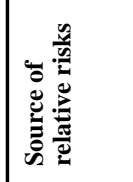 & 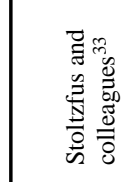 & 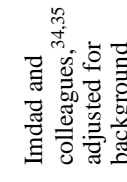 & 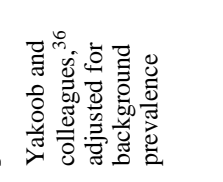 & & 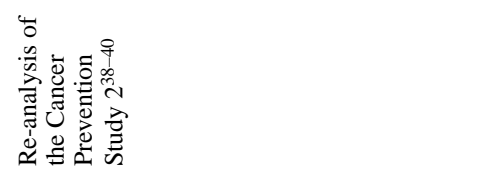 \\
\hline 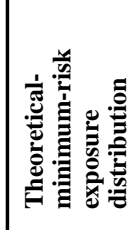 & 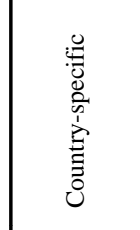 & 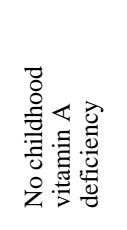 & 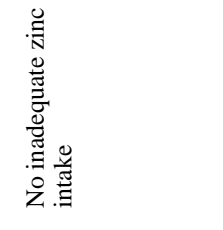 & & 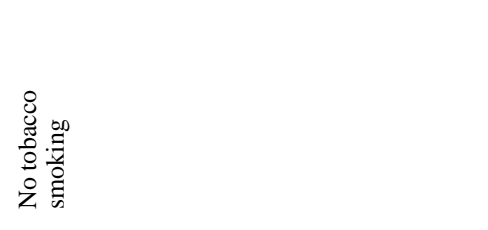 \\
\hline 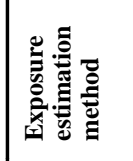 & 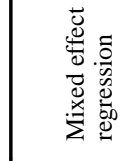 & 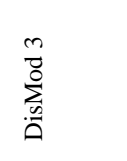 & 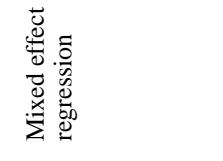 & & $\begin{array}{l}\sum_{i=1}^{n} \\
\text { on }\end{array}$ \\
\hline 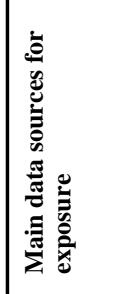 & 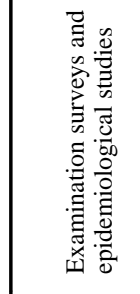 & 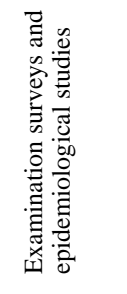 & 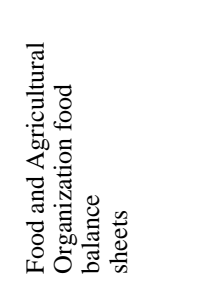 & & 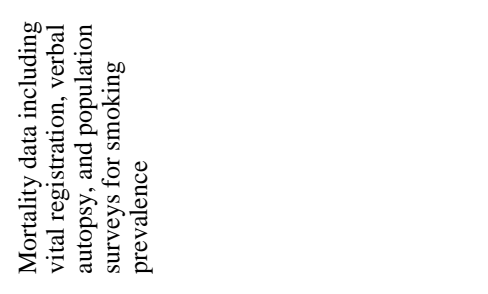 \\
\hline & 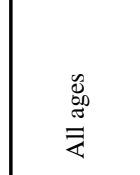 & 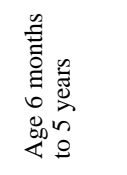 & 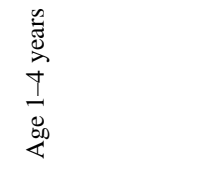 & & 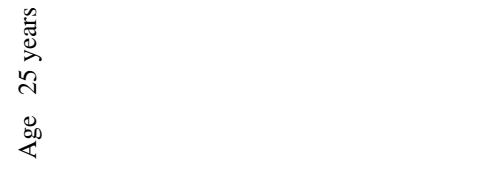 \\
\hline 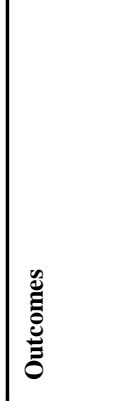 & 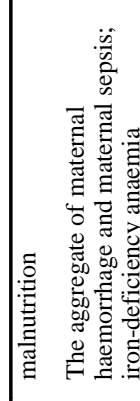 & 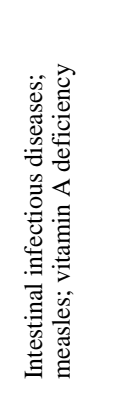 & 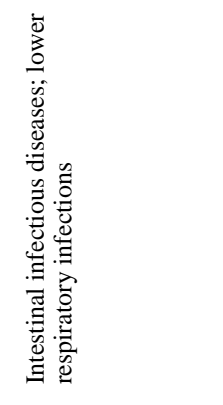 & & 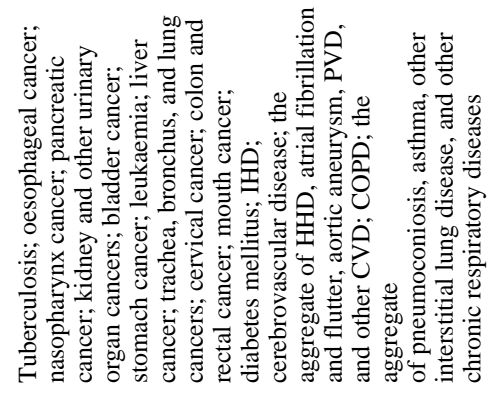 \\
\hline 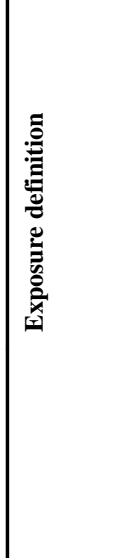 & 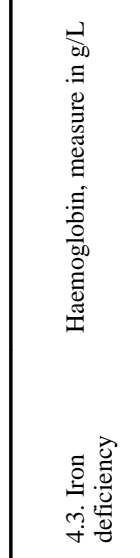 & 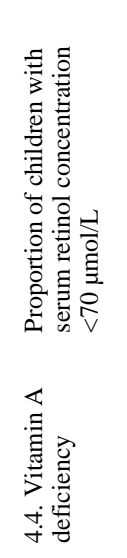 & 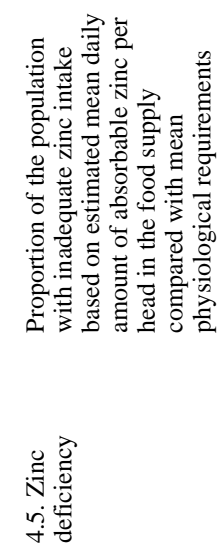 & 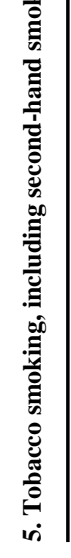 & 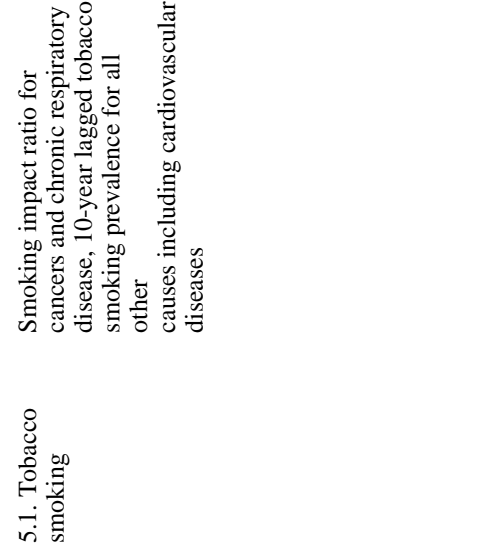 \\
\hline
\end{tabular}




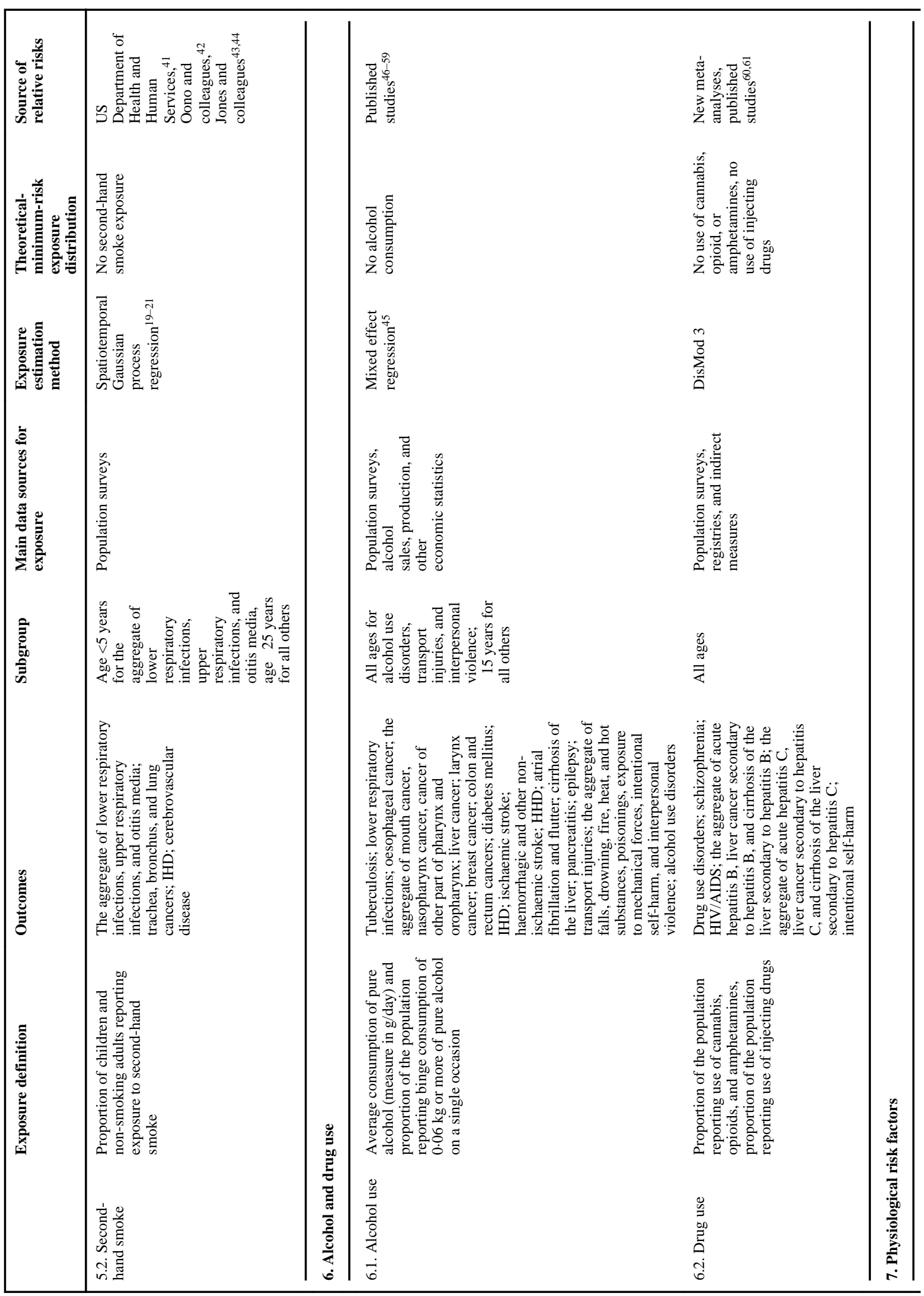




\begin{tabular}{|c|c|c|c|c|c|c|c|}
\hline 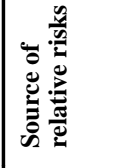 & 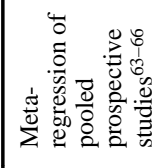 & 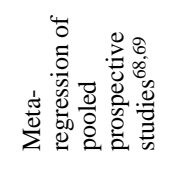 & 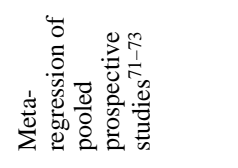 & 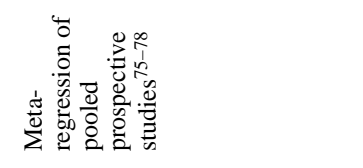 & 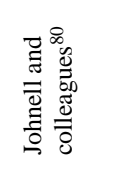 & & 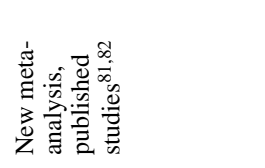 \\
\hline 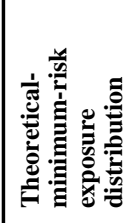 & 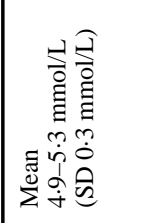 & 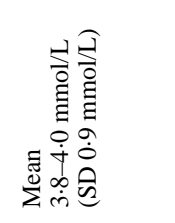 & 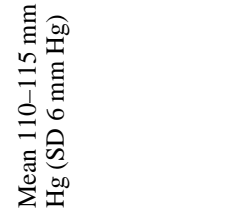 & 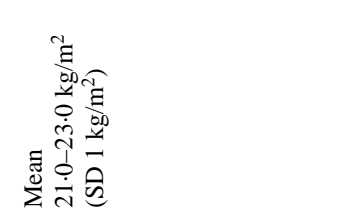 & 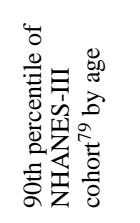 & & 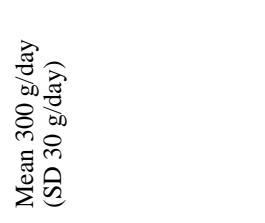 \\
\hline 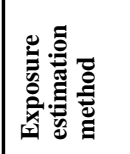 & 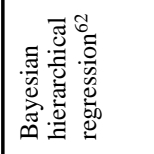 & 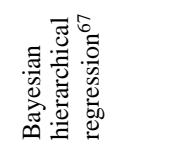 & 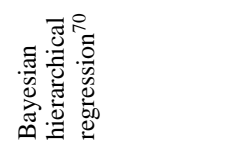 & 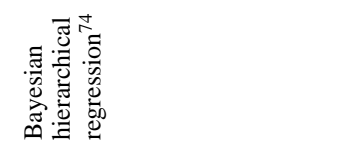 & 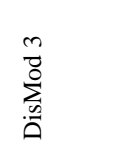 & & 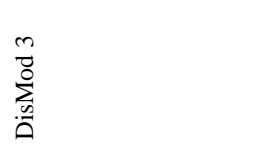 \\
\hline 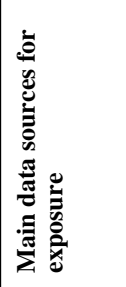 & 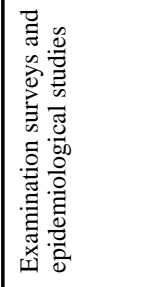 & 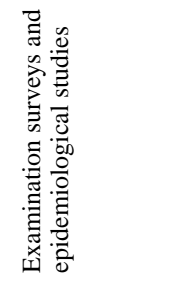 & 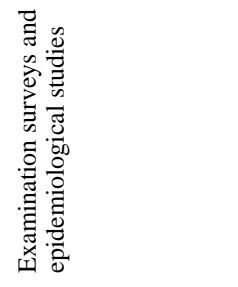 & 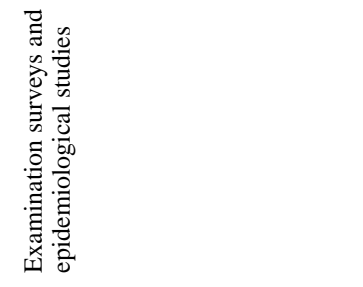 & 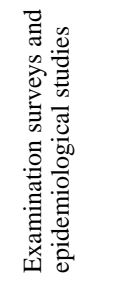 & & 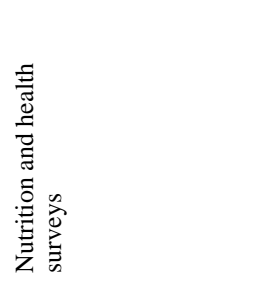 \\
\hline & 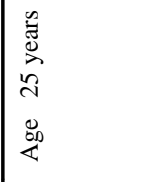 & 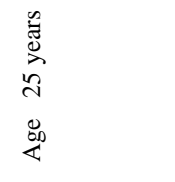 & 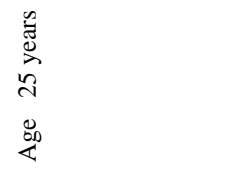 & 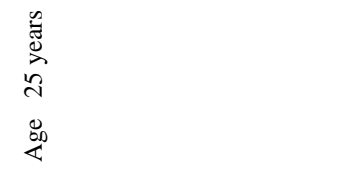 & 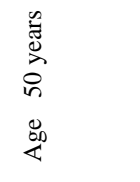 & & 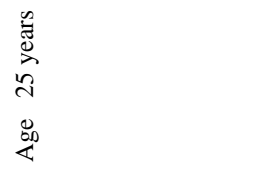 \\
\hline 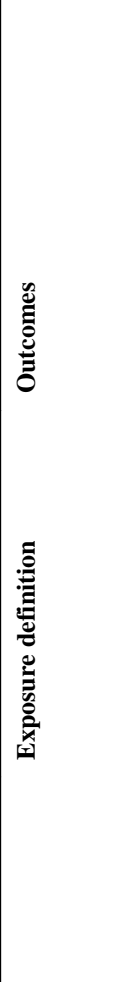 & 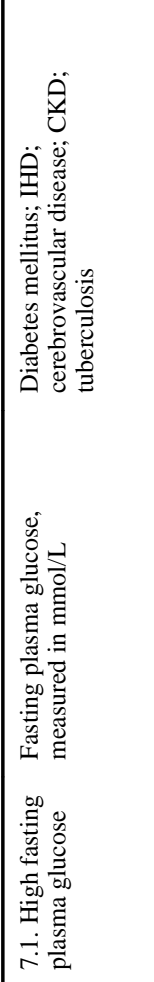 & 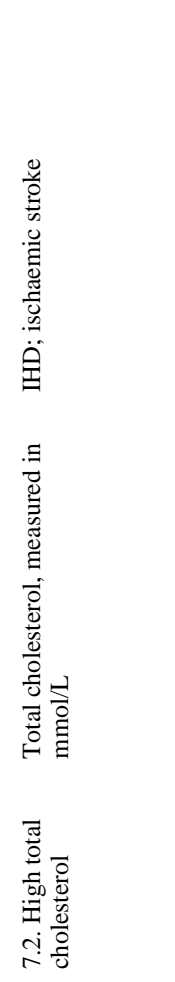 & 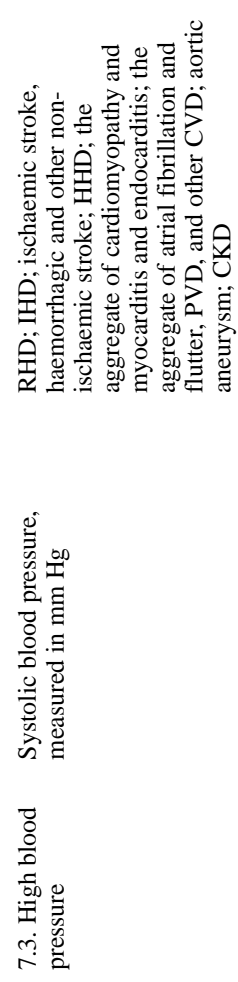 & 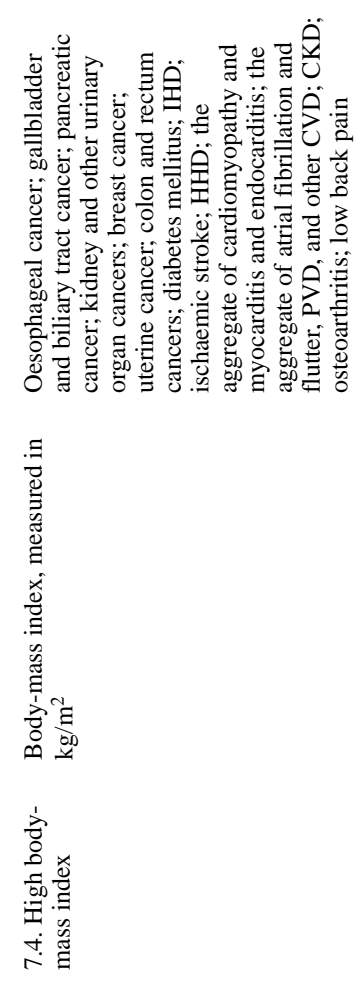 & 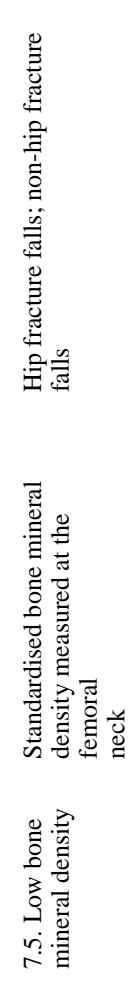 & 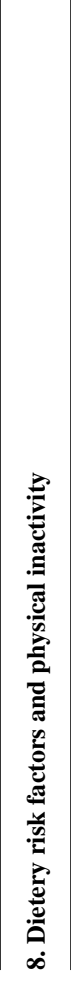 & 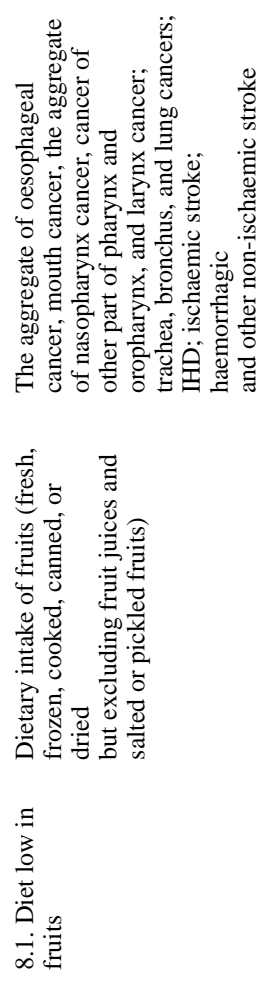 \\
\hline
\end{tabular}




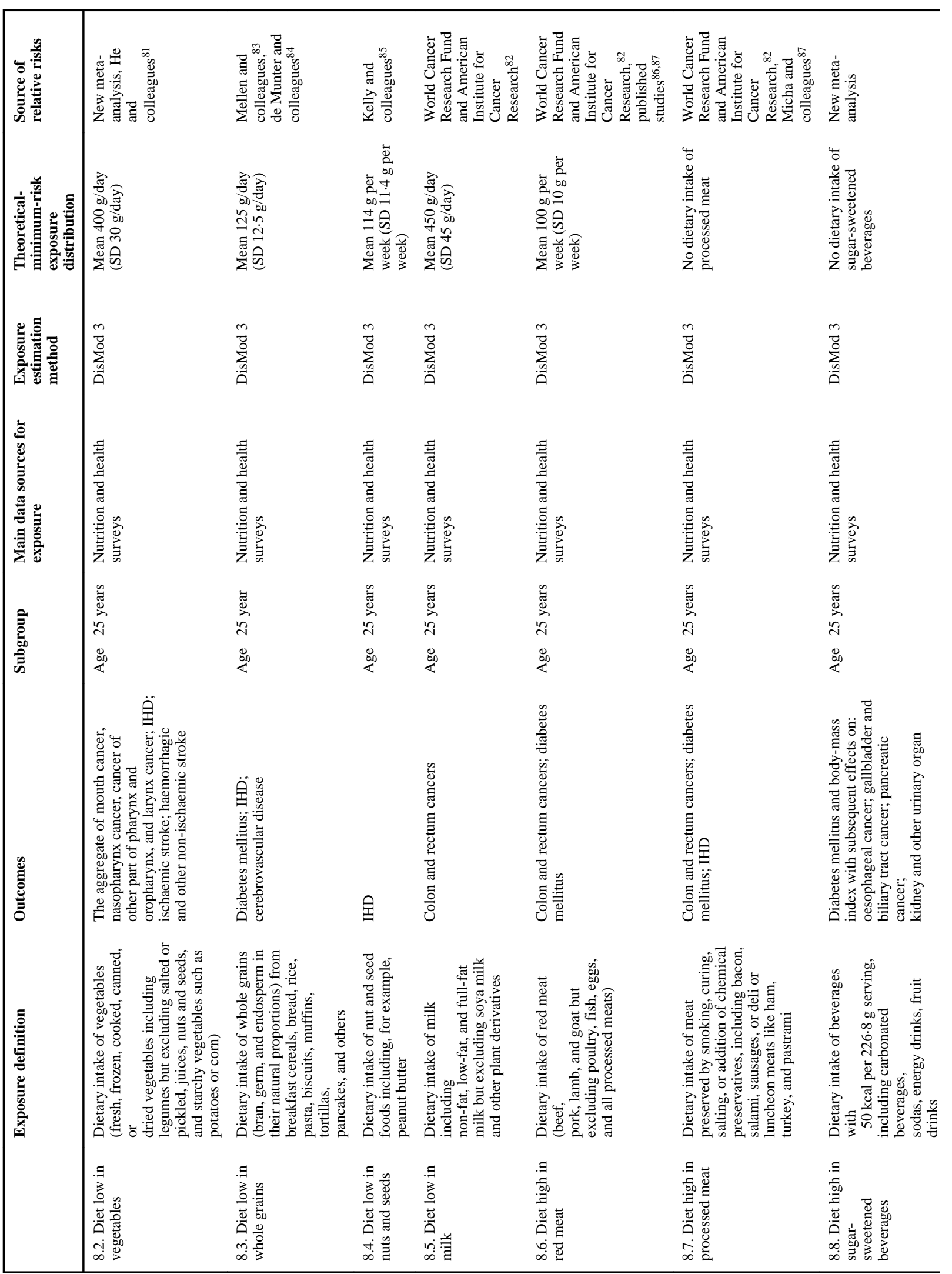




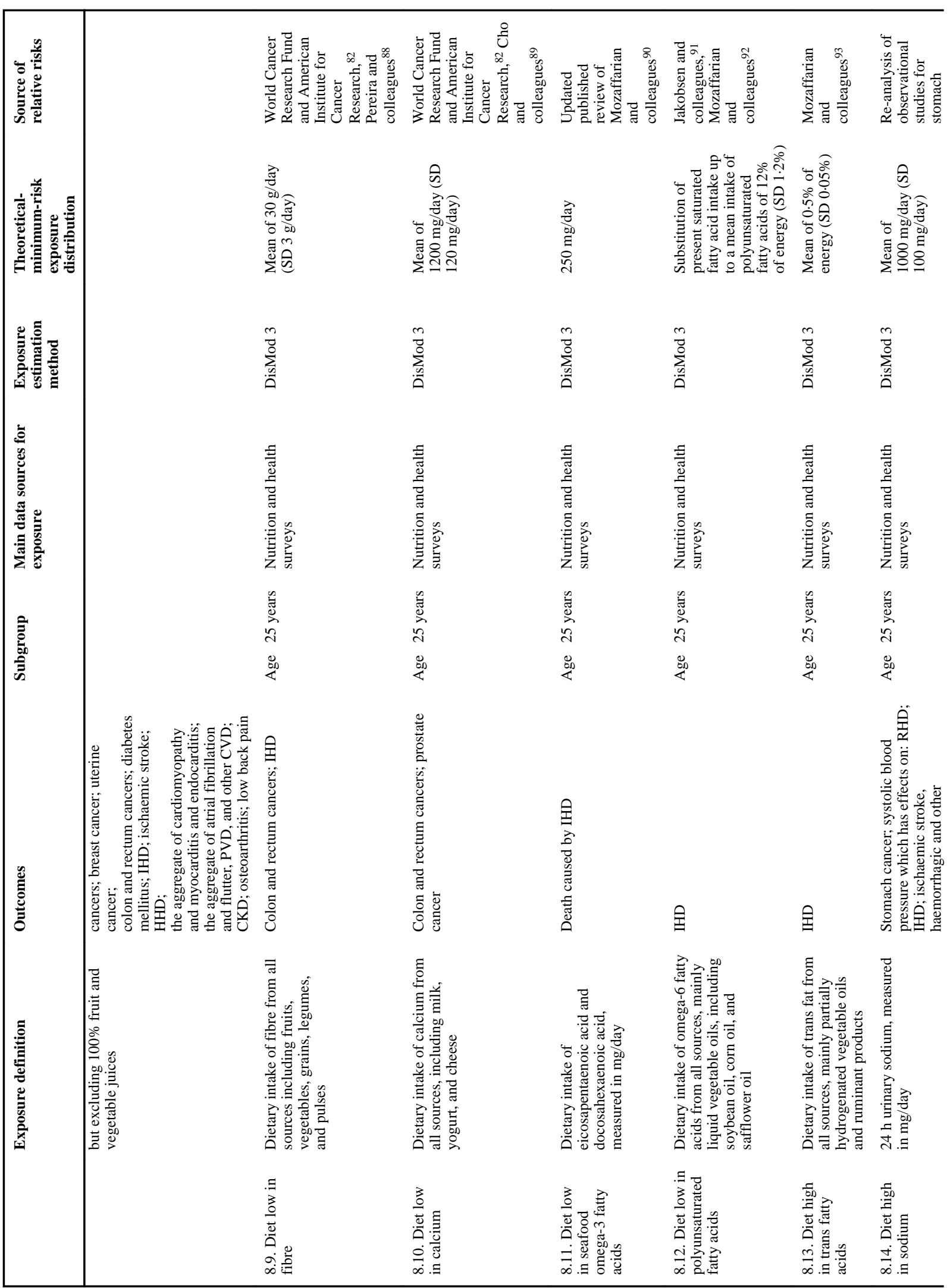




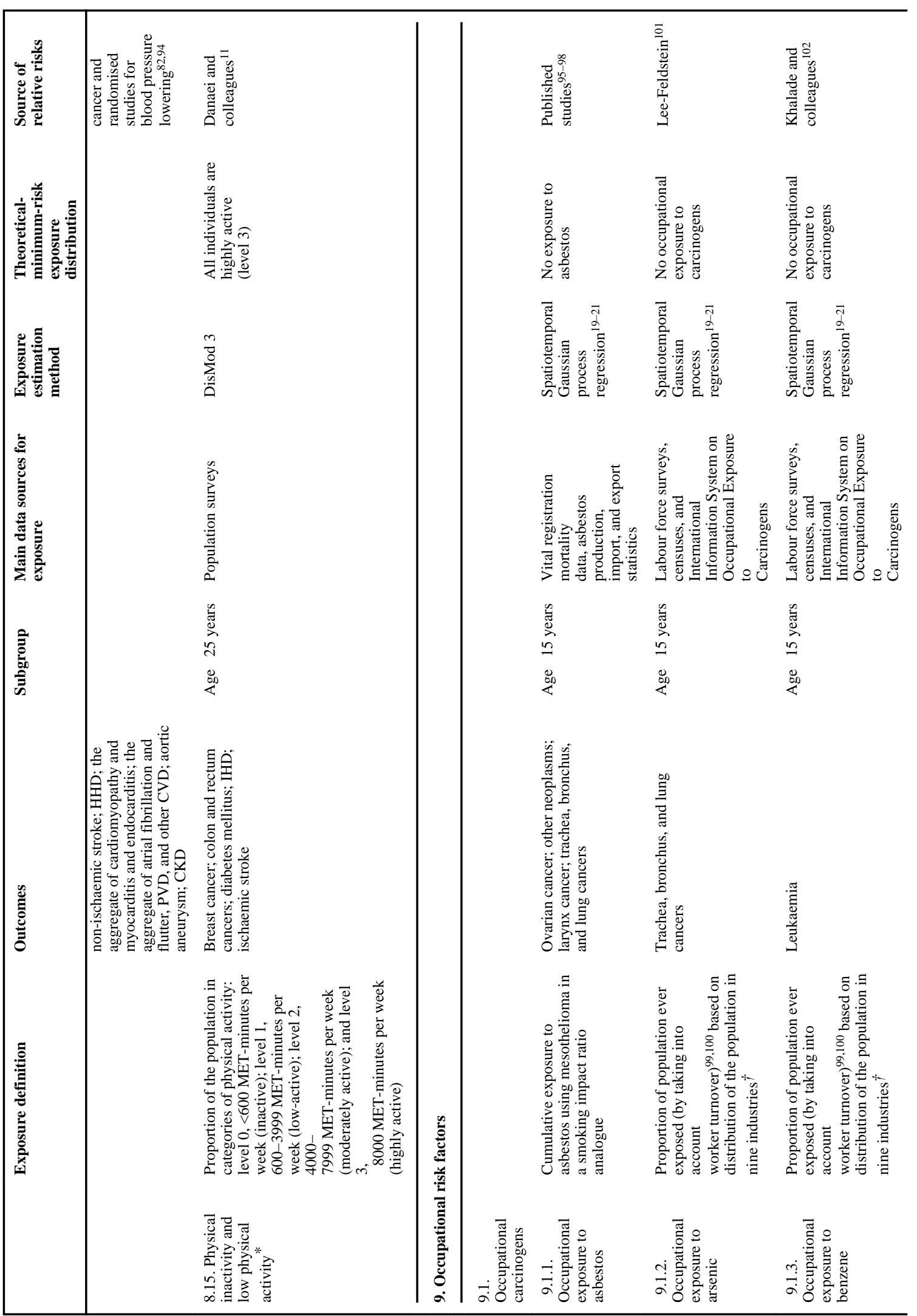




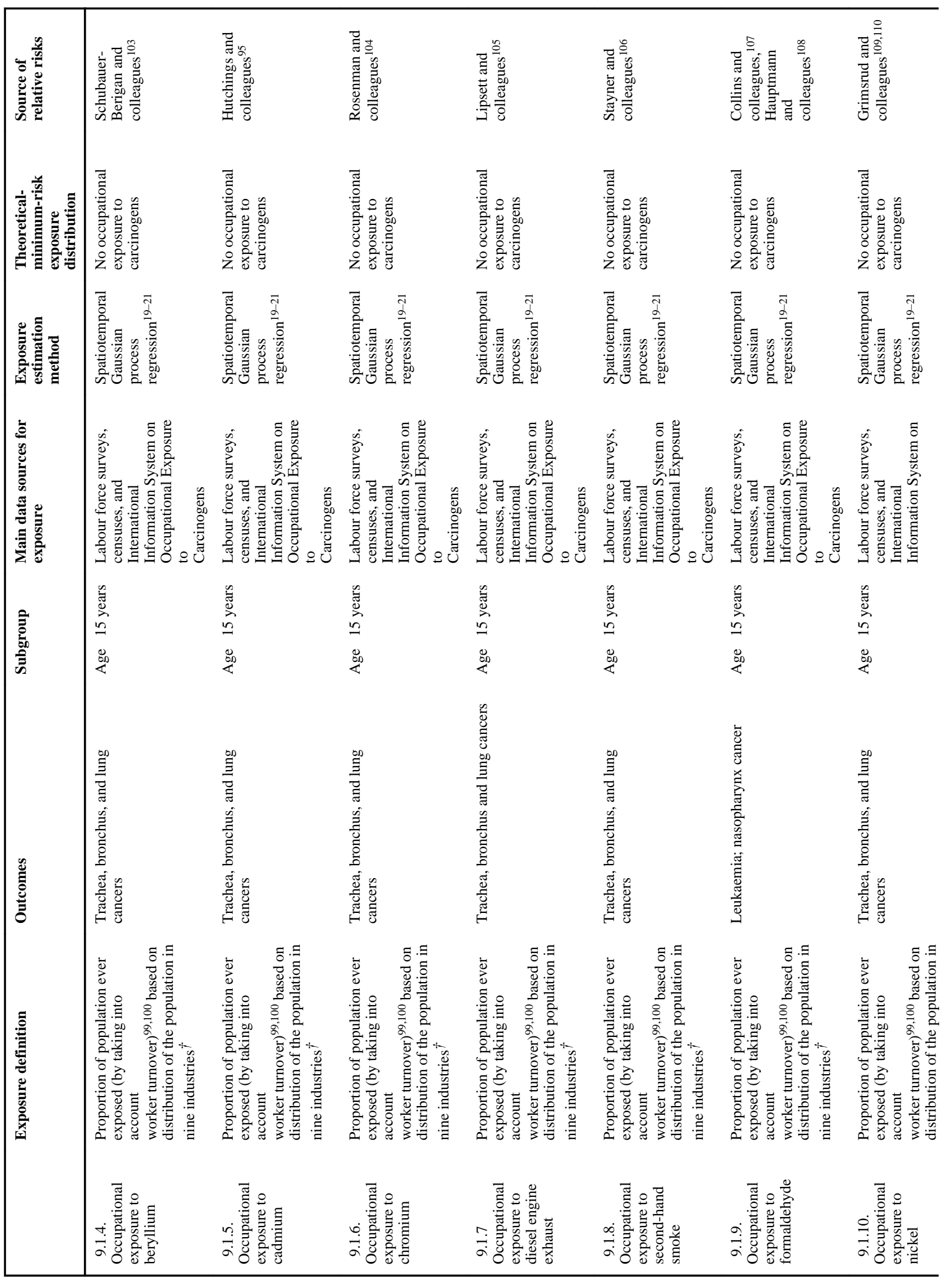




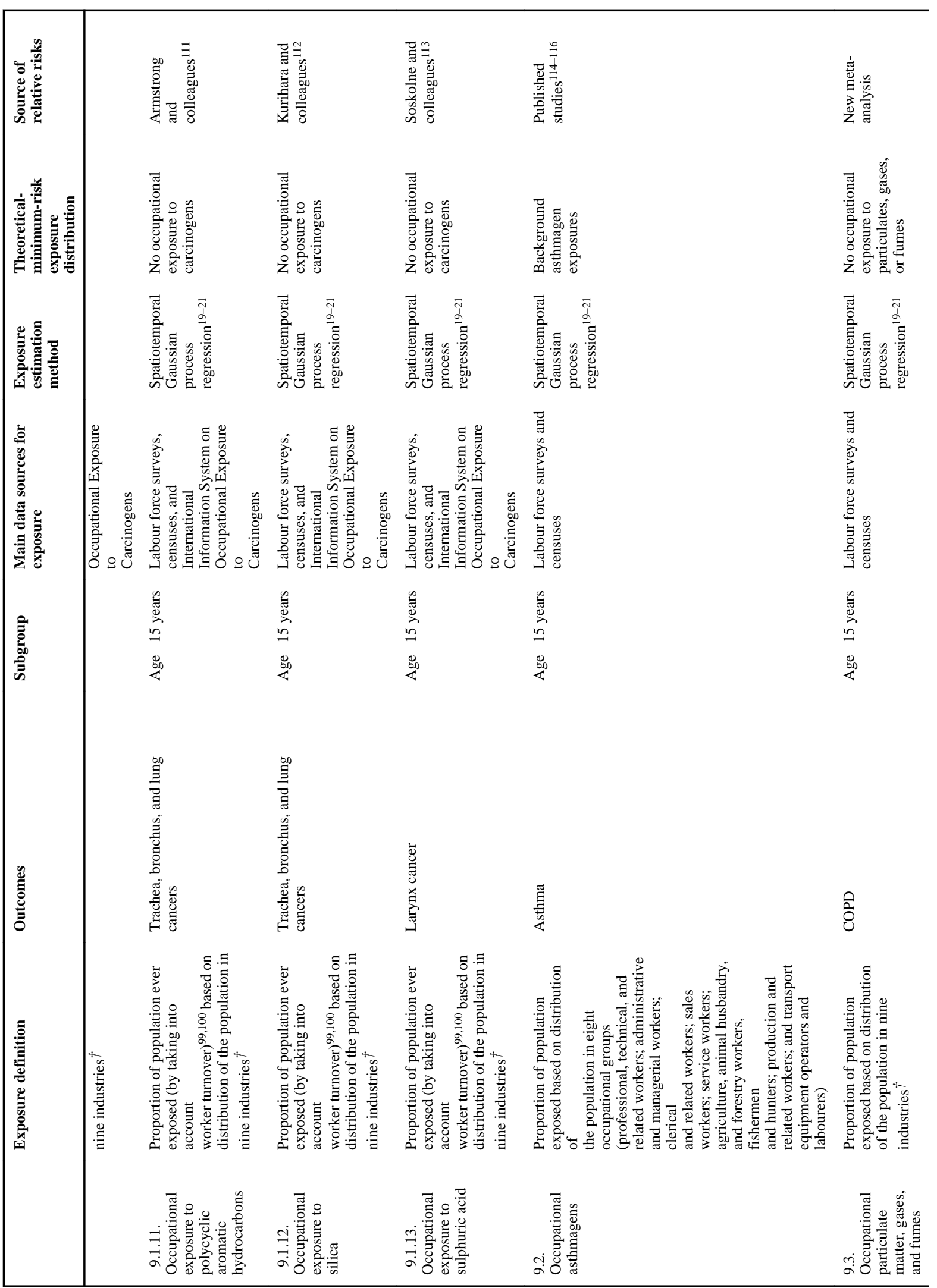




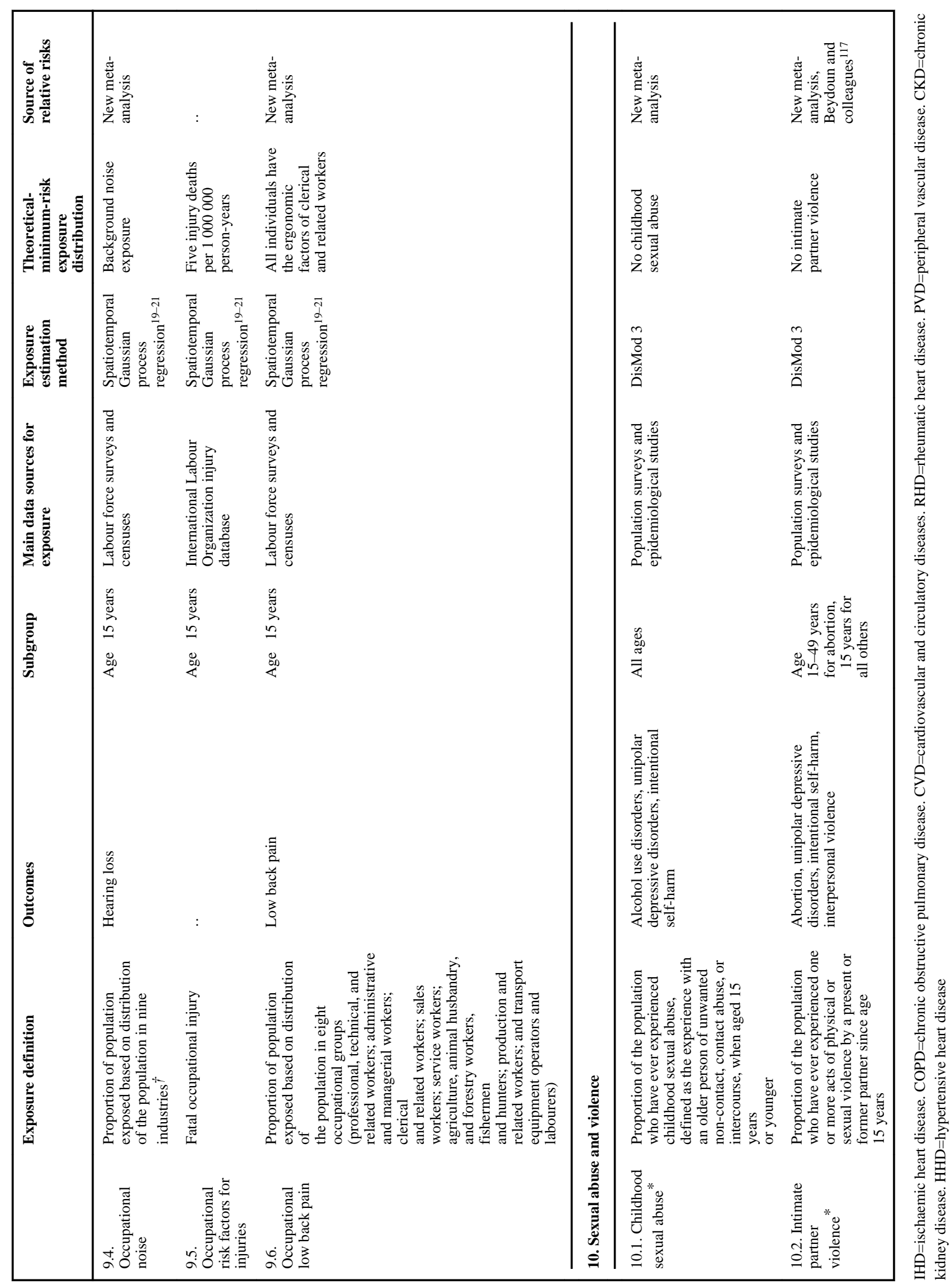




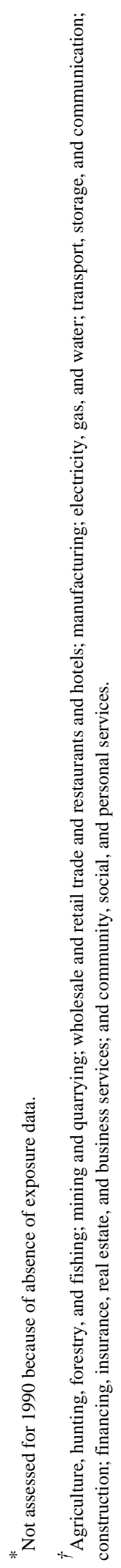




\section{Table 2}

Proportion of ischaemic heart disease disability-adjusted life-years attributable to individual risk factors, worldwide, 2010

\begin{tabular}{|lr|}
\hline & $\begin{array}{r}\text { Disability-adjusted } \\
\text { life-years (\%) }\end{array}$ \\
\hline Physiological risk factors & $53 \%$ \\
High blood pressure & $29 \%$ \\
High total cholesterol & $23 \%$ \\
High body-mass index & $16 \%$ \\
High fasting plasma glucose & $33 \%$ \\
\hline Alcohol use & $31 \%$ \\
\hline Tobacco smoking, including second-hand smoke & \\
\hline Dietary risk factors and physical inactivity & $40 \%$ \\
Diet low in nuts and seeds & $31 \%$ \\
Physical inactivity and low physical activity & $30 \%$ \\
Diet low in fruits & $22 \%$ \\
Diet low in seafood omega-3 fatty acids & $17 \%$ \\
Diet low in whole grains & $17 \%$ \\
Diet high in sodium & $13 \%$ \\
Diet high in processed meat & $12 \%$ \\
Diet low in vegetables & $11 \%$ \\
Diet low in fibre & $92 \%$ \\
Diet low in polyunsaturated fatty acids & $9 \%$ \\
Diet high in trans fatty acids & $2 \%$ \\
Diet high in sugar-sweetened beverages & $18 \%$ \\
\hline Air pollution & \\
Ambient particulate matter pollution & \\
Household air pollution from solid fuels & \\
\hline Other environmental risks & \\
Lead exposure & \\
\hline
\end{tabular}




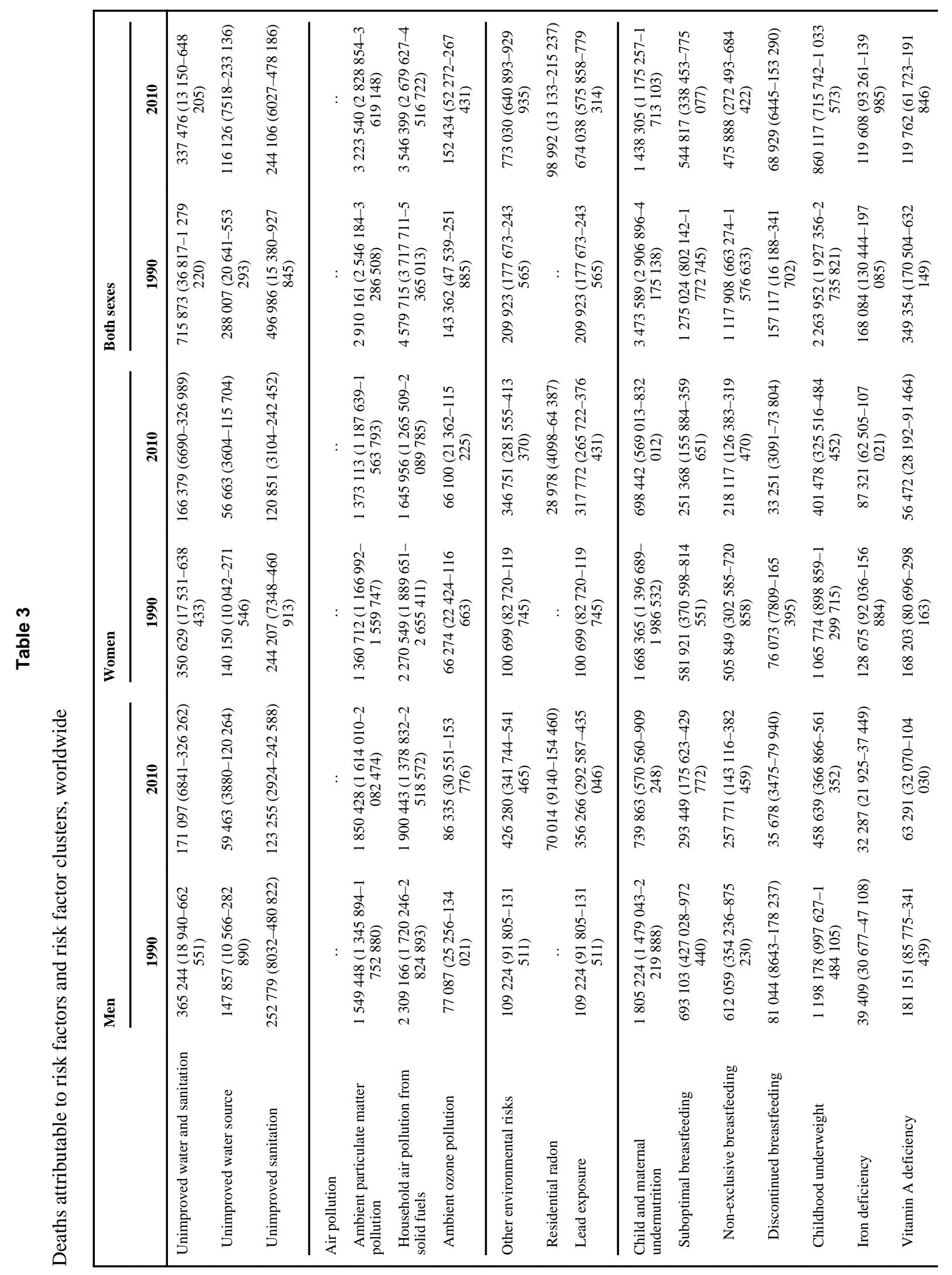




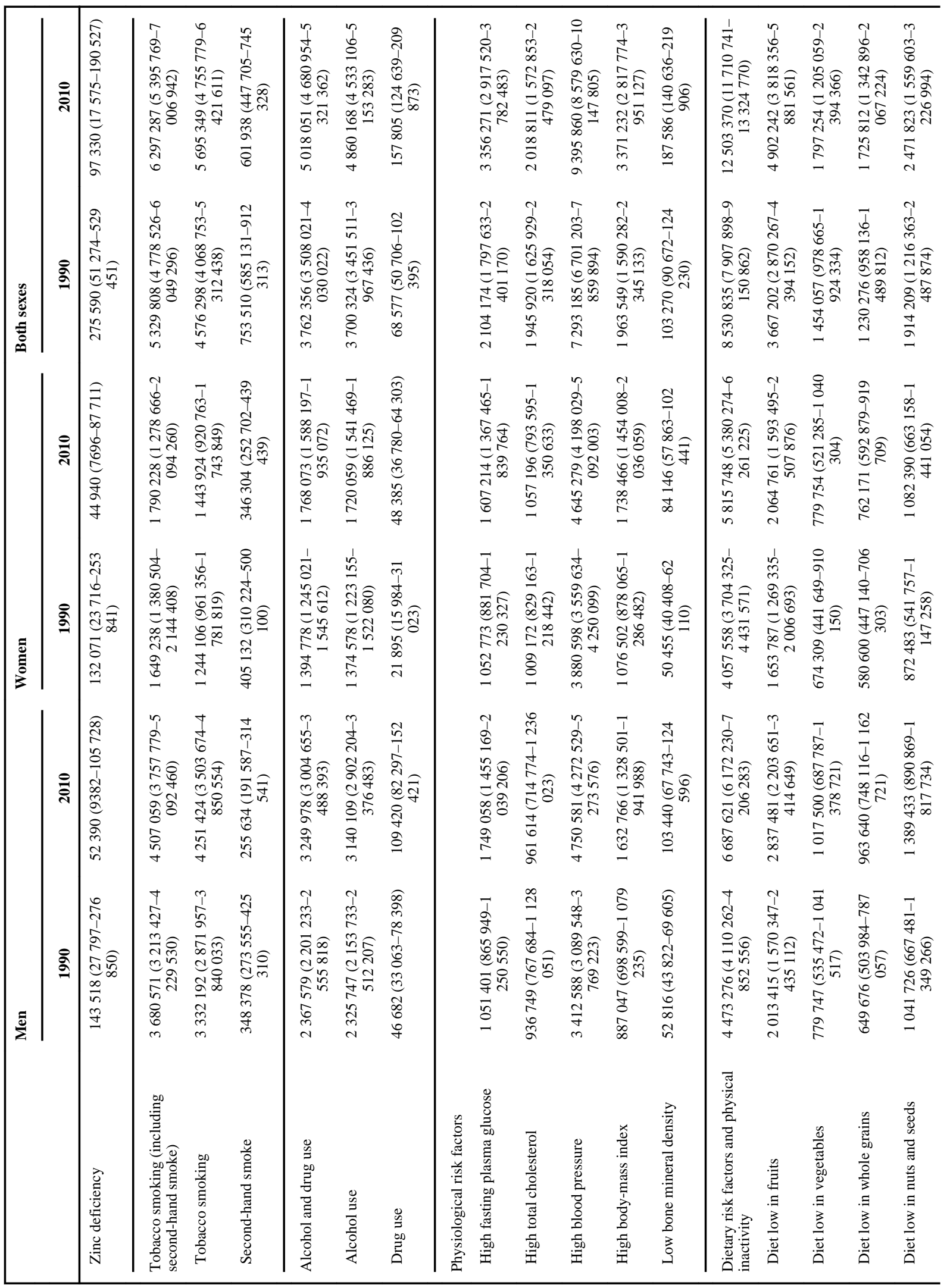




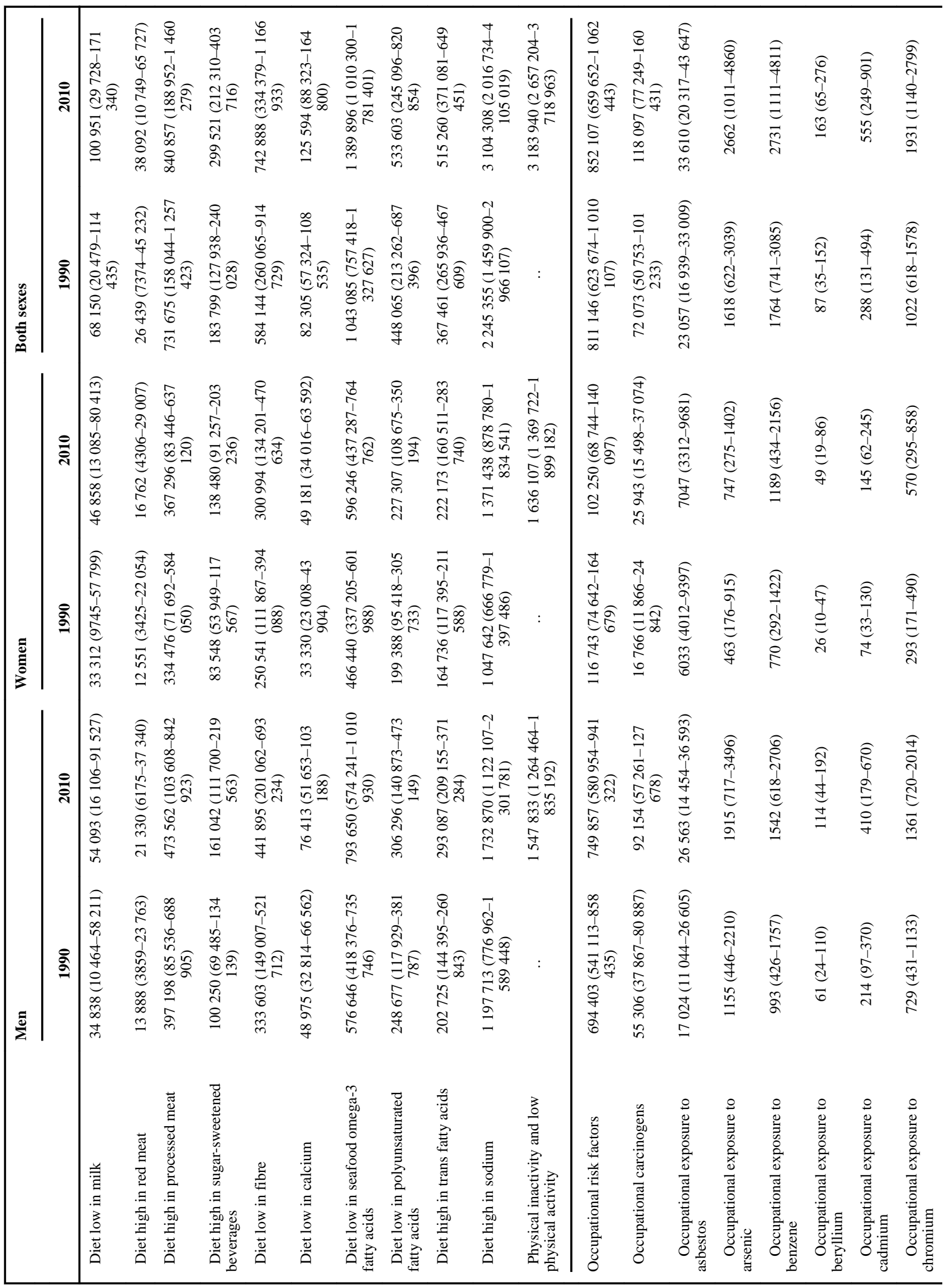




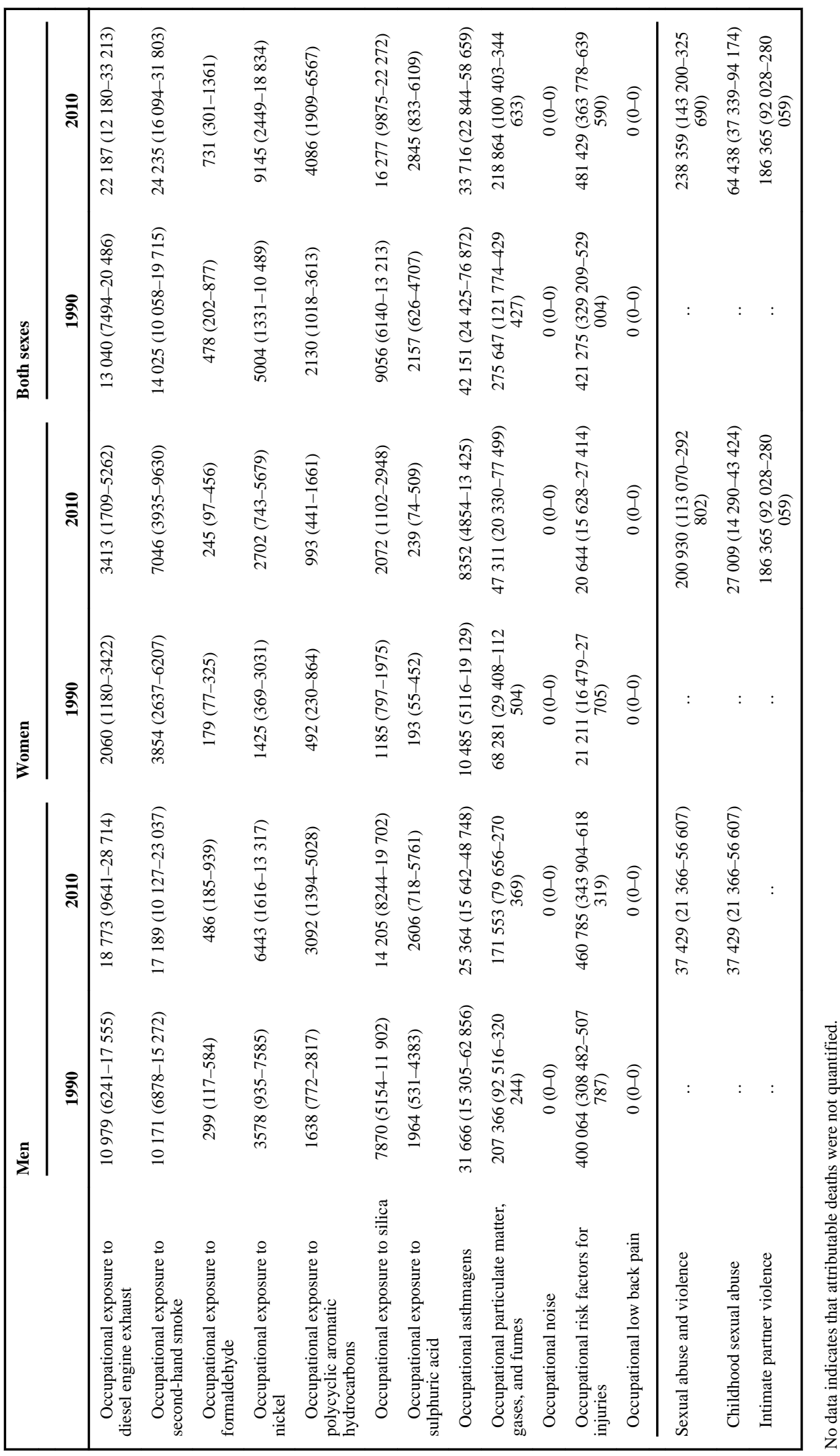




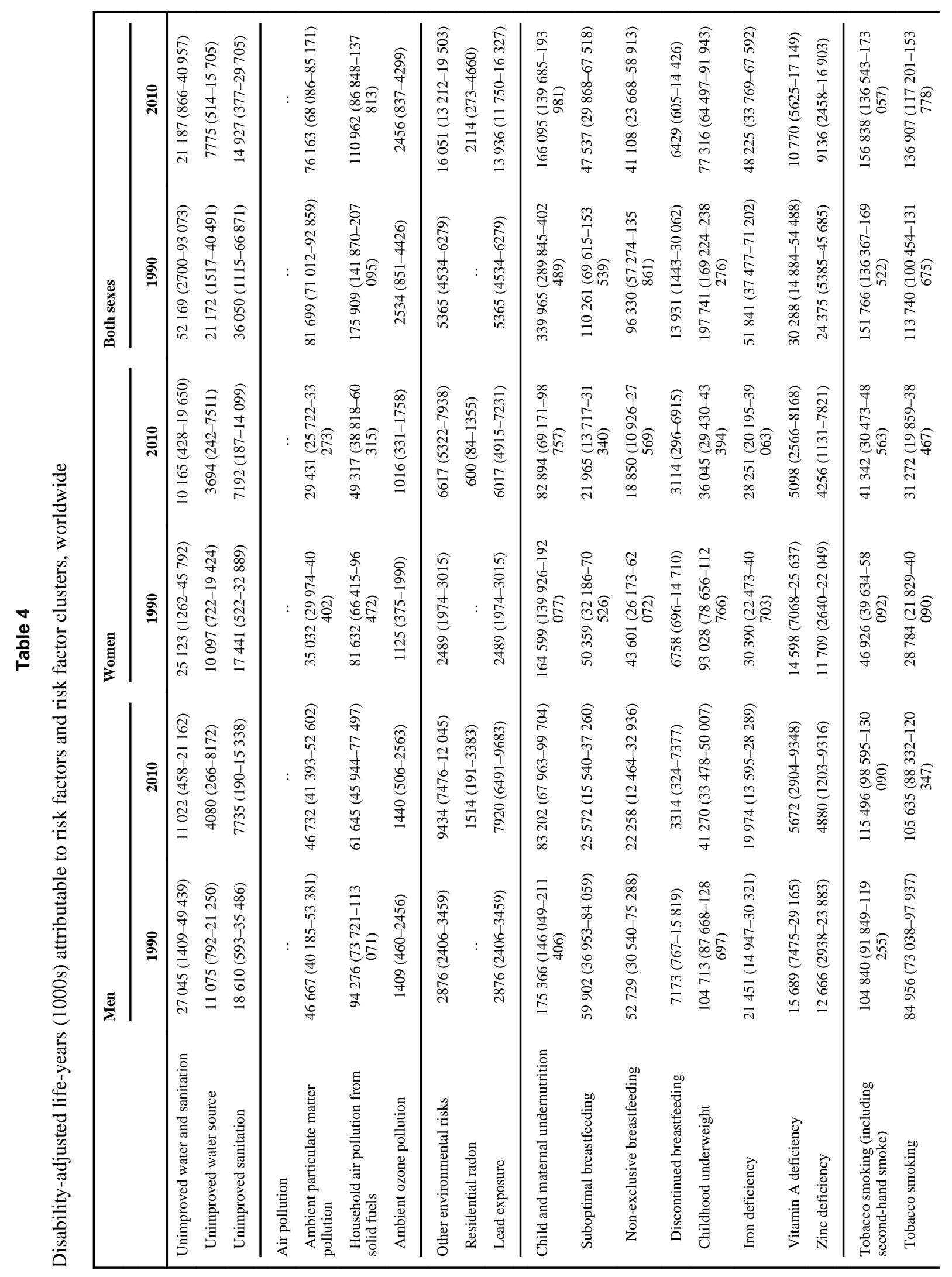




\begin{tabular}{|c|c|c|c|c|c|c|c|c|c|c|c|c|c|c|c|c|c|c|c|}
\hline & $\stackrel{\overline{\mathrm{N}}}{\mathrm{H}}$ & 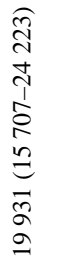 & 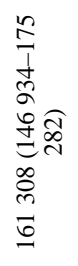 & 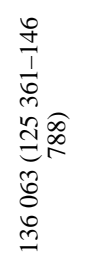 & 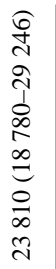 & 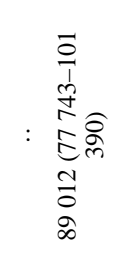 & 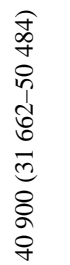 & 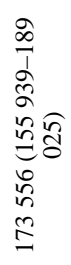 & 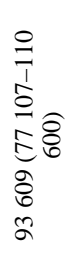 & 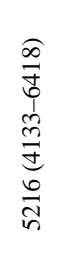 & 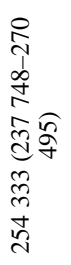 & 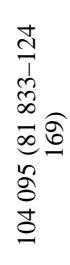 & 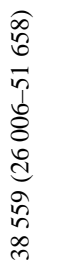 & & 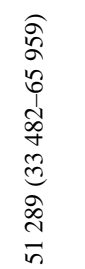 & 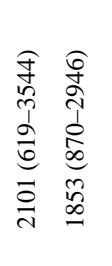 & 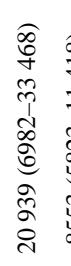 & 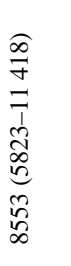 & 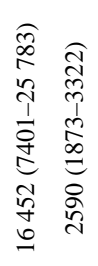 \\
\hline 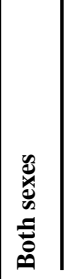 & 亏ิ & 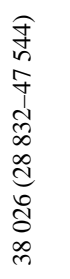 & 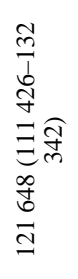 & 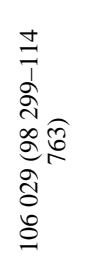 & 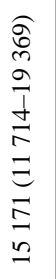 & 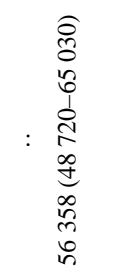 & 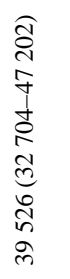 & 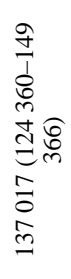 & 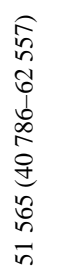 & 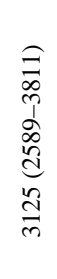 & 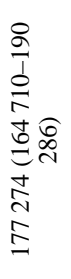 & 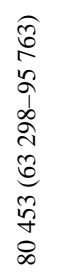 & 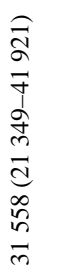 & & 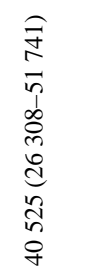 & 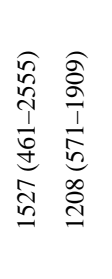 & 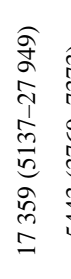 & 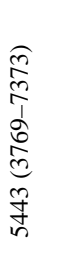 & 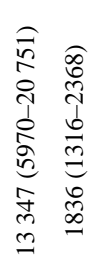 \\
\hline & 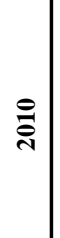 & 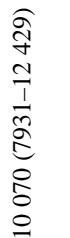 & 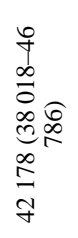 & 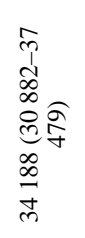 & 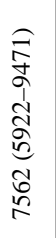 & 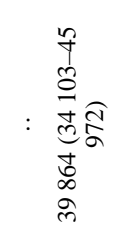 & 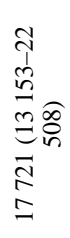 & 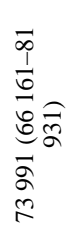 & 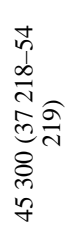 & 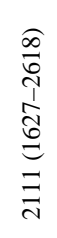 & 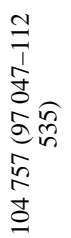 & 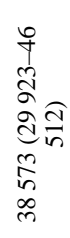 & 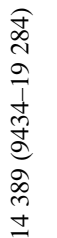 & 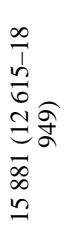 & 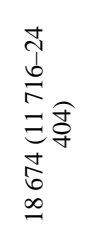 & 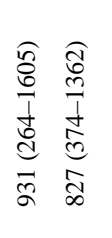 & 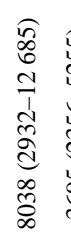 & 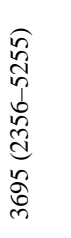 & 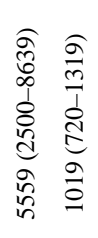 \\
\hline 节 & $\stackrel{\Xi}{2}$ & 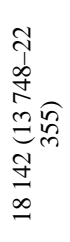 & 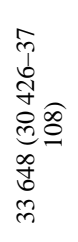 & 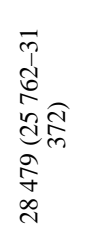 & 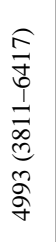 & 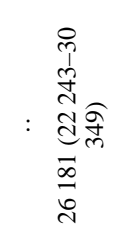 & 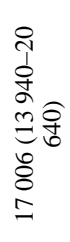 & 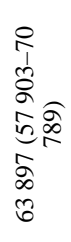 & 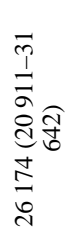 & 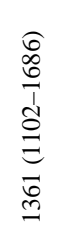 & 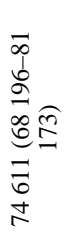 & 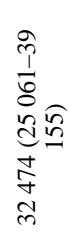 & 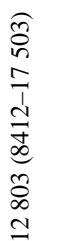 & 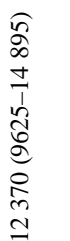 & 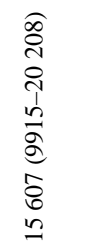 & 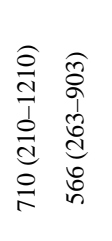 & 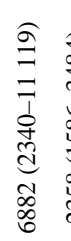 & 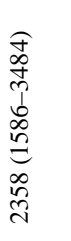 & 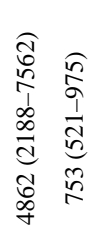 \\
\hline & $\stackrel{\bar{~}}{\circ}$ & 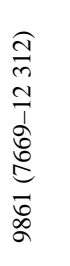 & 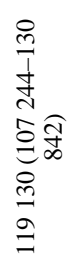 & 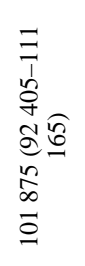 & 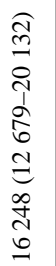 & 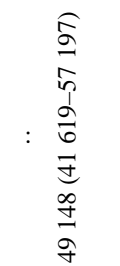 & 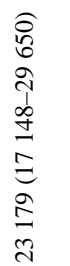 & 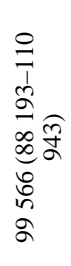 & 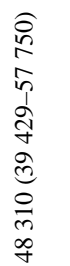 & 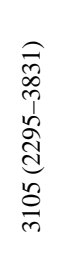 & 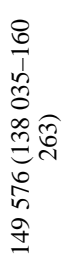 & 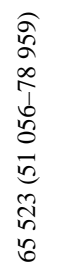 & 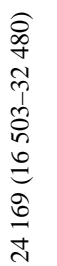 & 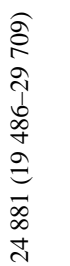 & 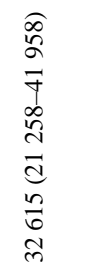 & 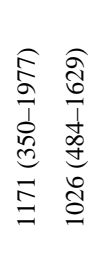 & 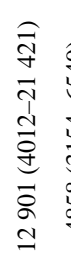 & 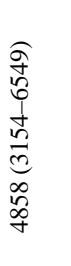 & 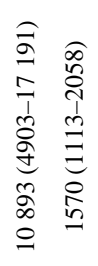 \\
\hline$\stackrel{\Xi}{\Sigma}$ & g & 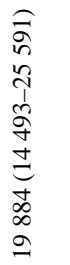 & 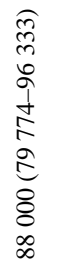 & 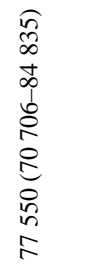 & $\begin{array}{l}\widehat{0} \\
\hat{0} \\
m \\
\frac{1}{1} \\
\infty \\
0 \\
\infty \\
\infty \\
\vdots \\
0\end{array}$ & 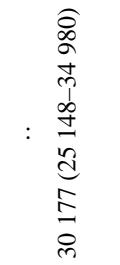 & 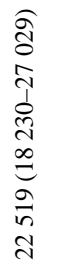 & 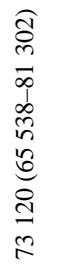 & 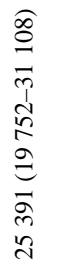 & 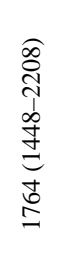 & 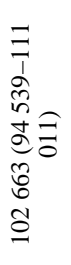 & 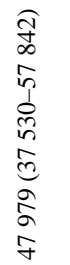 & 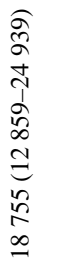 & 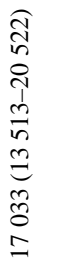 & 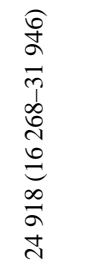 & 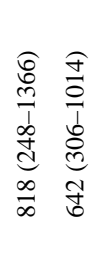 & 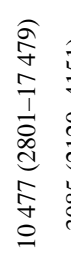 & 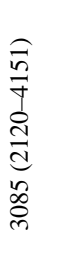 & 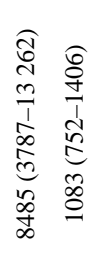 \\
\hline & & 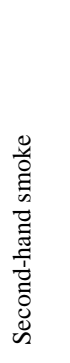 & 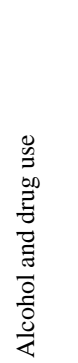 & $\begin{array}{l}0 \\
0 \\
\frac{0}{0} \\
\frac{0}{0} \\
\frac{0}{<}\end{array}$ & 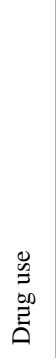 & 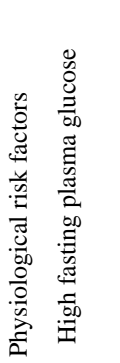 & 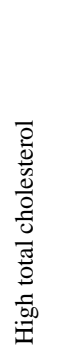 & 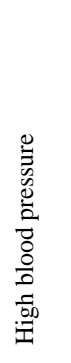 & 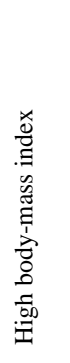 & 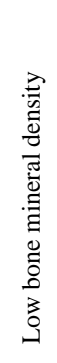 & 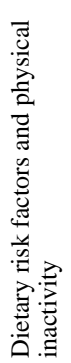 & 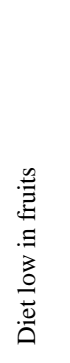 & 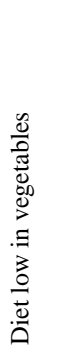 & 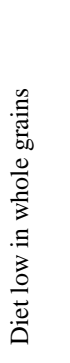 & 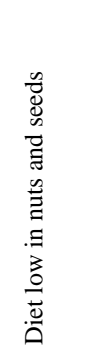 & 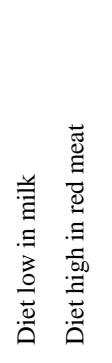 & 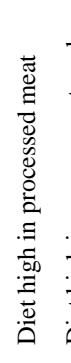 & 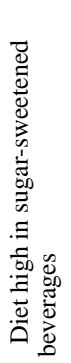 & 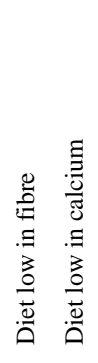 \\
\hline
\end{tabular}




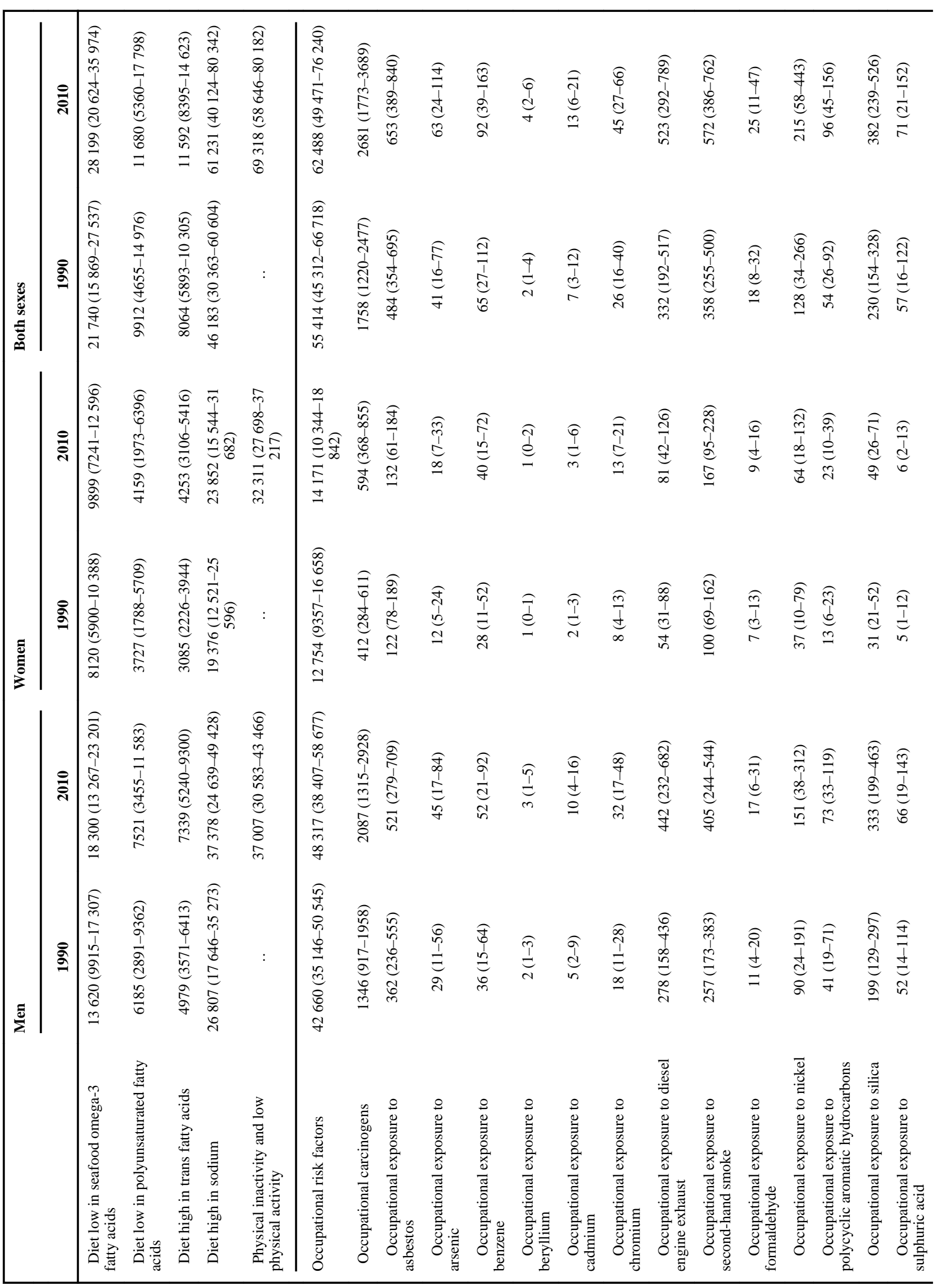




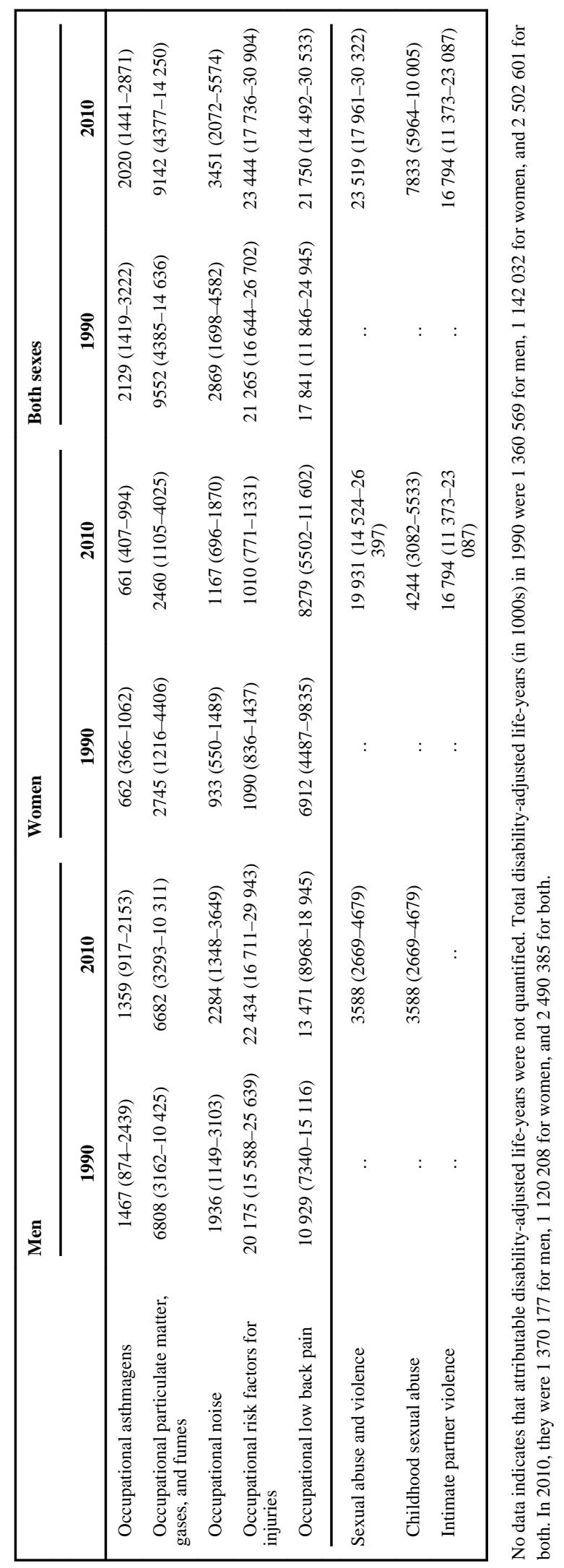

